\title{
Addendum
}

For this thesis independent batches of Arabidopsis seeds and flg22-peptide were used to achieve comparable results. Nevertheless, it has to be mentioned that the phenotype of the

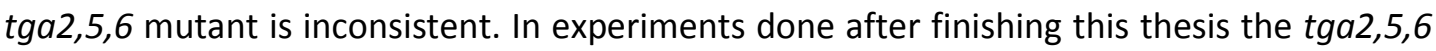
mutant did not show significant difference to the Columbia wild type regarding to flg22inducible FRK1 expression, callose deposition or stomata closure. 


\title{
The Role of
}

\section{Arabidopsis Class-II TGA Transcription Factors in PAMP-mediated Defense Responses}

\author{
Dissertation \\ zur Erlangung des Doktorgrades \\ der Mathematisch-Naturwissenschaftlichen Fakultäten \\ der Georg-August-Universität zu Göttingen
}

vorgelegt von

Katja Rindermann geb. Rakowski

aus Korbach

Göttingen 2010 
D7

Referent:

Prof. Dr. Christiane Gatz

Korreferent:

PD Dr. Wolfgang Dröge-Laser

Tag der mündlichen Prüfung:

28. April 2010 
"Gíb jedem Tag die chance, der schönste deines Lebens zu werden" 


\section{Contents}

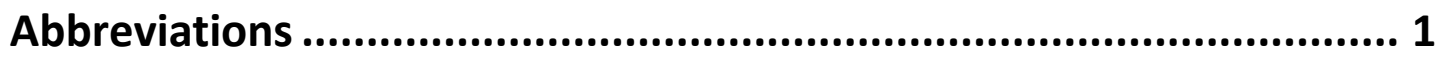

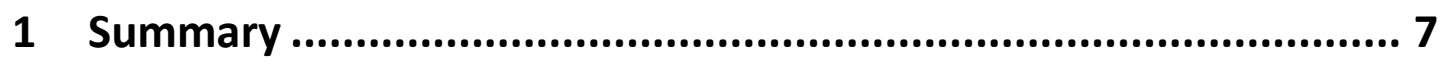

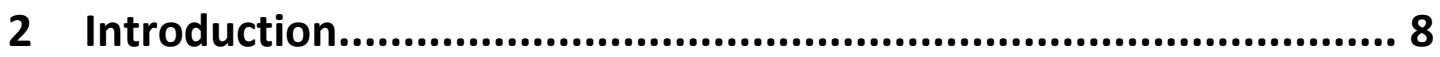

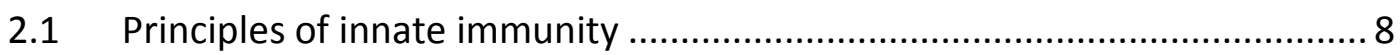

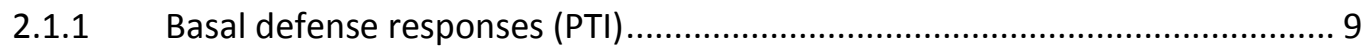

2.1.2 R-gene-mediated resistance (ETI) ………................................................ 14

2.2 Bacterial weapons to counter-act PTI .................................................... 15

2.3 Phytohormones coordinating plant defense responses .......................... 15

2.3.1 Hormonal networks to finetune plant defense .......................................... 18

2.3.2 Suppression of host defense by the bacterial toxin coronatine .................... 19

2.4 TGA transcription factors as regulators of defense responses ................... 20

2.5 WRKY transcription factors: key players of plant immunity ...................... 22

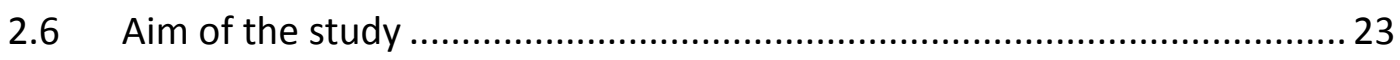

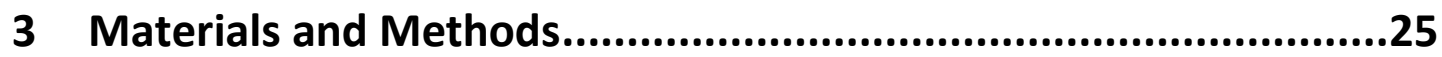

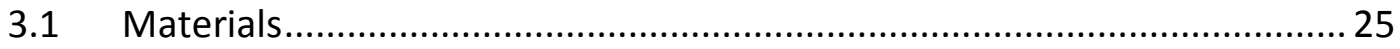

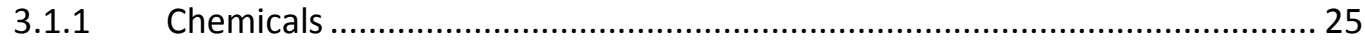

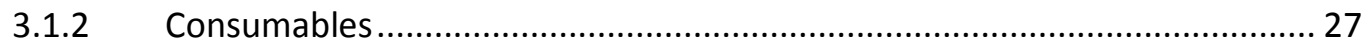

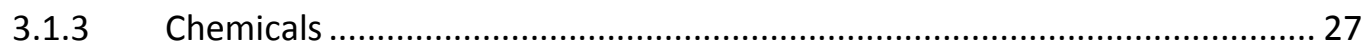

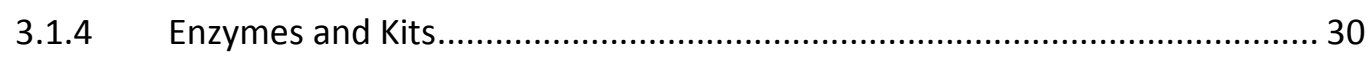

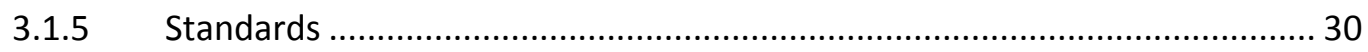

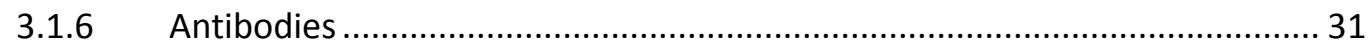

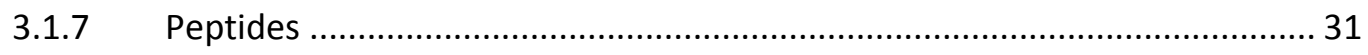

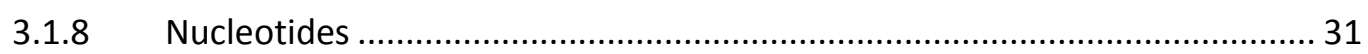

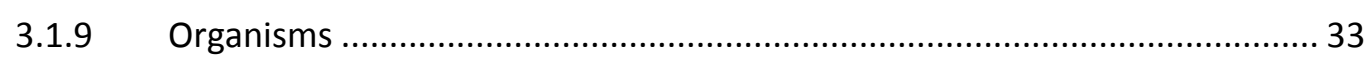

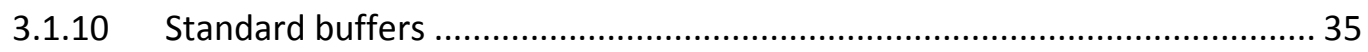

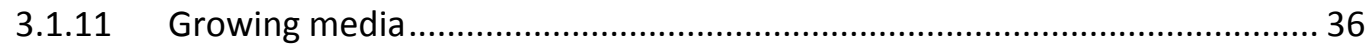

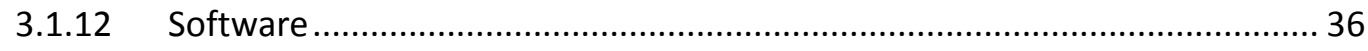

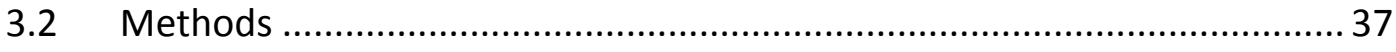

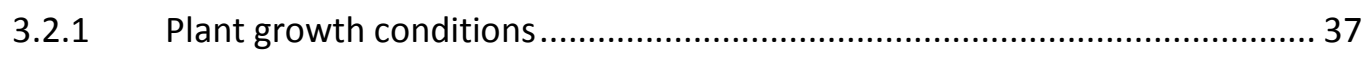

3.2.2 Generation of quadruple mutants ........................................................ 37

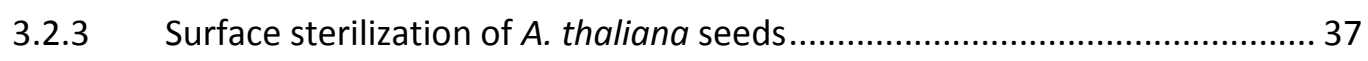

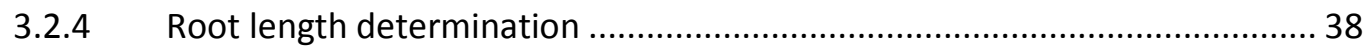




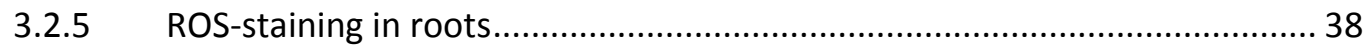

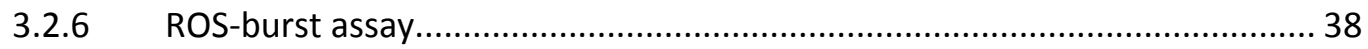

3.2.7 Callose staining in seedlings and soil grown plants ..................................... 39

3.2.8 Measurement of stomatal response to different treatments ....................... 39

3.2.9 Induction of gene expression in A. thaliana ................................................. 39

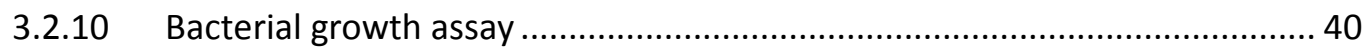

3.2.11 Standard molecular methods..................................................................... 40

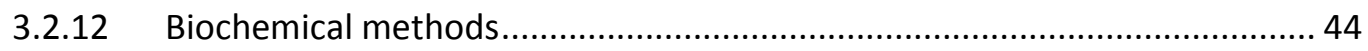

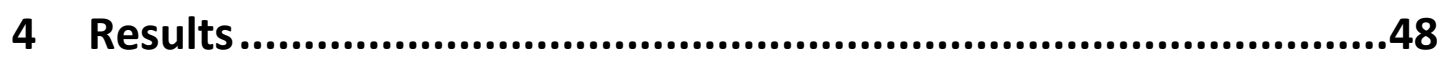

4.1 The growth inhibition effect of flg22 is strongly increased in the

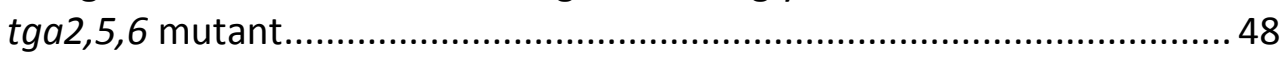

4.2 Roots of the tga2,5,6 mutant contain higher ROS levels than the

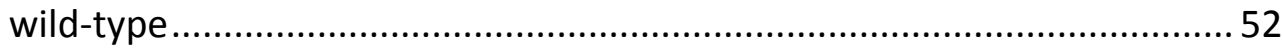

4.3 PAMP-induced ROS burst is not influenced in the tga2,5,6 mutant .......... 55

4.4 Gene expression analysis show an enhanced activation of early flg22inducible genes in the tga2,5,6 mutant

4.5 The effect of flg22 on late cell wall-based defense responses is fortified in the tga2,5,6 mutant

4.6 The tga2,5,6 mutant fails to develop callose deposition after wounding .. 65

4.7 tga2,5,6 mutants show no altered callose deposition after bacterial infection

4.8 tga2,5,6 mutant plants are not longer sensitive to coronatine (COR) triggered stomatal closure

4.9 Class-II TGA factors are involved in flg22-triggered defense against Pst DC3000

4.10 COR suppresses flg22-induced FRK1 expression in Col-0 and tga2,5, 6 mutant 72

4.11 SA and flg22 act synergistically on FRK1-expression in Col-0 seedlings ..... 73

4.12 Expression of FRK1 is not influenced in mutants of the SA or JA pathway. 75

4.13 TGA-dependent suppression of early flg22-induced genes occurs indirectly

\section{Discussion}

5.1 flg22-induced growth inhibition is damped by class-II TGA factors 79

5.2 Class-II TGA factors are not involved in PAMP-induced ROS burst.

5.3 The tga2,5,6 mutant shows enhanced sensitivity to many early defense responses

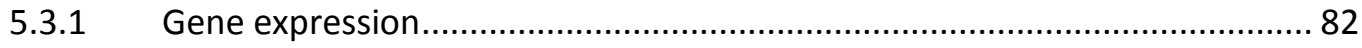

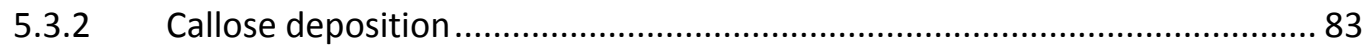


5.4 Ectopic expression of TGA2 is sufficient to restore the wild-type situation.

5.5 The absence of class-II TGA factors partially rescues the enhanced susceptibility phenotype of the sid2-2 mutant regarding flg22-triggered

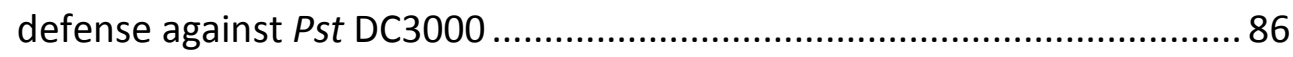

5.6 Influence of SA and JA on flg22-induced gene expression........................ 87

5.7 Functional analysis of class-II TGA factors in basal resistance .................... 88

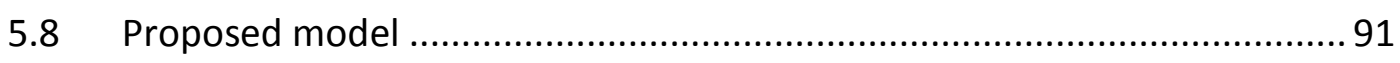

6 Supplemental data......................................................92

7 Bibliography ..............................................................98

8 Acknowledgement........................................................114

9 Curriculum Vitae ..............................................................116 


\section{Abbreviations}

\begin{tabular}{|c|c|}
\hline aa & amino acids \\
\hline A & Ampere \\
\hline A & adenosine \\
\hline$A B A$ & abscisic acid \\
\hline ACS & 1-aminocyclopropane-1-carboxylic acid synthase \\
\hline APS & ammoniumpersulfate \\
\hline as-1 & activating sequence 1 \\
\hline AT & marks a protein from Arabidopsis thaliana \\
\hline A. thaliana & Arabidopsis thaliana \\
\hline avr & avirulence \\
\hline B. cinerea & Botrytis cinerea \\
\hline BHA & Butylated hydroxyanisole \\
\hline bp & base pairs \\
\hline BSA & bovine serum albumine \\
\hline bZIP & basic leucine zipper \\
\hline C & cytosine \\
\hline Cals & callose synthase \\
\hline CaMV & cauliflower mosaic virus \\
\hline cDNA & copy DNA \\
\hline ChIP & chromatin immunoprecipitation \\
\hline COI1 & CORONATINE INSENSITIVE 1 \\
\hline Col-0 & Arabidopsis thaliana ecotype Columbia \\
\hline COR & coronatine \\
\hline $\mathrm{CT}$ & threshold cycle \\
\hline C-terminal & carboxy-terminal \\
\hline CTR1 & CONSTITUTIVE TRIPLE RESPONSE 1 \\
\hline
\end{tabular}




\begin{tabular}{|c|c|}
\hline CYP & cytochrome P450 \\
\hline $\mathrm{Da}$ & Dalton \\
\hline ddNTPs & didesoxy nucleotides \\
\hline DMSO & dimethylsulfoxide \\
\hline DMTU & Dimethylthiourea \\
\hline DNA & desoxyribonucleic acid \\
\hline DNase & desoxyribonuclease \\
\hline dNTP & desoxyribonucleotides \\
\hline dpi & days past infection \\
\hline DPI & diphenyleneiodonium chloride \\
\hline DOC & sodium deoxycholate \\
\hline DTT & dithiotreitol \\
\hline $\mathrm{ECL}$ (kit) & enhanced chemoluminescence (kit for western detection) \\
\hline E. coli & Escherichia coli \\
\hline EDS1 & ENHANCED DISEASE SYMPTOMS 1 \\
\hline EDTA & ethylenediaminetetraacetic acid \\
\hline EF-Tu & translation elongation factor $\mathrm{Tu}$ \\
\hline EIN & ETHYLENE INSENSITIVE \\
\hline EIL1 & ETHYLENE INSENSITIVE3-LIKE1 \\
\hline elf18/elf26 & Petides derived from bacterial EF-Tu \\
\hline ERF & ETHYLENE RESPONSE FACTOR \\
\hline ET & ethylene \\
\hline et al. & et alii (and others) \\
\hline ETI & effector-triggered immunity \\
\hline EtOH & ethanol \\
\hline ETR1 & ETHYLENE RESISTANT 1 \\
\hline ETS & effector-triggered susceptibility \\
\hline $\mathrm{F}$ & Farad \\
\hline flg22 & peptide derived from bacterial flagellin \\
\hline FLS2 & FLAGELLIN-SENSING 2 \\
\hline
\end{tabular}


FRK1

g

g

G

GA

GB

GC

GFP

GRX

GST (U)

GUS

h

$\mathrm{H}_{2} \mathrm{O}_{2}$

hpi

HPLC

$H R$

HSP

IAA

ICS

IGS

Ile

INA

JA

JAZ

k

L

LOX

LPS

LRR

$\mu$

\section{FLG22-INDUCED RECEPTORKINASE 1}

gravitation

gram

guanine

gibberellic acid

gradient buffer

guard cell

green fluorescence protein

glutaredoxin

glutathione-S-transferase

glucuronidase

hours

hydrogen peroxide

hours past infection

high presure liquid chromatography

hypersensitive response

herring sperm DNA

auxin

isochorismate synthase

4-methoxy-indol3-ylmethl glucosinolate

isoleucine

2,6-dichloroisonicotinic acid

jasmonic acid

Jasmonate ZIM-domain

kilo (103)

litre

lipoxygenase

lipopolysaccharide

leucine rich repeat

micro $\left(10^{-6}\right)$ 


\begin{tabular}{|c|c|}
\hline $\mathrm{m}$ & mili $\left(10^{-3}\right)$ \\
\hline $\mathrm{m}$ & meter \\
\hline M & molarity $[\mathrm{mol} / \mathrm{L}]$ \\
\hline MAMP & microbial-associated molecular patterns \\
\hline MAP & Mitogen activated-protein \\
\hline MAPK & MAP kinase \\
\hline Me-SA & methyl salicylate \\
\hline $\min$ & minutes \\
\hline mRNA & messenger RNA \\
\hline MS & Murahige and Skoog \\
\hline$n$ & nano $\left(10^{-9}\right)$ \\
\hline NBS & nuclear binding site \\
\hline NLS & nuclear localization sequence \\
\hline NPR1 & NON-EXPRESSOR of $P R$-GENES 1 \\
\hline N-terminal & amino-terminal \\
\hline$\Omega$ & Ohm \\
\hline OD & optical density \\
\hline OE & over expressing \\
\hline OGA & oligogalacturonic acid \\
\hline$o / n$ & over night \\
\hline $\mathrm{p}$ & pico $\left(10^{-12}\right)$ \\
\hline PAA & polyacrylamide \\
\hline PAD4 & PHYTOALEXIN DEFICIENT 4 \\
\hline PAGE & polyacrylamide gelelectrophoresis \\
\hline PAMP & pathogen-associated molecular pattern \\
\hline PCR & polymerase chain reaction \\
\hline PCD & programmed cell death \\
\hline PDF1.2 & Plant defensin 1.2 \\
\hline $\mathrm{pH}$ & negative $\log _{10}$ of proton concentration \\
\hline PMSF & phenyl-methyl-sulfonyl-fluoride \\
\hline
\end{tabular}




\begin{tabular}{|c|c|}
\hline$P R$ & Pathogenesis related \\
\hline PRR & pattern recognition receptor \\
\hline Pst & Pseudomonas syringae pv. tomato \\
\hline PTI & PAMP-triggered immunity \\
\hline pv. & pathovar \\
\hline PVDF & polyvinylidene fluoride \\
\hline qRT-PCR & quantitative real time PCR \\
\hline Rboh & RESPIRATORY BURST OXIDASE HOMOLOGUE \\
\hline REN & restriction endonucleases \\
\hline RES & reactive electrophile species \\
\hline RK & receptor kinase \\
\hline RLK & receptor like kinase \\
\hline RNA & ribonucleic acid \\
\hline RNase & ribonuclease \\
\hline ROS & reactive oxygen species \\
\hline rpm & rotations per minute \\
\hline RPS4 & RESISTANCE TO PSEUDOMONAS SYRINGAE 4 \\
\hline RT & room temperature \\
\hline s & second \\
\hline SA & salicylic acid \\
\hline SAG & SA 2-o-ß-D-glucoside \\
\hline SAR & systemic acquired resistance \\
\hline SB & sonic buffer \\
\hline S. cerevisiae & Saccharomyces cerevisiae (bakers yeast) \\
\hline SCL14 & SCARECROW-LIKE 14 \\
\hline SCF & skip-cullin-F-box \\
\hline SD & standard deviation \\
\hline SDS & sodium dodecylsulfate \\
\hline SEM & Standard error mean \\
\hline SID2 & SA INDUCTION-DEFICIENT 2 \\
\hline
\end{tabular}




$\begin{array}{ll}\text { SOD } & \text { superoxide dismutase } \\ \text { T } & \text { thymine } \\ \text { TE } & \text { tris-EDTA buffer } \\ \text { TEMED } & \text { N,N, } N^{\prime}, N^{\prime} \text {-tetraethylenediamine } \\ \text { TGA } & \text { as-1 (TGACG motive) binding bZIP transcription factors } \\ \text { TMV } & \text { tobacco mosaic virus } \\ \text { Tris } & \text { tris-hydroxymethylamino methane } \\ \text { TTSS } & \text { type three secretion system } \\ \text { u } & \text { unit (quantity for enzyme activity) } \\ \text { U } & \text { uracil } \\ \text { UV } & \text { ultra violet } \\ \text { V } & \text { Volt } \\ \text { VSP2 } & \text { VEGETATIVE STORAGE PROTEIN 2 } \\ \text { V/v } & \text { volume per volume } \\ \text { W } & \text { Watt } \\ \text { Ws-0 } & \text { Arabidopsis thaliana ecotype Wassilewskija } \\ \text { WT } & \text { wildtype } \\ \text { W/v } & \text { weight per volume }\end{array}$




\section{Summary}

The primary immune response in plants is induced upon recognition of invariant microbial structures like flagellin, chitin, glycoproteins and lipopolysaccharides. These pathogenassociated molecular patterns (PAMPs) are recognized by specific receptors, which in turn initiate diverse downstream signaling events leading to the synthesis of the stress signaling hormone salicylic acid (SA) and to the activation of basal defense.

Transcriptional reprogramming is essential in plant defense responses. The redundant classII TGA transcription factors TGA2, TGA5 and TGA6 are well known as important activators of SA-induced expression of PATHOGENESIS-RELATED $(P R)$ genes and systemic acquired resistance illustrating their role in innate immunity.

In this thesis, the influence of class-II TGA factors in PAMP-induced early defense reactions was investigated using the $\operatorname{tga2,5,6}$ mutant. This mutant shows hyper-induced responses to flg22 as revealed by enhanced root growth inhibition, hyper-induced expression of early defense genes including WRKY transcription factors and increased callose deposition. Hyperinduction of flg22-induced root growth inhibition still occurs in the tga2,5,6/sid2-2 which is deficient in flg22-induced SA synthesis. Thus, TGA factors dampen PAMP -triggered immune responses in an SA-independent manner. Inhibition of flg22-induced stomatal closure, a process that is dependent on SA, by the jasmonic acid-isoleucine (JA-lle) mimic coronatine (COR) depends on the presence of class-II TGA factors, illustrating a role of TGA factors in coronatine-mediated processes. Likewise, wound-induced callose deposition depends on the presence of class-II TGA factors, substantiating their role in JA-induced processes. In contrast, SA-independent flg22-induced FRK1 expression is antagonized by COR in a TGA-independent manner.

After flg22 pretreatment, the tga2,5,6/sid2-2 quadruple mutant is more resistant to the hemibiotrophic bacterial pathogen Pseudomonas syringae than the sid2-2 single mutant. However, tga2,5,6 mutants showed higher susceptibility than the wild type, suggesting an SA-dependent positive function and an SA-independent negative function of class-II TGA factors in defense responses. 


\section{Introduction}

\subsection{Principles of innate immunity}

Recognition of non-self structures and activation of defense against the attacking pathogen is known from all multi-cellular organisms. Although plants lack an adaptive immune system, they effectively deploy a series of preformed and induced defenses to combat microbial invasion. We can distinguish two branches of the inducible plant immune system. One uses transmembrane pattern recognition receptors (PRRs) that respond to slowly evolving microbial- or pathogen-associated molecular patterns (MAMPs or PAMPs). The second acts inside the cell, using NBS-LRR proteins encoded by disease resistance $(R)$ genes. They are named after their characteristic nucleotide binding site (NBS) and leucine rich repeat (LRR) domains (Nimchuk et al., 2003). The current view of the plant immune system can be represented as a 'zigzag' model (Figure 2-1; Jones and Dangl, 2006).

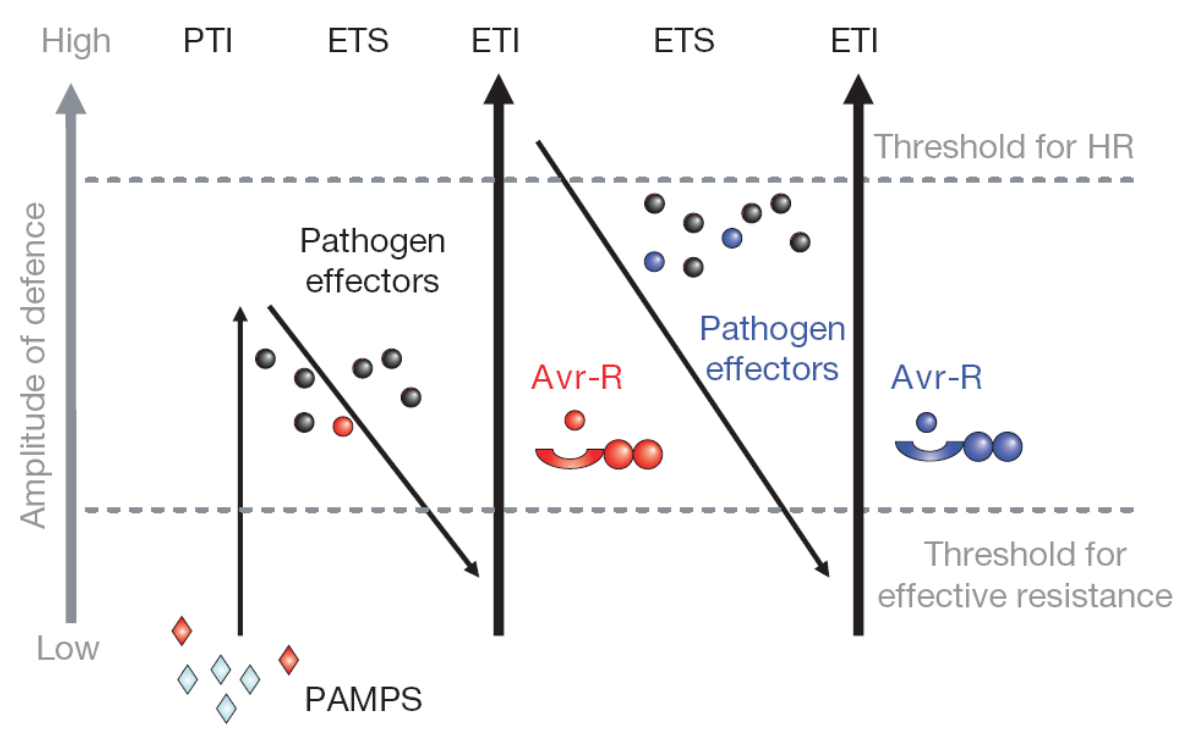

Figure 2-1 | Zigzag model of the plant immune system. Phase 1: Recognition of PAMPs resulting in PTI. Phase 2: Release of effectors by the pathogen disturbs PTI causing ETS. Phase 3: Effector recognition by $\mathrm{R}$ proteins leads to ETI (Jones and Dangl 2006) 
PAMPs are recognized by PRRs, resulting in basal defense responses, also called PAMPtriggered immunity (PTI) that can stop further colonization by the pathogen. Adapted pathogens release effectors that contribute to pathogen virulence and disturb PTI. This leads to effector-triggered susceptibility (ETS). A given effector is specifically recognized by one of the NBS-LRR proteins, causing effector-triggered immunity (ETI). ETI is a faster and stronger PTI response, resulting in disease resistance and, mostly, a hypersensitive cell death response (HR) at the infection site.

\subsubsection{Basal defense responses (PTI)}

The first line of inducible defense relies on the recognition of PAMPs by PRRs of the host. PAMPs are conserved structures essential for the microorganism, widely distributed among different microbes and absent in the host. Typical PAMPs are bacterial derived lipopolysaccharides (LPS) and flagellin or fungal structures like chitin (Newman et al., 2002; Felix et al., 1999; Gust et al., 2007).

Flagellum-based motility is important for bacterial pathogenicity in plants (Felix et al., 1999). The highly conserved 22 amino acid N-terminal domain of flagellin (flg22) is an extracellular PAMP which is recognized by most plant species. Interestingly, not all PAMPs are extracellular components of the microbe. For example, the translation elongation factor Tu (EF-Tu), which also function as a PAMP, is an intracellular protein (Zipfel and Felix, 2005). In Arabidopsis, flg22 induces callose formation, accumulation of defense proteins like PATHOGENESIS-RELATED 1 (PR-1), and strong inhibition of seedling growth (Gómez-Gómez et al., 1999). Growth inhibition was used in a mutant screen that identified a number of flg22-insensitive mutants. One of the mutated loci, FLAGELLIN-SENSING 2 (FLS2), encodes a LRR receptor kinase (LRR-RK) (Gómez-Gómez and Boller, 2000). FLS2 acts together with the kinase BAK1, but FLS2 alone carries the specificity towards flg22. BAK1 is also involved in cell death control and brassinosteroid signaling in Arabidopsis and appears to be a general heterodimerisation partner of LRR-RLKs (Kemmerling et al., 2007).

fls2 mutants exhibit enhanced sensitivity to spray application of the bacterial phytopathogen Pseudomonas syringae pv. tomato DC3000 (Pst DC3000), but not to syringe infiltration into the leaf apoplast (Zipfel et al., 2004). Under natural conditions, Pst DC3000 enters host plants through wounds or natural openings such as stomata, and then spreads 
and multiplies in intercellular spaces (Katagiri et al., 2002). Thus, the infiltration of bacteria with a syringe seems to bypass the first steps of the natural defense that rely on PAMPinduced stomatal closure (Melotto et al., 2006).

The second known receptor like kinase (RLK) in Arabidopsis involved in PAMP perception is EFR which recognizes the elongation factor EF-Tu, one of the most abundant and most conserved proteins of bacteria. Peptides corresponding to the acetylated $\mathrm{N}$ terminus of EFTu, called elf18 and elf26, trigger PAMP responses in Arabidopsis at subnanomolar concentrations. Responsiveness to elf18/elf26 was found in various Brassicaceae species but not in members of other plant families tested, indicating that perception of EF-Tu as a PAMP has specifically developed in Brassicaceae (Kunze et al., 2004).

Fragments of chitin, the main building component of fungal cell walls, are classical PAMPs (Felix et al., 1993). The rice chitin elicitor-binding protein, CEBiP, contains two LysM motifs that are involved in the recognition of chitin oligosaccharides (Kaku et al., 2006). On the basis of this finding, two groups examined Arabidopsis insertion mutants encoding LysMdomain-containing proteins, and found one of them to be completely nonresponsive to chitin fragments (Miya et al., 2007; Wan et al., 2008). The gene affected could be allocated to an RLK, called CERK1 (Miya et al., 2007) or LysM RLK1b (Wan et al., 2008). As it has proven difficult so far to detect chitin binding in Arabidopsis, it remains elusive if LysM RLK1 (CERK1) directly binds chitin or acts via cooperation with another protein (Miya et al., 2007; Wan et al., 2008).

PAMP perception initiates intracellular signaling that results in a number of responses thought to contribute to defense against the invading microbe. Depending on their first appearance these responses are separated in early and late signaling responses. Smooth transition exists between them, whereas early responses occur few minutes until 1 hour after PAMP perception mostly in a transient way, late responses are more long-lasting and starts after one hour or later.

\subsubsection{Early signaling responses}

Ion fluxes and oxidative burst. In soybean roots, seconds to minutes after PAMP treatment an alkalinization of the growth medium is detectable due to changes of the ion flux across the plasma membrane causing depolarization (Mithöfer et al., 2005). Also, in other plant species, including Arabidopsis thaliana, a flagellin-induced alkalinization response in suspension-cultured cells takes place (Felix et al., 1999). An influx of $\mathrm{Ca}^{2+}$ from the apoplast 
occurs and causes a rapid increase in cytoplasmic $\mathrm{Ca}^{2+}$ concentrations, which might serve as second messengers to promote the opening of other membrane channels in Arabidopsis (Ali et al., 2007), or to activate calcium-dependent protein kinases in tobacco (Ludwig et al., 2005). Simultaneously, an oxidative burst takes place with extracellular generation of reactive oxygen species $\left(\mathrm{O}_{2}^{-}\right.$and its dismutation product $\left.\mathrm{H}_{2} \mathrm{O}_{2}\right)$ by membrane localized NADPH oxidases RESPIRATORY BURST OXIDASE HOMOLOGUE D and F (RbohD and RbohF) (Torres et al., 2002).

Localized extracellular ROS have been detected during plant-pathogen interactions (Thordal-Christensen et al., 1997), and has been found to have an antimicrobial effect on phytopathogens (Lamb and Dixon, 1997). A moderate concentration of ROS activates the cellular defense response (Levine et al., 1994). Tobacco plants inoculated with the tobacco mosaic virus (TMV) developed systemic acquired resistance (SAR) that was mediated by a burst of ROS (Lamb et al., 1997) and a rapid production of ROS could also inhibit pathogen growth by restricting pathogen penetration via cross-linking of cell wall glycoproteins (Bradley et al., 1992) or by induction of defense-related genes (Desikan et al., 2001).

Activation of MAPKs. Another early PAMP triggered response is the activation of Mitogen activated-protein (MAP) kinases (MAPK). In Arabidopsis, two MAPK cascades containing MAP kinase (MPK3)/MPK6 or MPK4 are activated by flg22 and other PAMPs (Mészáros et al., 2006). This activation occurs within 5 min after treatment, even in the presence of cycloheximide, which inhibits translation, indicating a direct link between receptors and the initiation of the MAPK signaling pathways. The MPK3/MPK6-cascade activates the early flg22-induced expression of the defense-related genes WRKY29 (WRKY DNA-BINDING PROTEIN 29) and FRK1 (FLG22-INDUCED RECEPTORKINASE 1) in protoplasts (Asai et al., 2002), whereas the MPK4-cascade acts negatively on the same responses (SuarezRodriguez et al., 2007; Petersen et al., 2000). Activation of MAPK is accompanied by changes in protein phosphorylation. It could be shown that WRKY25 and WRKY33 are substrates of MPK4 (Andreasson et al., 2005), which are likely to serve as the first WRKY proteins activated in response to PAMP-triggered MAPK signaling. Furthermore, a number of membrane proteins that display flg22-responsive phosphorylation in Arabidopsis cells could be identified. Interestingly, RbohD, the NADPH oxidase that mediates the oxidative burst, is among these proteins (Benschop et al., 2007; Nühse et al., 2007).

Receptor endocytosis. Within $20-40$ min of treatment, flg22 was found to specifically trigger accumulation of the normally plasma membrane-resident FLS2 into intracellular 
vesicles (Robatzek et al., 2006). FLS2 contains a PEST-like motif which is reported to mediate receptor endocytosis via mono-ubiquitination in yeast and mammals (Hammond et al., 2001). FLS2 mutants with a point mutation in this motif were not only defective in endocytosis but also affected in flg22 responses. These findings strongly support the notion that FLS2 endocytosis contributes to flg22 signaling (Robatzek et al., 2006).

Gene activation. Treatment of Arabidopsis plants with flg22 causes the induction of nearly 1000 genes and the downregulation of about 200 genes within 30 min (Zipfel et al., 2004). Other PAMPs such as elf26 and fungal chitin seem to induce a similar set of genes (Zipfel et al., 2006; Libault et al., 2007). An extensive number of the flg22-upregulated genes can be classified as being involved in signal perception, signal transduction, transcriptional regulation and potential antimicrobial action (Zipfel et al., 2004).

\subsubsection{Late defense responses}

Ethylene synthesis. Ethylene (ET) modulates developmental and defense events in the plant. The synthesis of this simple hydrocarbon gas is regulated by diverse plant hormones like auxin and cytokinin and greatly enhanced by diverse abiotic and biotic stresses. Infiltration of Arabidopsis leaves with flg22 or elf18 leads to a transient ET release (Kunze et al., 2004; Li et al., 2009). The flg22-activatable MPK6 is involved in ET biosynthesis by stabilization of 1-aminocyclopropane-1-carboxylic acid synthase (ACS), the rate-limiting enzyme of ethylene biosynthesis (Liu and Zhang, 2004). The Arabidopsis transcription factors ETHYLENE INSENSITIVE3 (EIN3) and ETHYLENE INSENSITIVE3-LIKE1 (EIL1) mediate ethylene signaling. Furthermore, the ein3-1/eil1-1 double mutant display enhanced PAMPrelated defense responses in the absence of ET integrating EIN3 and EIL1 as negative regulators in PTI defenses (Chen et al., 2009). More downstream components of the ethylene cascade are transcription factors of the Ethylene Response factor Family. One member of this family, ERF104, was recently identified to interact with MPK6. This interaction is disrupted after flg22 perception and requires ET biosynthesis and signaling. Many defense-related genes are up-regulated in ERF104 over expressing plants and it is supposable that ERF104 is a positive regulator for PAMP-triggered immunity activated by ET (Bethke et al., 2009). 
Callose deposition. Deposition of callosic plugs or papillae at sites of fungal penetration or bacterial entry is a widely recognized response of host plants to microbial attack. Biosynthesis and deposition of the polyglucan callose in the extracellular space is a relative late defense-associated response. The callose synthase isoform CalS12 (Hong et al., 2001)/GSL5 (Jacobs et al., 2003)/PMR4 (Nishimura et al., 2003) plays a crucial role in inducible callose accumulation upon wounding and during biotic stress.

Flg22-induced callose requires induction of multiple pathways, including an ethylene/MYB51-dependent indole-3-glucosinolate (I3G) biosynthesis pathway and a cytochrome CYP81F2 monooxygenase pathway, essential for pathogen-induced accumulation of 4-methoxy-indol3-ylmethl glucosinolate (IGS). Glucosinolates are secondary metabolites with potential antimicrobial effect. Mutants involved in both pathways failed in PAMP-triggered callose deposition (Clay et al., 2009).

Stomatal closure. To gain access to the intercellular spaces and internal leaf tissues, microbial pathogens must cross the cuticle and epidermis. Bacteria and many fungi cannot directly penetrate the leaf epidermis and must enter leaf tissues through natural openings or wounds on the leaf surface. Stomata are small pores on the surface of plant leaves that are composed of a pair of specialized epidermal cells referred to as guard cells. Through stomata, plants conduct gas exchange necessary for photosynthesis and control water loss by regulating the width of the pore. Plants regulate the opening and closing of these pores through changes in turgor pressure within the guard cells. The plant hormone abscisic acid (ABA) plays a major role in guard cell signaling leading to stomatal closure. Stomatal movements are influenced by numerous environmental cues including light intensity, air humidity, $\mathrm{CO}_{2}$ concentration and drought stress (Underwood et al., 2007). In addition to abiotic stresses, stomata have also been found to respond to various microbe-derived compounds. The fungal elicitors oligogalacturonic acid (OGA) and chitosan both induce stomatal closure in tomato (Lee et al., 1999).

More recently, Arabidopsis stomata were found to respond to the presence of living bacteria or PAMPs (Figure 2-2). Perception of flg22 induces closure of stomata in epidermal peels of Arabidopsis leaves in a FLS2 dependent manner (Melotto et al., 2006), demonstrating that recognition of bacterial PAMPs through PRRs leads to stomatal closure. This suggests a potential role for stomata in the plant innate immune response against bacteria. Consistently, stomata respond to suspensions of Pseudomonas syringae and the human pathogen Escherichia coli (Melotto et al., 2006). 


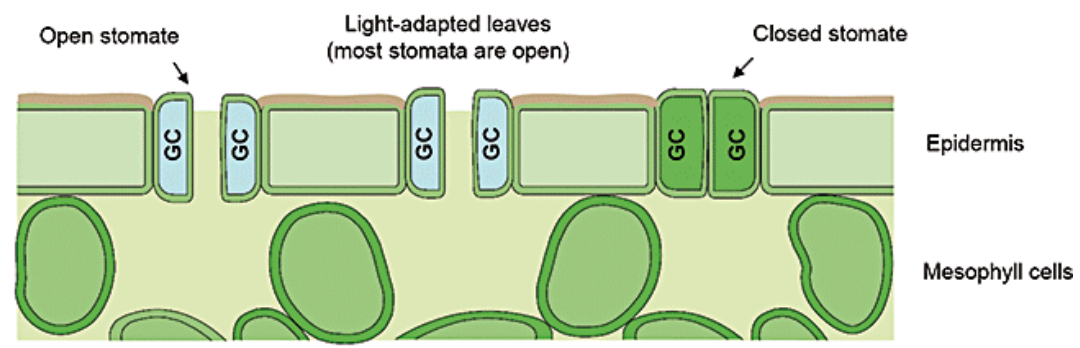

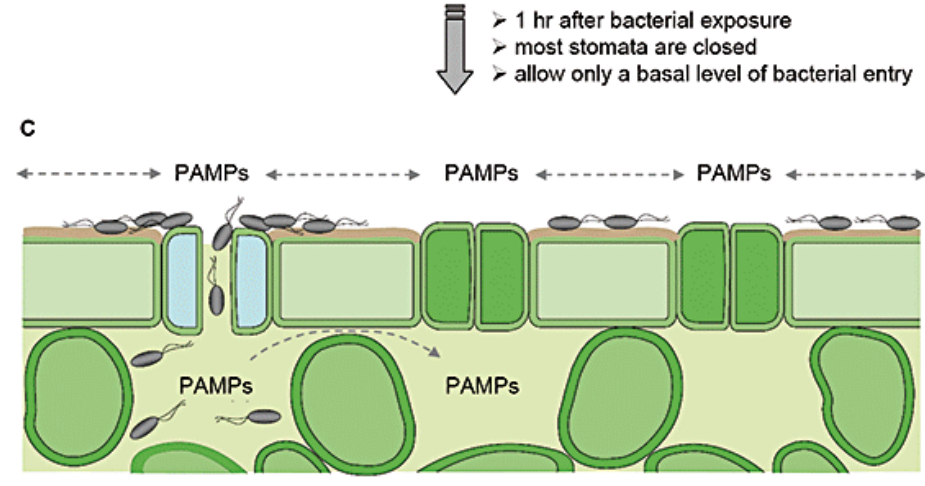

Figure 2-2 | Stomata as entry sites for bacterial invasion. Stomata formed by guard cells (GC) in light adapted leaves are mostly fully open. Upon bacterial attack the guard cells recognize PAMPs and many stomata close within $1 \mathrm{~h}$. Some stomata stay open and serve as entry sites for bacteria into the intercellular space (adapted from Underwood et al. 2007)

\subsubsection{R-gene-mediated resistance (ETI)}

Plants have developed a defense strategy against bacterial derived effectors based on disease $R$-genes. $R$-genes are only effective if a specific avirulence (avr) gene is present in the pathogen. This gene-for-gene hypothesis was introduced by Flor in the 1940s, and dozens of $R$-avr -gene combinations have since been characterized (Dangl and Jones, 2001). R-protein-mediated defenses include the hypersensitive response (HR), a rapidly induced programmed cell death. The cell death is localized near the site of recognition, and kills both the plant cell and the attacking pathogen with the aim of limiting pathogen spread (Lam, 2004).

Most R-proteins are intracellular located and have a NBS-LRR, with either a coiled-coil domain or a Toll-interleukin-1-like domain at the $\mathrm{N}$ terminus. As most bacterial avr genes encode cytoplasmic type III effectors, it has been postulated that R-proteins function as intracellular receptors that directly interact with type III effectors after they are released into the host cell. Surprisingly, a direct interaction between an R-protein and a type III effector has been identified only in few cases (Tang et al., 1996; Deslandes et al., 2003). 


\subsection{Bacterial weapons to counter-act PTI}

To successfully colonize plants, $P$. syringae and other plant pathogenic bacteria have evolved a variety of virulence factors to subvert host defenses and to obtain nutrients. The type three secretion system (TTSS) is structurally related to the bacterial flagellum and forms a pilus to inject a large number of virulence effector proteins into the host cell (Abramovitch et al., 2006). Over thirty effectors are secreted by Pst. Some of these effectors have diverse enzymatic activities but most effectors have no sequence similarity to known proteins and their functions have remained unknown. Two secreted effectors, AvrPto and AvrPtoB physically interact with the kinase domains of FLS2, EFR or BAK1 (Xiang et al., 2008; Göhre et al., 2008; Shan et al., 2008). AvrPtoB contains a E3 ubiquitin ligase initiating the degradation of PRRs (Göhre et al., 2008; Gimenez-Ibanez et al., 2009). This observation explains that this effector suppresses a variety of responses of PTI, including callose deposition, activation of kinase cascades and expression of PAMP-responsive genes (Hauck et al., 2003; He et al., 2006).

\subsection{Phytohormones coordinating plant defense responses}

The regulation of the defense network which translates the pathogen-induced early signaling events into the activation of long lasting defense responses depends on the action of phytohormones. The importance of salicylic acid (SA) (Loake and Grant, 2007), jasmonates (JAs) (Katsir et al., 2008) and ET (van Loon, Geraats, et al., 2006) as signals in the regulation of the plant's immune response is well known. Also other phytohormones like abscisic acid (ABA) (Mauch-Mani and Mauch, 2005), auxins (Navarro et al., 2006) and cytokinins (Walters and McRoberts, 2006) are involved, but their significance is less well understood. Pathogen infection stimulates the plant to synthesize one or more hormonal signals depending on the type of attacker (De Vos et al., 2005). According to their lifestyles, plant pathogens are generally divided into biotrophs and necrotrophs. Biotrophs take nutrients from living host tissues without disrupting it, whereas necrotrophs first destroy host cells, often through the production of phytotoxins, after which they feed on the contents. Many plant pathogens, like Pseudomonas syringae display both lifestyles, depending on the stage of their life cycle, and are called hemibiotrophs. To examine the 
role of the different phytohormones in plant immune response, different mutants and transgenic lines of Arabidopsis and tobacco impaired in hormone biosynthesis, recognition or signaling were generated. In general, biotrophic pathogens are generally sensitive to SAinduced defense responses, whereas pathogens with a necrotrophic lifestyle are opposable by defenses that are controlled by JAs and ET (Glazebrook, 2005). The wound response, which is effective against insect herbivores, is also regulated by the JA signaling pathway (León et al., 2001).

Jasmonic acid. The oxylipin JA is produced via the oxidative metabolism of polyunsaturated fatty acids by enzymes of the octadecanoid pathway. The COI1 (CORONATINE INSENSITIVE 1) protein is required for all known JA-dependent signaling events and serves as a receptor of the JA conjugate JA-isoleucine (JA-Ile) (Katsir et al., 2008). coi1-1 mutants exhibit increased susceptibility to necrotrophic fungi and herbivores and the induction of JAresponsive marker genes like LIPOXYGENASE2 (LOX2) and VEGETATIVE STORAGE PROTEIN 2 (VSP2) or PDF1.2, a plant defensin, is completely abolished (Reymond et al., 2004; Stintzi et al., 2001). The COI1 protein is an E3-ligase that forms the multi protein complex SCF ${ }^{\mathrm{CO} 11}$ (skip-cullin-F-box) to target proteins of the JAZ (Jasmonate ZIM-domain) family for ubiquitination and subsequent degradation by the $26 \mathrm{~S}$ proteasome (Katsir et al., 2008). The JAZ proteins analyzed so far are negative regulators of the JA response and bind to activators of JA-dependent genes. Degradation of these repressors is required for the activation of JA responses (Fonseca et al., 2009).

Ethylene. Beside its function in basal defense, ET signaling also contributes to resistance against necrotrophic pathogens (Thomma et al., 1999). Central regulators of this pathway are the ET receptor ETR1 (ETHYLENE RESISTANT 1), the suppressor CTR1 (CONSTITUTIVE TRIPLE RESPONSE 1), the membrane-located positive regulator EIN2 (ETHYLENE INSENSITIVE 2) and the transcription factors EIN3 and EIL1. CTR1 suppresses ET signaling in the absence of the hormone and EIN3 is targeted constantly for degradation through the 265 proteasome by the two EIN3-binding F-box proteins EBF1 and EBF2. CTR1 is inactivated upon binding of ET to the ETR1 receptor, which subsequently leads to a MAP-kinase (mitogen-activated protein)-mediated phosphorylation cascade and a stabilization of EIN3 (Guo and Ecker, 2003). EIN3 and EIL1 activate ETHYLENE RESPONSE FACTOR1 (ERF1) and other primary responsive genes containing EIN3-binding sites in their promoter regions (Yoo et al., 2009). 
Salicylic acid. The SA pathway is crucial for basal and $R$-gene mediated resistance against biotrophic pathogens (Tsuda et al., 2008). After pathogen attack, SA is synthesized from chorismate, derived from the shikimate pathway, by the enzyme isochorismate synthase (ICS1) localized in the stroma of chloroplasts (Wildermuth et al., 2001). A mutation of the ICS1 gene (sid2; SA INDUCTION-DEFICIENT 2) causes a reduction of SA accumulation after infection to only $5-10 \%$ of the wild-type level and a decrease in PTI and ETI (Wildermuth et al., 2001). In case of resistance mediated via the $R$-gene RPS4 (RESISTANCE TO PSEUDOMONAS SYRINGAE 4), key regulatory proteins upstream of ICS1 are the two lipaselike proteins EDS1 (ENHANCED DISEASE SYMPTOMS 1) and PAD4 (PHYTOALEXIN DEFICIENT 4), which function in a positive feedback loop to increase SA biosynthesis and their own expression (Feys et al., 2001). Treatment of Arabidopsis plants with the SA analog 2,6dichloroisonicotinic acid (INA) produces a biphasic change of cellular redox potential. First a pro-oxidative effect and then an antioxidant effect of INA takes place (Mou et al., 2003). These changes of the redox status lead to the activation of different sets of target genes. Early SA-responsive genes play a role in detoxifying oxidative stress, like glutathione-Stransferases or glucosyltransferases (Blanco et al., 2009). Later, expression of pathogenesis related (PR)-genes like PATHOGENESIS RELATED-1 (PR-1) takes place (Lebel et al., 1998; van Loon, Rep, et al., 2006).

SA is an electrophilic compound and high concentrations can cause harmful effects due to xenobiotic stress. To avoid this, plants are able to form the bioinactive SA conjugate SA 2-oB-D-glucoside (SAG), which can be stored in the vacuole and serves as a hydrolysable source for SA. In Arabidopsis, the enzymes responsible for this conversion are the UDPglucosyltransferases UGT74F1 and UGT74F2 (Dean and Delaney, 2008).

The establishment of systemic acquired resistance (SAR) generates an increased protection against a wide range of pathogens not only at the local site of infection, but also in the whole host plant to prevent a subsequent invasion of the pathogen. SAR is usually described as a phenomenon whereas localized inoculation with a pathogen renders a plant more resistant to subsequent pathogen infection. Localized application of PAMPs or the SA analogon INA also causes local and systemic induction of endogenous SA levels and defense gene expression, similar to SAR-like disease resistance (Mishina and Zeier, 2007; Zhang et al., 2003). SAR is associated with an activation of signal transduction pathways, the accumulation of PR proteins and increase of SA in local and systemic tissues (Uknes et al., 1992; Van Loon, 1997; Durrant and Dong, 2004). This enhanced capacity to mobilize infection-induced cellular defense responses is called "priming" (Conrath et al., 2002). 
Plants which are impaired in SA signaling are not able to develop SAR and do not show $P R$ gene activation upon pathogen infection, which indicates that $S A$ is a necessary signal molecule for the initiation of SAR (Mauch-Mani and Metraux, 1998; Durrant et al., 2004). At least in Arabidopsis, the mobile signal that travels from the site of infection through the plant to develop SAR in distal tissues has remained unknown. Reciprocal grafting experiments with NahG rootstocks and wildtypic scions in tobacco demonstrate that SA is not important for the generation of the mobile signal (Vernooij et al., 1994). More recently, it was shown that the SA derivative methyl salicylate (MeSA) acts as a long-distance mobile signal for SAR in tobacco (Park et al., 2007). Other studies suggest a lipid-based molecule to be one of the key mobile signals in SAR. The dir1 (DEFECTIVE IN INDUCED RESISTANCE 1) mutant carries a mutation in a gene similar to lipid transfer proteins (LTPS) and displays normal local resistance to pathogens, while the generation of SAR and induction of $P R$ genes in systemic tissues fails (Maldonado et al., 2002).

Moreover, it could be shown that an interaction between PAMP- and SA-signaling exists. PAMPS induce SA accumulation in a SID2-dependent manner and expression profiling discovered that some PAMP-induced genes are SA independent, whereas other genes become SA dependent at later time points. Furthermore, SA signaling is required for PAMPtriggered resistance to Pseudomonas syringae, but a part of the response is SA-independent (Tsuda et al., 2008). SA is also involved in other basal defense responses. Defense through stomatal closure (Melotto et al., 2006) and some branches of PAMP-triggered callose deposition are SA-dependent (Clay et al., 2009; Adams-Phillips et al., 2010).

So far, the receptor for SA could not be identified, still many compounds downstream in the signaling cascade are known, as NONEXPRESSOR OF PATHOGENESIS-RELATED GENES1 (NPR1) and TGA transcription factors, which function as key regulators of SAR and are necessary for activation of $P R$ gene expression (Zhang et al., 2003).

\subsubsection{Hormonal networks to finetune plant defense}

Due to the different kinds of defense responses required against biotrophic, hemibiotrophic and necrotrophic pathogens as well as herbivorous insects, a tightly regulated fine tuning of the hormonal pathways is essential for the fitness of the plant. Activation of the SA signaling cascade causes a negative cross-talk on JA signaling, as revealed by a lack of PDF1.2 induction after combined exogenous application of SA and JA (Kunkel and Brooks, 2002). This negative regulation depends on NPR1 (Spoel et al., 2003), but the NPR1 
dependency is lost when ET signaling modulates the SA/JA cross-talk (Leon-Reyes et al., 2009).

\subsubsection{Suppression of host defense by the bacterial toxin coronatine}

Pathogens exploit the complex interplay between hormonal signaling pathways and evolved strategies to manipulate the immune response of the plant to increase pathogenicity. The phytotoxin coronatine (COR) is produced by different pathovars of $P$. syringae (Bender et al., 1999). COR is required for full virulence on several host species. COR- mutants of Pst DC3000 do not grow to wild-type levels or induce typical disease symptoms on either dip-inoculated Arabidopsis thaliana or tomato (Brooks et al., 2004; Penaloza-Vazquez et al., 2000). Recently, it was shown that COR binds to COI1 (Yan et al., 2009) and consequently acts as a molecular mimic of JA-Ile with a high biological activity to activate JA signaling (Feys et al., 1994; Weiler et al., 1994; Bender et al., 1999) and finally suppresses SA-dependent defenses, thereby promoting susceptibility of the plant to this pathogen (Brooks et al., 2005; Uppalapati et al., 2007).

In addition to the described observations, COR is able to suppress innate immune responses. COR was found to overcome PAMP- and bacteria-induced stomatal closure downstream of ABA in a COI1-dependent way (Melotto et al., 2006). Interestingly, a CORdefective mutant could not cause disease when inoculated onto the leaf surface but caused wild-type infection if infiltrated directly into the apoplast, bypassing the epidermis (Mittal and Davis, 1995). These results suggest that suppression of stomatal defense is the primary function of COR in local leaves and that the COR-mediated suppression of stomatal defense is critical for Pst DC3000 infection of host plants (Figure 2-3).

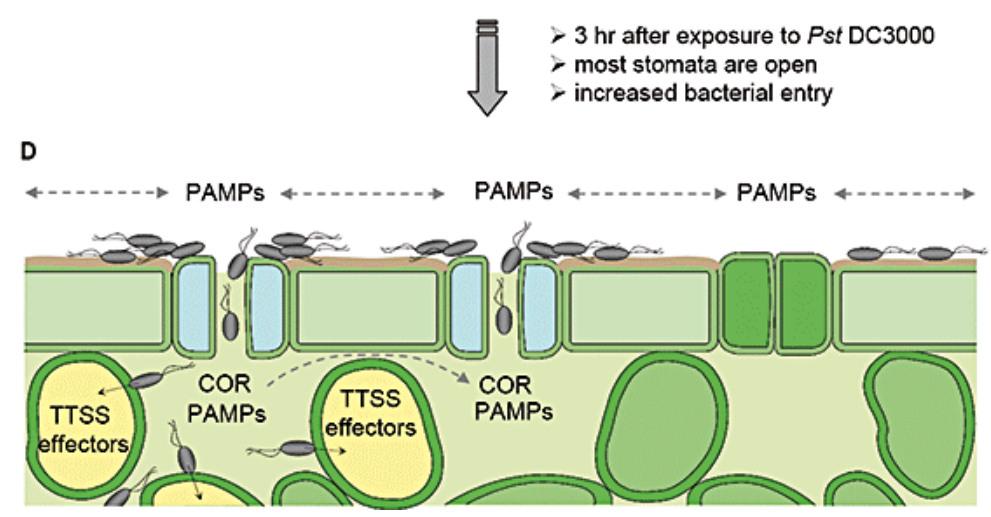

Figure 2-3 | Virulent Pst DC3000 produce coronatine (COR) to overcome PAMP induced stomatal closure. 3h after infection bacteria produce COR to re-open closed stomata, thereby increasing the number of entry sites for bacterial invasion. In addition, bacteria inject TTSS effectors to suppress host defenses (adapted from Underwood et al. 2007) 


\subsection{TGA transcription factors as regulators of defense responses}

As mentioned above, the current model of the SA signal transduction chain needs NPR1 and TGA transcription factors for activation of $P R$-gene expression. NPR1 does not contain any known DNA interaction domains. Several yeast two hybrid screens identified TGA transcription factors, a subgroup of the large family of bZIP transcription factors, as interaction partners of NPR1 (Jakoby et al., 2002). The name of the TGA family is derived from their ability to bind TGACG motifs in regulatory promoter regions (Katagiri et al., 1989). They were first characterized in tobacco by their ability to bind the activating sequence 1 (as-1) element of the CaMV $35 \mathrm{~S}$ promoter, a 20-bp element containing two TGACG boxes, and to promote transcription (Katagiri et al., 1989). The consensus as-1 element is TGACGTCAg---TGACGTCA, where the central bases are not conserved and the spacing between the palindromes in late-regulated promoters such as $P R-1$ is larger and more variable (Krawczyk et al., 2002). In vitro, the TGACG motif is sufficient for TGA factor binding (Lam et al., 1989).

In Arabidopsis, ten closely related group members of TGA factors exist (Figure 2-4). TGA2, TGA3, TGA5, TGA6 and TGA7 are able to interact with NPR1 (Després et al., 2000; Kim and Delaney, 2002; Zhang et al., 2003; Zhou et al., 2000), whereas TGA1 and TGA4 show only weak interaction in yeast unless two cystein residues are reduced (Després et al., 2003). Based on sequence similarities, the TGA factors are grouped into different classes (Miao et al., 1994). TGA1 and TGA4 form class I, TGA2, TGA5 and TGA6 build class II, and TGA3 and TGA7 represent class III.

TGA4 together with the second class I member TGA1 are sensors for changes in the cellular redox state. Although both proteins show no interaction with NPR1 in yeast, the interaction takes place in planta after SA induction, linking the two TGA factors to defense gene expression and resistance. In both proteins, two conserved cysteine residues (Cys260 and Cys266) form a disulfide bond under non-induced conditions. If the redox potential changes to a more reducing environment, the disulfide bond dissociates and the TGA factors are able to interact with NPR1 (Després et al., 2003). Analysis of the tga1 and tga4 double mutants revealed a partially redundant role in regulation of basal resistance, whereas the single mutants have only moderate effects on PR-gene expression (Kesarwani et al., 2007). 


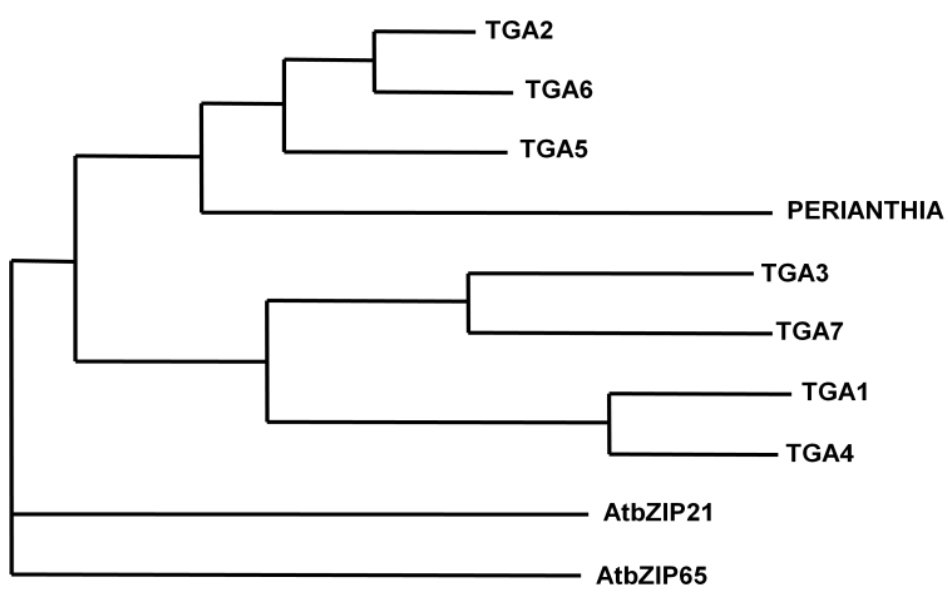

Figure 2-4 | Phylogenetic tree of the TGA transcription factor family of Arabidopsis thaliana.

The class-II TGA transcription factors are redundant regulators of $P R$-gene expression and SAR. tga2 tga5 tga6 triple mutants $(\operatorname{tga} 2,5,6)$ show a similar phenotype like npr1-1 regarding a compromised SAR and an increased sensitivity to SA (Zhang et al., 2003) but are not impaired in basal defense (Kesarwani et al., 2007). Furthermore, the basal expression of $P R$-genes is increased, demonstrating a dual function for TGA factors as transcriptional activators and repressors (Kesarwani et al., 2007). Conflicting data have been reported about their role for induction of $P R-1$, ranging from a complete loss of $P R-1$ induction (Zhang et al., 2003) to delayed induction kinetics upon treatment with SA or INA (Blanco et al., 2009). Class-II TGA transcription factors are also involved in NPR1-independent detoxification processes induced by oxylipins, formed in consequence of accumulation of xenobiotic compounds or ROS (Fode et al., 2008; Mueller et al., 2008). The NPR1independent induction of detoxification related stress responses uses the GRAS protein SCL14 (SCARECROW-LIKE 14) as co-regulator of TGA2, TGA5 and TGA6 (Fode et al., 2008).

Recently it could be shown that TGA2, TGA5 and TGA6 are essential for the activation of JAand ET-dependent defense mechanisms which counteract necrotrophic pathogens. In this case, the TGA factors act antagonistically to JIN1/AtMYC2 which functions as a negative regulator on JA/ET signaling and is necessary to install SA-mediated suppression of JA/ETinduced defense responses (Zander et al., 2009).

Further proteins known to interact with members of class-II TGAs belong to the glutaredoxin (GRX) family. GRXs catalyze thiol disulfide reductions and therefore are implicated in regulatory processes regarding the redox state of the cell (Lemaire, 2004). The 
expression of GRX480 is induced by SA with induction requiring a subset of TGA factors and NPR1 (Ndamukong et al. 2007).

The tga3-1 mutant of subclass III TGA factor TGA3 was found to be defective in basal defense. Additionally, the increased PR-1 background expression observed in the tga2,5,6 mutant is normalized in the tga2,3,5,6 quadruple mutant, once more displaying the complex interconnection of the TGA family members (Kesarwani et al., 2007). The function of the TGA factors AtbZIP21 and AtbZIP65 is still unclear.

\subsection{WRKY transcription factors: key players of plant immunity}

The 74 members of the WRKY family represent plant-specific transcription factors most of them involved in SAR or basal defense. Common to these proteins is a DNA-binding region with the conserved sequence motif WRKYGQK neighboring to a zinc-finger motif. WRKY factors have been implicated in the regulation of many plant processes like pathogen defense, wound response and senescence (Eulgem et al., 2000; Robatzek and Somssich, 2002; Dong et al., 2003). The regulation of gene expression by WRKY factors occurs with recognition of $\mathrm{W}$-box sequences $(\mathrm{C} / \mathrm{T}) \mathrm{TGAC}(\mathrm{T} / \mathrm{C})$ in the promoters of target genes (Eulgem et al., 2000).

In Arabidopsis, 49 out of 72 tested WRKY genes respond to bacterial infection or SA treatment. A considerable enrichment of $W$ boxes in the promoter regions of these defense regulated WRKY genes could be examined. These results strongly suggest that WRKY proteins themselves play an important role in the differential regulation of their own expression during the activation of plant defense responses (Dong et al., 2003).

On the one hand, some of the pathogen-induced WRKY proteins function as important positive regulators of plant disease resistance. As mentioned above, WRKY22 and WRKY29 are induced by a MAPK pathway that confers resistance to both bacterial and fungal pathogens and expression of WRKY29 in transiently transformed leaves led to reduced disease symptoms (Asai et al., 2002; Andreasson et al., 2005). Furthermore, mutations of WRKY7O enhances plant susceptibility to both biotrophic and necrotrophic pathogens (Li et al., 2004; AbuQamar et al., 2006; Li et al., 2006).

On the other hand, many WRKY proteins can function as negative regulators of plant defense. For example, mutations of Arabidopsis WRKY7, WRKY11, WRKY17 and WRKY48 
enhance basal plant resistance to virulent $P$. syringae strains (Journot-Catalino et al., 2006; Kim et al., 2006). Likewise, mutations of Arabidopsis WRKY25 enhance tolerance to $P$. syringae and overexpression of either WRKY25 or closely related WRKY33 enhances susceptibility to the bacterial pathogen and suppresses SA-regulated $P R 1$ gene expression (Zheng et al., 2006, 2007). The structurally related WRKY18, WRKY40, and WRKY60 also function partially redundant as negative regulators in plant resistance against $P$. syringae (Xu et al., 2006) and the fungal biotrophic pathogen Golovinomyces orontii (Shen et al., 2007). Among these, WRKY18 was described as direct target of NPR1 and TGA transcription factors (Wang et al., 2006).

\subsection{Aim of the study}

PTI is a very important mechanism to attack pathogens and assures the survival of plants living in a stressful environment. To understand the signal transduction-pathways behind this defense reaction, it is necessary to identify the involved components and their function. It could be shown that PAMPs are able to induce an SAR-like defense with activation of $P R$ genes in local and systemic tissue indicating an interaction between PAMPtriggered and SA-mediated signaling (Mishina et al., 2007). PAMP-triggered resistance is partially SA-dependent and microarray analysis discovered a group of genes induced by PAMPs in a SID2-dependent manner (Tsuda et al., 2008).

Class-II TGA transcription factors play important roles to regulate different branches of defense responses. In several studies, it could be shown that they are included in SAdependent (Zhang et al., 2003; Kesarwani et al., 2007) as well as JA/ET dependent pathways (Zander et al., 2009). As revealed by mutant analysis, class-II TGA factors together with NPR1 are also important for the SA-JA crosstalk (Spoel et al., 2003; Ndamukong et al., 2007). So far, a function of TGA factors in PAMP signaling is unknown.

In a root growth assay it could be shown that the tga2,5,6 mutant is more sensitive to growth inhibition induced by flg22. Based on these observations, the aim of this study was to investigate a possible involvement of class-II TGA factors in basal defense responses based on PAMP-signaling. For this work, the tga2,5,6 mutant, impaired in all three members of the class-II family, should be investigated in different assays to test basal defense responses. Different assays should be used to analyze root growth inhibition, ROSburst, gene expression, callose deposition and stomata closure. Beside flg22, other PAMPs 
should be used to find out, if the phenoptype of the tga2,5,6 mutant is flg22 specific. Moreover, treatment with SA or the JA mimic coronatine should elucidate, if phytohormones are involved. 


\section{$3 \quad$ Materials and Methods}

\subsection{Materials}

\subsubsection{Chemicals}

\begin{tabular}{|c|c|c|}
\hline Device & Model & Source \\
\hline Autoclave & 3870 ELV & Tuttnauer \\
\hline Automatic pipettes & pipetman & Gilson \\
\hline Balance & SPO52; SAC62; 1207MP2 & Scaltec; Satorius \\
\hline Bio imager & BAS 1000 & Fuji \\
\hline Blotting device & & University of Göttingen \\
\hline $\begin{array}{l}\text { Chambers for gel } \\
\text { electrophoreses }\end{array}$ & & University of Göttingen \\
\hline $\begin{array}{l}\text { Chemiluminescence plate } \\
\text { reader }\end{array}$ & Tecan infinite 200 & Tecan \\
\hline Cooling centrifuge & Sorvall RC 5B Plus & DuPont \\
\hline $\begin{array}{l}\text { Cooling centrifuge with } \\
\text { overhung rotor }\end{array}$ & Rotina 35A & Hettich \\
\hline Digital camera & Powershot A510 & Canon \\
\hline Gel documentation device & & MWG Biotech \\
\hline Heat block & & Boekel Scientific \\
\hline Heated stirrer & RCT basic & IKA Labortechnik \\
\hline Heated shaker & Thermomixer 5436 & Eppendorf \\
\hline homogenizer & Miccra-D8 & ART Labortechnik \\
\hline Ice machine & Af20 & Scotsman \\
\hline Locker for incubations & & WTC binder; Memmert \\
\hline
\end{tabular}




\begin{tabular}{|c|c|c|}
\hline Device & Model & Source \\
\hline Microscope & DM 5000B + CTR 5000 & Leica \\
\hline PCR cycler & iCycler & BioRad \\
\hline pH-Meter & HI 9321 & Hanna Instruments \\
\hline Photometer & Unikon 720 LC & Kontron \\
\hline $\begin{array}{l}\text { Photometer for microtiter } \\
\text { plates }\end{array}$ & MRX Dynex Plate Reader & Dynex \\
\hline Radiation monitor & Contamat & Eberline \\
\hline Realtime PCR cycler & MyiQ + iCycler & BioRad \\
\hline RNA-/DNA-Calculator & GeneQuant II & Pharmacia \\
\hline $\begin{array}{l}\text { RNA-/DNA-Calculator } \\
\text { (Spectrophotmeter) }\end{array}$ & NanoVue & GE Healthcare \\
\hline Rotary mixer & IntelliMixer RM-2L & ELMI \\
\hline Scanner & GT 9600 & Epson \\
\hline Sequencer & ABI PRISM 3100 & Perkin-Elmer \\
\hline Shaker & ST5M & Zipperer GmbH \\
\hline Sterile bench & Microflow Laminar & Nunc \\
\hline Sterile bench & Microflow Biohazard & Nunc \\
\hline Table-top micro centrifuge & Biofuge pico & Heraeus Christ \\
\hline $\begin{array}{l}\text { Table-top micro centrifuge, } \\
\text { cooled }\end{array}$ & Micro $200 \mathrm{R}$ & Hettich \\
\hline Ultrasonic homogenisator & Labsonic M & Satorius \\
\hline UV transilluminator & FLX-20 M & Vilber Lourmat \\
\hline Water deionization device & Option 4, Maxima & ELGA \\
\hline Vacuum pump & MD-1C & Vaccuumbrand \\
\hline Vortex & L46 & Labinco BV, Niederlande \\
\hline Water bath & 1086 & GFL \\
\hline
\end{tabular}




\subsubsection{Consumables}

\begin{tabular}{|l|l|}
\hline Product & Source \\
\hline Filter paper Miracloth & Calbiochem \\
\hline Flow paper 3MM & Whatman \\
\hline 96well microtiter- plates, white, flat- bottom & Greiner bio-one \\
\hline Microtiter plates & Roth \\
\hline nylon membrane Hybond N+ & Amersham \\
\hline Para-film M & American National Can ${ }^{\mathrm{TM}}$ \\
\hline Plastics one-way material & Biozym; Eppendorf; Greiner; Roth; Sarstedt \\
\hline pump aerosol can & Roth \\
\hline PVDF membrane Immobilon ${ }^{\mathrm{TM}}-\mathrm{P}$ & Millipore \\
\hline X-ray film Cronex 5 & Agfa, Belgium \\
\hline Ultra clear adhesive tape & TESA \\
\hline
\end{tabular}

\subsubsection{Chemicals}

\begin{tabular}{|l|l|} 
Chemical & Source \\
\hline $\begin{array}{l}30 \% \quad(\mathrm{w} / \mathrm{v}) \quad \text { Acrylamide: } \\
\text { Methylenebisacrylamide }(37,5: 1)\end{array}$ & Roth \\
\hline Agarose SeaKem LE & Biozym \\
\hline Aniline blue diammonium salt & Sigma \\
\hline Ampicillin & AGS \\
\hline APS (Ammonium persulfate) & Biometra \\
\hline Bradford-Reagent & Roth \\
\hline Bromophenol blue & Roth \\
\hline BSA & Serva \\
\hline
\end{tabular}




\section{Chemical}

Source

\begin{tabular}{|c|c|}
\hline BHA (Butylated hydroxyanisole) & Sigma \\
\hline Chitin from crab shells & Sigma-Aldrich \\
\hline Chitosan from crab shells & Sigma-Aldrich \\
\hline Coomassie brilliant blue G-250 & BioRad \\
\hline$\left[\alpha-{ }^{32} \mathrm{P}\right] \mathrm{dATP} ; 800 \mathrm{Ci} / \mathrm{mmol}$ & Hartmann Analytic \\
\hline Dimethyl sulfoxide (DMSO) & Sigma \\
\hline Dithiothreitol (DTT) & Sigma \\
\hline DMTU (Dimethylthiourea) & Sigma \\
\hline dNTPs & $\mathrm{MBI}$ \\
\hline DPI & diphenyleneiodonium chloride \\
\hline Ethylene diaminetetraacetate (EDTA) & AppliChem \\
\hline Ethidiumbromide & Roth \\
\hline Fat-free milk powder & Glücksklee \\
\hline Fluoresceine & BioRad \\
\hline Gelrite & Duchefa \\
\hline Glycogen G-8751 & Sigma-Aldrich \\
\hline HEPES & Roth \\
\hline Horse radish peroxidase & Sigma \\
\hline Hydrogen peroxide & Roth \\
\hline Herring sperm DNA (HSP) & Sigma \\
\hline Kanamycine & Sigma \\
\hline Luminol & Sigma \\
\hline$\beta$-Mercaptoethanol & Roth \\
\hline MES & Roth \\
\hline Murashige and Skoog (MS) medium & Duchefa \\
\hline Orange G & Sigma \\
\hline Percoll & Sigma \\
\hline
\end{tabular}




\begin{tabular}{|l|l|}
\hline Chemical & Source \\
\hline Phenol & Sigma \\
\hline Phenylmethane sulfonylchloride (PMSF) & Fluka \\
\hline PIPES & Roth \\
\hline Ponceau S & Sigma \\
\hline Protein A agarose beads & Sigma \\
\hline Proteose Peptone No. 3 & BD \\
\hline Rifampicine & Duchefa \\
\hline X-ray developer LX24 & Kodak \\
\hline X-ray fixer AL4 & Kodak \\
\hline Salicylic acid (SA) & Merck \\
\hline Select Agar & Life Technologies \\
\hline Select Yeast Extract & GlBCO BRL \\
\hline Sucrose & Roth \\
\hline SYBR Green I & Cambrex \\
\hline TEMED & Roth \\
\hline Triton X-100 & Roth \\
\hline Trypton & Oxoid \\
\hline Tween20 & Roth \\
\hline Futher standard & fhom the following \\
\hline
\end{tabular}

Further standard chemicals were purchased from the following companies: Boehringer, Fluka, Merck, Serva, Sigma and Roth 


\subsubsection{Enzymes and Kits}

\begin{tabular}{|c|c|}
\hline Enzyme/Kit & Source \\
\hline BCA Protein Assay Kit & Thermo Scientific \\
\hline $\begin{array}{l}\text { BigDye }^{\mathrm{TM}} \text { Terminator Cycle Sequencing Ready } \\
\text { Reaction Kit v.3.1 }\end{array}$ & Perkin-Elmer Corporation \\
\hline BioTaq DNA polymerase & Bioline \\
\hline desoxyribonuclease I (DNasel) RNase-free & MBI Fermentas \\
\hline Enhanced Chemiluminescence Plus ${ }^{\mathrm{TM}} \mathrm{Kit}(\mathrm{ECL}+)$ & GE Healthcare \\
\hline HiDi-Mix & ABI PRISM \\
\hline $\begin{array}{l}\text { Image-iT LIVE Green Reactive Oxigen Species } \\
\text { Detection Kit }\end{array}$ & Molecular Probes \\
\hline Immolase DNA polymerase & Bioline \\
\hline iProof high fidelity DNA polymerase & BioRad \\
\hline Klenow DNA polymerase exo ${ }^{-}$ & MBI Fermentas \\
\hline Megaprime DNA labeling system & Amersham \\
\hline Nucleo Spin ${ }^{\circledR}$ Extract II & Macherey-Nagel \\
\hline Nucleo Spin ${ }^{\circledR}$ Plasmid & Macherey-Nagel \\
\hline Reverse transcriptase $\mathrm{H}$ - & MBI Fermentas \\
\hline Restriction enzymes & MBI Fermentas, New England Biolabs \\
\hline RNase A (DNase-free) & Qiagen \\
\hline RNase inhibitor & MBI Fermentas \\
\hline T4 DNA-ligase & MBI Fermentas \\
\hline T4 DNA-polymerase & MBI Fermentas \\
\hline
\end{tabular}

\subsubsection{Standards}

\section{Standard}

GeneRuler DNA Ladder Mix

Prestained Protein Ladder

\section{Source}

MBI Fermentas

MBI Fermentas 


\subsubsection{Antibodies}

\begin{tabular}{l|l|l|l|}
\hline Antibody & \multicolumn{2}{l}{ Ppecificity } & Reference \\
\hline $\begin{array}{l}\text { ATGA2/5 (serum) } \\
\text { (SA 4364) }\end{array}$ & $\begin{array}{l}\text { TGA2 and TGA5 C- } \\
\text { terminal region } \\
\text { including the zipper } \\
\text { domain }\end{array}$ & $\begin{array}{l}\text { polyclonal from rabbit } \\
(1: 1000)\end{array}$ & (Fode et al., 2008) \\
\hline
\end{tabular}

\subsubsection{Peptides}

The following peptides were synthesized by EZBiolab, Westfield USA:

\begin{tabular}{|c|c|c|c|}
\hline Peptide & aa sequence & Purity & Reference \\
\hline elf18 & Ac-SKEKFERTKPHVNVGTIG & $95 \%$ & (Kunze et al., 2004) \\
\hline flg22 & QRLSTGSRINSAKDDAAGLQIA & $85 \%$ & (Felix et al., 1999) \\
\hline
\end{tabular}

\subsubsection{Nucleotides}

\subsubsection{Plasmids}

\begin{tabular}{|l|l|l|}
\hline \multicolumn{1}{|l|}{ Plasmid } & \multicolumn{1}{l|}{ Reference } \\
\hline pSK-T & $\begin{array}{l}\text { Cloning and sequenicing } \\
\text { vector; } \\
\text { pBluescriptll SK (Stratagene, } \\
\text { Cedar Cree, Texas) was } \\
\text { restricted } \\
\text { with EcoRV and treated with } \\
\text { terminal transferase in } \\
\text { presence of } \\
\text { ddTTP; lacZa, amp }{ }^{r}\end{array}$ & Guido Kriete, unpublished \\
\hline pSK-T_QPR1 & $\begin{array}{l}\text { pSK-T vector with amplificat } \\
\text { derived from PCR with } \\
\text { Quantitect PR-1 primer } \\
\text { assay }\end{array}$ & this thesis \\
\hline
\end{tabular}




\subsubsection{Primers and Oligos}

Primers were synthesized by Invitrogen. QuantiTect Primer Assays from Qiagen contain both, forward and reverse primer. They are indicated as "QPA" and are described on: http://www1.qiagen.com/Products/Pcr/QuantiTect/PrimerAssays.aspx False QuantiTect primers (FQ) are designed on basis of sequence analysis of the PCR fragment after amplification with the original primer assays. PCR-product was ligated in vector PSK-T and DNA sequencing was done with UNI and REV primers. The design of PCRprimers was done with respect to avoid secondary structures and that an annealing temperature of $55^{\circ} \mathrm{C}$ was obtained. These primers were diluted and mixed to $4 \mu \mathrm{M}$ stock solution containing forward and reverse primer.

\begin{tabular}{|c|c|c|c|}
\hline Gene & Primer & Sequence $5^{\prime} \rightarrow 3^{\prime}$ & Source \\
\hline & \multicolumn{3}{|l|}{ qRT-PCR } \\
\hline $\begin{array}{l}\text { FRK1 } \\
\text { (At2g19190) }\end{array}$ & QT00752444 & QPA & Qiagen \\
\hline $\begin{array}{l}\text { ICS1 } \\
\text { (At1g74710) }\end{array}$ & QT00893473 & QPA & Qiagen \\
\hline $\begin{array}{l}\text { PMR4 } \\
\text { (At4g03550) }\end{array}$ & QT00798077 & QPA & Qiagen \\
\hline $\begin{array}{l}\text { PR-1 } \\
\text { (At2g14610) }\end{array}$ & $\begin{array}{l}\text { QPR1 forw } \\
\text { QPR1 rev }\end{array}$ & $\begin{array}{l}\text { CTG ACT TTC TCC AAA CAA CTT G } \\
\text { GCG AGA AGG CTA ACT ACA ACT AC }\end{array}$ & $\mathrm{FQ}$, this work \\
\hline $\begin{array}{l}\text { RbohD } \\
\text { (At5g47910) }\end{array}$ & QT00741104 & QPA & Qiagen \\
\hline $\begin{array}{l}\text { CYP79B2 } \\
\text { (At4g39950) }\end{array}$ & $\begin{array}{l}\text { RT CYP79B2 forw } \\
\text { RT CYP79B2 rev }\end{array}$ & $\begin{array}{l}\text { GTA ACT TCG GAG CAT TCG T } \\
\text { TCG CCG GAT ATC ACA TCC }\end{array}$ & (Clay et al., 2009) \\
\hline $\begin{array}{l}\text { CYP81F2 } \\
\text { (At5g57220) }\end{array}$ & $\begin{array}{l}\text { RT CYP81F2 forw } \\
\text { RT CYP81F2 rev }\end{array}$ & $\begin{array}{l}\text { CTC ATG CTC AGT ATG ATG C } \\
\text { CTC CAA TCT TCT CGT CTA TC }\end{array}$ & (Clay et al., 2009) \\
\hline $\begin{array}{l}\text { UBQ5 } \\
\text { (At3g62250) }\end{array}$ & $\begin{array}{l}\text { UBQ5 fwd. RT } \\
\text { UBQ5 rev RT }\end{array}$ & $\begin{array}{l}\text { GAC GCT TCA TCT CGT CC } \\
\text { GTA AAC GTA GGT GAG TCC A }\end{array}$ & $\begin{array}{l}\text { (Kesarwani et al., } \\
2007 \text { ) }\end{array}$ \\
\hline $\begin{array}{l}\text { WRKY22 } \\
\text { (At4g01250) }\end{array}$ & QT00809886 & QPA & Qiagen \\
\hline \multirow[t]{2}{*}{$\begin{array}{l}\text { WRKY29 } \\
\text { (At4g23550) }\end{array}$} & QT00813645 & QPA & Qiagen \\
\hline & \multicolumn{3}{|l|}{ genotyping } \\
\hline $\begin{array}{l}\text { PMR4 } \\
\text { (At4g03550) }\end{array}$ & $\begin{array}{l}\text { pmr4-1-Nhel-F } \\
\text { pmr4-1-Nhel-R }\end{array}$ & $\begin{array}{l}\text { TTA CCA GCC CAA CCA ATT TC } \\
\text { AGA TCA GGG ACA TGG GAC AG }\end{array}$ & $\begin{array}{l}\text { (Nishimura et al., } \\
\text { 2003) }\end{array}$ \\
\hline $\begin{array}{l}\text { ICS1 } \\
\text { (At1g74710) }\end{array}$ & $\begin{array}{l}\text { sid2-2 Hindlll forw } \\
\text { sid2-2 Dral rev }\end{array}$ & $\begin{array}{l}\text { CTC AAT TAG GTG TCT GCA GTG AAG C } \\
\text { GTT GTA GCA AAA ACC GTA ATG ATC G }\end{array}$ & $\begin{array}{l}\text { (Wildermuth et } \\
\text { al., 2001) }\end{array}$ \\
\hline
\end{tabular}




\begin{tabular}{|c|c|c|c|}
\hline Gene & Primer & Sequence $5^{\prime} \rightarrow 3^{\prime}$ & Source \\
\hline $\begin{array}{l}\text { TGA2 } \\
\text { (At5g06950) } \\
\text { TGA5 } \\
\text { (At5g06960) }\end{array}$ & $\begin{array}{l}\text { TGA25genom forw } \\
\text { TGA25wtrev } \\
\text { TGA25genom rev }\end{array}$ & $\begin{array}{l}\text { GTC AAT CCG GTT TCA TAT TCT CCT C } \\
\text { CCG CAT AAA CAA TAA ACC AAG AGA G } \\
\text { GAG CGA CAA CTC CTT TCA ACT СAT C }\end{array}$ & this thesis \\
\hline \multirow[t]{2}{*}{$\begin{array}{l}\text { TGA6 } \\
\text { (At3g12250) }\end{array}$} & $\begin{array}{l}\text { TGA6genom forw } \\
\text { TGA6genom rev }\end{array}$ & $\begin{array}{l}\text { TTC TCA CTT TGT GAT TTG CCT TTG G } \\
\text { TGG GCA ATC TTG CTA TGA TTT CAA G }\end{array}$ & this thesis \\
\hline & \multicolumn{3}{|l|}{ northern probe } \\
\hline \multirow[t]{7}{*}{$\begin{array}{l}\text { FRK1 } \\
\text { (At2g19190) }\end{array}$} & $\begin{array}{l}\text { FRK1cDNA forw } \\
\text { FRK1cDNA rev }\end{array}$ & $\begin{array}{l}\text { TCT TTC ATC GAT TTT ATT CAC AAG C } \\
\text { TAG TTT TCC TGA TCA GTC ACT ATG CC }\end{array}$ & this thesis \\
\hline & \multicolumn{3}{|l|}{ sequencing } \\
\hline & UNI & ACG ACG TTG TAA AAC GAC GGC CAG & \\
\hline & REV & TTC ACA CAG GAA ACA GCT ATG ACC & \\
\hline & \multicolumn{3}{|l|}{ cDNA synthesis } \\
\hline & oligodT & TTT TTT TTT TTT TTT TTT TT & \\
\hline & random nonamere & NNN NNN NNN & \\
\hline
\end{tabular}

\subsubsection{Organisms}

\subsubsection{Plant genotypes}

\begin{tabular}{|c|c|c|}
\hline Genotype & Description & Reference \\
\hline Columbia, Col-0 & wild type & $\begin{array}{l}\text { NASC Stock Nr. N1092, NASC } \\
2002\end{array}$ \\
\hline cpr5 & constitutive expressor of $P R$ genes & (Bowling et al., 1997) \\
\hline NahG & Col-0 carrying NahG-transgene & (Delaney et al., 1994) \\
\hline npr1-1 & point-mutation in NPR-1 gene & (Cao et al., 1997) \\
\hline pmr4-1 & Callose synthase CalS12 deficient & (Nishimura et al., 2003) \\
\hline sid2-2 & SA-induced deficient & (Wildermuth et al., 2001) \\
\hline
\end{tabular}




\begin{tabular}{|c|c|c|}
\hline Genotype & Description & Reference \\
\hline $\operatorname{tga1,4}$ & TGA1 and TGA4 double mutant & $\begin{array}{l}\text { Y. Zhang, (Kesarwani et al., } \\
\text { 2007) }\end{array}$ \\
\hline $\operatorname{tga3}-1$ & Single knock out of TGA3 & $\begin{array}{l}\text { Y. Zhang, (Kesarwani et al., } \\
\text { 2007) }\end{array}$ \\
\hline $\operatorname{tga} 6-1$ & Single knock out of TGA6 & Y. Zhang, (Zhang et al., 2003) \\
\hline $\operatorname{tg} a 2,5$ & TGA2 and TGA5 double mutant & Y. Zhang, (Zhang et al., 2003) \\
\hline $\operatorname{tg} a 2,5,6$ & $\begin{array}{l}\text { Knock out line lacking all three class II } \\
\text { TGA transcription factors, impaired in } \\
\text { SAR }\end{array}$ & X. Dong, (Zhang et al., 2003) \\
\hline $\operatorname{tga} 2,3,5,6$ & $\begin{array}{l}\text { Knock out line lacking all three class II } \\
\text { TGA transcription factors and TGA3 }\end{array}$ & X. Dong, (Zhang et al., 2003) \\
\hline $\operatorname{tga} 2,5,6 / p m r 4$ & & this work \\
\hline $\operatorname{tga} 2,5,6 / \operatorname{sid} 2$ & & this work \\
\hline $\begin{array}{l}\operatorname{tga} 2,5,6:: \\
35 S: T G A 2\end{array}$ & $\begin{array}{l}\text { Over-expression line, expressing the } \\
T G A 2 \text { gene under control of the CaMV } \\
35 S \text { promoter }\end{array}$ & $\begin{array}{l}\text { M. Zander , (Zander et al., } \\
\text { 2009) }\end{array}$ \\
\hline $\begin{array}{l}\operatorname{tga2}, 5,6:: \\
\text { 35S:TGA5 }\end{array}$ & $\begin{array}{l}\text { Over-expression line, expressing the } \\
\text { TGA5 gene under control of the CaMV } \\
35 S \text { promoter }\end{array}$ & $\begin{array}{l}\text { M. Zander , (Zander et al., } \\
\text { 2009) }\end{array}$ \\
\hline $\begin{array}{l}\operatorname{tga2}, 5,6:: \\
\text { 35S:TGA6 }\end{array}$ & $\begin{array}{l}\text { Over-expression line, expressing the } \\
\text { TGA6 gene under control of the CaMV } \\
35 S \text { promoter }\end{array}$ & $\begin{array}{l}\text { M. Zander , (Zander et al., } \\
\text { 2009) }\end{array}$ \\
\hline
\end{tabular}

\subsubsection{Bacteria}

\begin{tabular}{|l|l|l|} 
Species & Properties & Reference \\
\hline $\begin{array}{l}\text { Escherichia coli } \\
\text { DH5 } \alpha\end{array}$ & $\begin{array}{l}\text { F-, gyrA96 (Nalr), recA1, } \\
\text { endA1, thi-1, hsdR17 } \\
\text { (rkmk+), glnV44, deoR, D } \\
\text { (lacZYA-argF) U169 } \\
\text { [p80dD(lacZ)M15] }\end{array}$ & \\
& & \\
\hline
\end{tabular}




\begin{tabular}{|c|c|c|}
\hline Species & Properties & Reference \\
\hline $\begin{array}{l}\text { Pseudomonas syringae pv. } \\
\text { tomato DC } 3000\end{array}$ & pLAFR3; rif $^{r}$ & (Innes et al., 1993) \\
\hline $\begin{array}{l}\text { Pseudomonas syringae pv. } \\
\text { tomato DC } 3000 \text { COR- }\end{array}$ & $\begin{array}{l}\text { Coronatine deficient; } \text { rif }^{r} \text {; } \\
\operatorname{kan}^{r}\end{array}$ & J. Zeier; (Zhao et al., 2003) \\
\hline $\begin{array}{l}\text { Pseudomonas syringae pv. } \\
\text { tomato DC } 3000 \mathrm{hrpA}-\end{array}$ & Deficient in TTSS; rif $^{r} ;$ kan $^{r}$ & $\begin{array}{l}\text { J. Zeier; (Mishina and Zeier, } \\
\text { 2007) }\end{array}$ \\
\hline $\begin{array}{l}\text { Pseudomonas syringae pv. } \\
\text { maculicola ES4326 }\end{array}$ & pLAFR3; rif $^{r}$ & (Whalen et al., 1991) \\
\hline
\end{tabular}

\subsubsection{Standard buffers}

\begin{tabular}{|c|c|}
\hline Buffer & Content \\
\hline PBS $(10 \mathrm{x})$ & $1.4 \mathrm{M} \mathrm{NaCl}, 27 \mathrm{mM} \mathrm{KCl}, 100 \mathrm{mM} \mathrm{Na}_{2} \mathrm{HPO}_{4}, 18 \mathrm{mM} \mathrm{KH}_{2} \mathrm{PO}_{4}, \mathrm{pH} 7.3$ \\
\hline PBS-T (1 x) & $1 \times$ PBS with $0.05 \%$ (v/v) Tween-20 \\
\hline TAE (20 x) & $0.8 \mathrm{M}$ Tris, $2.3 \%$ (v/v) acetic acid, $20 \mathrm{mM}$ EDTA \\
\hline TE & 10 mM Tris, 1 mM EDTA, pH 7.5 \\
\hline Buffer O+ & $\begin{array}{l}50 \mathrm{mM} \text { Tris- } \mathrm{HCl}\left(\mathrm{pH} 7.5 \text { at } 37^{\circ} \mathrm{C}\right) ; 10 \mathrm{mM} \mathrm{MgCl}_{2} ; 100 \mathrm{mM} \mathrm{NaCl} ; 0.1 \\
\mathrm{mg} / \mathrm{ml} \mathrm{BSA}\end{array}$ \\
\hline Buffer B+ & $10 \mathrm{mM}$ Tris- $\mathrm{HCl}\left(\mathrm{pH} 7.5\right.$ at $\left.37^{\circ} \mathrm{C}\right) ; 10 \mathrm{mM} \mathrm{MgCl}_{2} ; 0.1 \mathrm{mg} / \mathrm{ml} \mathrm{BSA}$ \\
\hline Buffer G+ & $\begin{array}{l}10 \mathrm{mM} \text { Tris- } \mathrm{HCl}\left(\mathrm{pH} 7.5 \text { at } 37^{\circ} \mathrm{C}\right) ; 10 \mathrm{mM} \mathrm{MgCl} 2 ; 50 \mathrm{mM} \mathrm{NaCl} ; 0.1 \mathrm{mg} / \mathrm{ml} \\
\text { BSA }\end{array}$ \\
\hline Buffer R+ & $\begin{array}{l}10 \mathrm{mM} \text { Tris- } \mathrm{HCl}\left(\mathrm{pH} 8.5 \text { at } 37^{\circ} \mathrm{C}\right) ; 10 \mathrm{mM} \mathrm{MgCl} \\
\text { BSA }\end{array}$ \\
\hline Buffer Y+ & $\begin{array}{l}33 \mathrm{mM} \text { Tris-Acetat }\left(\mathrm{pH} 7.9 \text { at } 37^{\circ} \mathrm{C}\right) ; 10 \mathrm{mM} \text { magnesium acetat; } 66 \mathrm{mM} \\
\text { potassium acetat; } 0.1 \mathrm{mg} / \mathrm{ml} \mathrm{BSA}\end{array}$ \\
\hline $\begin{array}{l}10 \times \text { DNA- } \\
\text { sample buffer }\end{array}$ & $67 \%$ succrose; 50 mM EDTA, pH 8.0; $0.42 \%$ (w/v) Orange G \\
\hline $\operatorname{SSC}(20 x)$ & $2 \mathrm{M} \mathrm{NaCl}, 0.3 \mathrm{M}$ sodiumcitrat, $\mathrm{pH} 7.0$ with $\mathrm{HCl}$ \\
\hline
\end{tabular}




\subsubsection{Growing media}

All media and heat-stable solutions were sterilized by autoclaving for $20 \mathrm{~min}$ at $121^{\circ} \mathrm{C}$. The heat sensitive solutions were sterilized by filtering through a $0.2 \mu \mathrm{m}$ membrane filter (Heinemann Labortechnik $\mathrm{GmbH}$, Germany). To solidify the media $8 \mathrm{~g} / \mathrm{L}$ select agar or $5 \mathrm{~g} / \mathrm{L}$ Gelrite were added.

\begin{tabular}{|c|c|}
\hline Medium & Content \\
\hline King's B & $\begin{array}{l}10 \mathrm{~g} / \mathrm{L} \text { Proteose-Pepton No } 3 ; 1,5 \mathrm{~g} / \mathrm{L} \mathrm{K}_{2} \mathrm{HPO}_{4} ; 15 \mathrm{~g} / \mathrm{L} \text { glycerol; } \mathrm{pH} 7 \\
\text { with } \mathrm{HCl} \text {; add after autoclaving } 5 \mathrm{ml} / \mathrm{l} 1 \mathrm{M} \mathrm{MgSO}_{4}\end{array}$ \\
\hline 1MS+MES & 1 \% sucrose,.4 g/L MS medium; 1g/L MES; pH 5.7 with $\mathrm{KOH}$ \\
\hline LB & $10 \mathrm{~g} / \mathrm{L}$ tryptone, $5 \mathrm{~g} / \mathrm{L}$ yeast extract, $10 \mathrm{~g} / \mathrm{L} \mathrm{NaCl}, \mathrm{pH} 7.0(\mathrm{NaOH})$ \\
\hline
\end{tabular}

\subsubsection{Software}

\begin{tabular}{|l|l|}
\hline \multicolumn{2}{|l|}{ Software } \\
\hline AIDA & Raytest \\
\hline GraphPad Prism 5 & GraphPad \\
\hline i-control & TECAN \\
\hline ImageJ & W. Rasband \\
\hline iQ5 & BioRad \\
\hline Leica Application Suite & Leica \\
\hline
\end{tabular}




\subsection{Methods}

\subsubsection{Plant growth conditions}

\subsubsection{Grow conditions on soil}

Plants were grown on steamed soil supplemented with Confidor $(50 \mathrm{mg} / \mathrm{l})$ and fertilizer $(0.5$ $\mathrm{ml} / / \mathrm{l}$ Wuxal) under short day conditions $\left(22^{\circ} \mathrm{C} / 18^{\circ} \mathrm{C}, \sim 70 \mu \mathrm{mol} / \mathrm{m}^{2} / \mathrm{s} \mathrm{Par}, 8 \mathrm{~h}\right.$ light $/ 16 \mathrm{~h}$ dark, $60 \%$ humidity). During germination, a transparent hood was used to reach a high humidity. After 5-6 weeks the plats can be used for investigations.

For infections with $P$. syringae 10-20 seed were spread out on peat balls (Jiffy Products International AS, Norway).

\subsubsection{Axenic growth conditions}

Approximately 200 seeds were surface sterilized (chapter 3.2.3) and sown on sterile $1 x$ MSplates comprise $1 \mathrm{~g} / \mathrm{L} \mathrm{MES}, \mathrm{pH}$ 5.7. After stratification for approximately two days the plants were grown for $10-14$ days at $22^{\circ} \mathrm{C}$ under long day conditions (16h light/ $8 \mathrm{~h}$ dark) and $60 \%$ humidity in a climate chamber.

\subsubsection{Generation of quadruple mutants}

To obtain tga2-1 tga5-1 tga6-1 pmr4-1 and tga2-1 tga5-1 tga6-1 sid1-2 quadruple mutant, tga2,5,6 was crossed with pmr4-1 and sid2-2, respectively. F1 plants were allowed to selffertilize and mutants were screened from the F2 population using PCR. TGA2 and TGA5 are located next to each other. tga6-1 tga2-1 tga5-1 were identified using primers within the deletions to confirm homozygosity at both loci (Zhang et al., 2003). The pmr4-1 allele was confirmed by PCR using the cleaved-amplified polymorphic sequence marker primers described in 3.1.8.1, followed by digestion with Nhel (Nishimura et al., 2003). The sid2-2 allele was also identified by PCR, using primers located in the big deletion site (Wildermuth et al., 2001).

\subsubsection{Surface sterilization of $\boldsymbol{A}$. thaliana seeds}

E-cups with open lid containing Arabidopsis seeds (up to a volume of approx. $100 \mu \mathrm{l}$ ) were placed in an exsiccator together with $100 \mathrm{ml}$ hypochloric solution and $5 \mathrm{ml}$ hydrochloric acid. To close the exsiccator firmly, a weak vacuum was used. After $5 \mathrm{~h}$ in chloric acid atmosphere the seeds are sterile to spread out. 


\subsubsection{Root length determination}

Approx. 40 seeds were placed with the help of a toothpick in a horizontal line on 1MS-MES medium plus GELRITE $(5 \mathrm{~g} / \mathrm{L})$, in square petri dishes. For every assay one control plate and a second containing flg22 peptide were used. After stratification, seedlings were grown for 10 days in vertical position under long day conditions. Pictures were taken with a digital camera. The computer software ImageJ was used to quantify the root length. In case of using a ROS inhibitor, the length of seven day old roots were measured five days after transfer to DPI, BHA or DMTU containing plates (concentrations as indicated).

\subsubsection{ROS-staining in roots}

Seedlings of $A$. thaliana were grown as described for the root inhibition assays (chapter 3.2.3). 7-day-old seedlings were spray-treated with $\mathrm{H}_{2} \mathrm{O}, 1 \mathrm{mM} \mathrm{SA}$ or $1 \mu \mathrm{M}$ flg22 for 60 min and then transferred to staining buffer (10 mM MES, $0.1 \mathrm{mM} \mathrm{KCl}, 0.1 \mathrm{mM} \mathrm{CaCl}_{2}, \mathrm{pH} 6.0$ ) plus $0.001 \%$ DMSO (unstained control) or staining solution ( $10 \mathrm{mM} \mathrm{H}_{2}$ DCFDA in staining buffer) plus $1 \mu \mathrm{M}$ SA or $1 \mu \mathrm{M}$ flg22 (and control). After 30 min of incubation in the dark, seedlings were washed with staining buffer. Root tips were immediately observed under a microscope (Leica DM 5000B + CTR 5000, fluorescence cube GFP) with 100x magnification. Quantification of the staining was performed with Leica application suite. The intensity of staining was calculated as average fluorescent intensity per $\mathrm{mm}^{2}$ root area.

\subsubsection{ROS-burst assay}

To analyse the production of reactive oxygen species after chitin and flagellin application a luminol based assay was used. When PAMPs are added, the leaves release reactive oxygen species and the horseradish peroxidase catalyses the oxidation of luminol to 3aminophthalate via several intermediates. The reaction is accompanied by emission of low intensity light at $428 \mathrm{~nm}$. This chemiluminescence can be quantified in a plate reader. Leaf discs from 4-6 weeks old soil-grown plants cultivated under short day conditions were used. Every well of a white 96-well microtiter plate was filled with $100 \mu l$ water. For each mutant/background line 16-24 leaf discs were harvested and incubated in water, until the wound response has worn off $(\mathrm{o} / \mathrm{n})$. The luminol solution $(10 \mathrm{mM}$ Tris $/ \mathrm{HCl}, \mathrm{pH} 9.5 ; 10 \mu \mathrm{g} / \mathrm{ml}$ horse radish peroxidase, $17 \mu \mathrm{g} / \mathrm{ml}$ luminol) was splitted off: to one half the designated PAMP was added to a final concentration of $100 \mu \mathrm{g} / \mathrm{ml}$ chitin or chitosan or $1 \mu \mathrm{M}$ flg22. The water was removed from the wells of the microtiter plate without wounding the leaf discs. To one half of the leaf discs $100 \mu$ l of luminol solution without PAMP and to the other half $100 \mu$ l luminol solution with PAMP was added with a multichannel pipette to be fast. The reaction starts immediately. The measurement of the chemiluminescence in a plate reader has to be done promptly for $60 \mathrm{~min}$ with measurement intervals of $1 \mathrm{~min}$. 


\subsubsection{Callose staining in seedlings and soil grown plants}

Seedlings were grown like described for the root length measurement (3.2.4). Callose deposition was induced by spray treatment with $1 \mu \mathrm{M}$ flg22 for $24 \mathrm{~h}$. The leaves were separated from the roots with the help of a scalpel blade and incubated in $80 \% \mathrm{EtOH}$ for several days for fixation and de-staining. For determination of callose deposition after pathogen infection, leaves of 4-6 weeks old soil grown plants were syringe infiltrated with the bacterial solution $\left(\mathrm{OD}_{600}=0.02\right)$. To accelerate the de-staining the solution can be exchanged several times until it becomes clear and the leaves are completely colorless. For rehydration the leaves were first incubated in $50 \% \mathrm{EtOH}$ and afterwards in $\mathrm{H}_{2} \mathrm{O}$. The get the tissue transparent $2 \mathrm{~h}$ incubation at $37^{\circ} \mathrm{C}$ with $10 \% \mathrm{NaOH}$ was conducted. Afterwards, several washing steps with $\mathrm{H} 2 \mathrm{O}$ were done until the $\mathrm{pH}$ value gets neutral. The water was changed with $150 \mathrm{mM} \mathrm{KH}_{2} \mathrm{PO}_{4}(\mathrm{pH}$ 12). The staining with aniline blue $(0.01 \%$ in $150 \mathrm{mM}$ $\mathrm{KH}_{2} \mathrm{PO}_{4}, \mathrm{pH} 12$ ) occurs on a shaking platform o/n. For analysis, the leaves were transferred on object slides with staining solution $+50 \%$ glycerol and observed under the microscope with UV light (filtercube $A$; Leica) and $25 x$ magnification. For quantification of the fluorescent spots the software AIDA was used. The intensity of staining was calculated for each image as the index of stained pixels of the leaf area normalized to the average of three points representing unstained area from all pictures taken in one experiment.

\subsubsection{Measurement of stomatal response to different treatments}

To assure that most stomata were open before beginning experiments, plants were kept under light for at least $3 \mathrm{hr}$. Fully expanded young leaves of 4-6 week old soil-grown plants cultivated under short day conditions were immersed in tab water, $5 \mu \mathrm{M}$ flg22 or flg22 in combination with $0.5 \mathrm{ng} / \mu \mathrm{l}$ COR. Alternatively, a bacterial solution of Psm ES4326 $\left(O D_{600}=0.2\right)$ was used. $3 \mathrm{~h}$ after treatment with chemical compounds, and $1 \mathrm{~h}$ and $3 \mathrm{~h}$ after bacterial inoculation, epidermal peels of three leaves was peeled off by applying the leaf lower surface on a piece of ultraclear adhesive tape and observed under a microscope (Leica DM 5000B). Pictures were taken of random regions. The width of the stomatal aperture was measured using the software ImageJ.

\subsubsection{Induction of gene expression in A. thaliana}

10-14 days old, sterile grown seedlings were treated by spraying with a pump aerosol can producing a fine drizzle until the seedings are equally moistened. The solutions were prepared freshly for every treatment with deionized water. The following solutions were used:

- $1 \mathrm{mM}$ salicylic acid

- $100 \mathrm{nM}$ or $1 \mu \mathrm{M}$ flg22 peptide as indicated

- $1 \mu \mathrm{M}$ elf18 peptide

- $100 \mu \mathrm{g} / \mathrm{ml}$ chitosan

- $100 \mu \mathrm{g} / \mathrm{ml}$ chitin

- $5 \mu \mathrm{M}$ coronatine 
Chitosan and chitin are not soluble in water. Therefore, grinding to fine powder was done before water was added.

\subsubsection{Bacterial growth assay}

The measurement of bacterial growth was done in collaboration with Jane Glazebrook (University of Minnesota, St Paul, USA) as previously described in (Tsuda et al., 2008). Pst $\mathrm{DC} 3000\left(\mathrm{OD}_{600}=0.0001,1 \times 10^{5} \mathrm{CFU} / \mathrm{ml}\right)$ bacterial suspensions were infiltrated into 5 -weekold plants 1 day after treatment with water or $1 \mu \mathrm{M}$ flg22. Each sample consisted of two leaf discs (total surface $0.57 \mathrm{~cm}^{2}$ ) taken from a single leaf. Leaf discs were pulverized in 400 $\mu \mathrm{l}$ of $5 \mathrm{mM} \mathrm{MgSO}_{4}$ and dilution series were made. Of each dilution, $10 \mu \mathrm{l}$ was streaked on King's B plates containing $25 \mu \mathrm{g} / \mathrm{ml}$ of rifampicin. The leaf bacterial titer was measured at 0 and 2 dpi for PstDC3000. From this data, the colony-forming units (CFU) per $\mathrm{cm}^{2}$ leaf surface area were calculated.

\subsubsection{Standard molecular methods}

\subsubsection{Transformation of chemical competent E. coli DH5a}

The transformation procedure was followed as described in Hanahan (1983). In brief, $200 \mu \mathrm{l}$ competent $E$. coli cells were thawed on ice for $20 \mathrm{~min}, 50 \mathrm{ng}$ of plasmid DNA were added to the cells and mixed gently. The mixture was incubated on ice for $30 \mathrm{~min}$. After a heat shock for $90 \mathrm{sec}$ at $42^{\circ} \mathrm{C}$ the cells were placed immediately on ice for at least $3 \mathrm{~min} .800 \mu \mathrm{l}$ of LB medium were added to the tube and the suspension was mixed on a roller for 45-60 min at $37^{\circ} \mathrm{C}$ depending on selectable antibiotic resistance marker. Different volumes of the culture were spread on plates containing LB medium supplemented with antibiotics. The plates were incubated overnight at $37^{\circ} \mathrm{C}$.

\subsubsection{Cryoconservation of bacteria}

For long-term storage, the overnight culture was supplemented with $20 \%$ glycerol and stored at $-80^{\circ} \mathrm{C}$.

\subsubsection{High-purity plasmid DNA isolation}

For sequencing and transformation purposes, high-purity plasmid DNA was isolated using Nucleospin Mini kit (Macherey-Nagel, Düren, Germany) following the manufacturer's instructions. Optional steps were always followed according to the manufacturer's recommendation. A $4 \mathrm{ml}$ overnight culture was used to isolate plasmid and the isolated DNA was eluted with $50 \mu$ l (high copy) or $30 \mu l$ (low copy) EB buffer. 


\subsubsection{Determination of DNA/ RNA concentrations}

The concentration of nucleic acids was estimated by measuring their absorption in a spectrophotometer at a wavelength of $260 \mathrm{~nm}$ (maximum nucleic acid absorption value; due to the $\pi$-electron systems of the heterocyclic nucleotides). At $10 \mathrm{~mm}$ path-length $O D_{260}$ $=1.0$ is equivalent to $50 \mu \mathrm{g} / \mathrm{mL}$ double-stranded DNA and $40 \mu \mathrm{g} / \mathrm{mL}$ RNA, respectively. Absorption at $280 \mathrm{~nm}$ (for the presence of aromatic rings from amino acids and phenol compounds) was used to give information about the purity of the DNA or RNA sample, where an optimal ratio $\mathrm{OD}_{260} / \mathrm{OD}_{280}$ is in the range of 1.9-2.0 for RNA and 1.8 for DNA.

\subsubsection{Ligation of DNA fragments}

The conventional cloning of a DNA fragment into a selected plasmid was performed using the T4-DNA ligase enzyme, which is able to catalyze the formation of a phosphodiester chemical bond between free $5^{\prime}$-phosphate and $3^{\prime}-\mathrm{OH}$ groups of double stranded DNA fragments and vectors. The donor DNA fragment (10 fold higher concentrated compared to the vector) was incubated with the vector DNA, $2 \mu$ l of ligation buffer and $1 \mu$ l of T4-DNA ligase for 2 hours at room temperature. Ligase was inactivated by heating at $65^{\circ} \mathrm{C}$ for 10 min before using the ligated DNA for transformation.

\subsubsection{DNA sequencing}

The DNA sequencing was done using the BigDye Terminator RR Mix Cycle Sequencing kit (Perkin-Elmer Corporation, Massachusetts, USA). The principle of DNA sequencing is based on the chain-termination method described by (Sanger et al., 1977). In the chaintermination method, didesoxynucleotides (terminators) are incorporated into a newly synthesized complementary chain that will lead to stop its elongation in a PCR reaction. Each of didesoxynucleotides is labeled with a specific fluorescent dye and the terminated chains can be specifically detected using an ABI Prism 310 Capillary Sequencer (Applied Biosystems). The PCR sequencing reaction was performed using 500-1000 ng plasmid DNA, 5 pmol primer, $2 \mu \mathrm{RR}$ mix (ready reaction) and $\mathrm{H}_{2} \mathrm{O}$ up to a total volume of $10 \mu \mathrm{l}$. The samples were subjected to 25 cycles of: $10 \mathrm{sec}$ at $95^{\circ} \mathrm{C}, 5 \mathrm{sec}$ at $50^{\circ} \mathrm{C}, 4 \mathrm{~min}$ at $60^{\circ} \mathrm{C}$ in a thermocycler. The DNA product was precipitated using $9.5 \mu \mathrm{l}$ water and $30.5 \mu \mathrm{l}$ of absolute ethanol and left for 1 hour. The DNA was collected by centrifugation for 20 min at 13000 $\mathrm{rpm}$. The pellet was washed using $125 \mu \mathrm{l} 70 \%$ ethanol and then centrifuged for 10 minutes at $13000 \mathrm{rpm}$, than dried at $95^{\circ} \mathrm{C}$ for $1 \mathrm{~min}$ and resuspended in $15 \mu \mathrm{l}$ of templatesuppression reagent (TSR, Perkin-Elmer). After the final denaturing step at $95^{\circ} \mathrm{C}$ for $2 \mathrm{~min}$ tubes were directly put on ice. The reaction was loaded on an ABI-Prism 310 capillary electrophoresis sequencing station for analysis.

\subsubsection{Separation of DNA on agarose gels}

The electrophoretic separation of DNA for analytical and preparative purpose was done in a horizontal agarose gel device (10 cm x $7 \mathrm{~cm} \times 0.3 \mathrm{~cm}, 16$ lanes) with $1 \times$ TAE as running buffer. An agarose concentration of $1 \%$ was used for separation of fragments bigger than $500 \mathrm{bp}$. For DNA fragments with lower size as $500 \mathrm{bp}$, a $2 \%$ agarose gel was used. DNA samples were mixed with $1 / 10$ volume of $10 x$ DNA loading buffer, applicated in separate lanes and electrophoretically separated at $120 \mathrm{~V}$ for 40-45 min. Incubation in Ethidiumbromide solution $(0.1 \% \mathrm{w} / \mathrm{v})$ for $10 \mathrm{~min}$ was used to visualize the DNA fragments. Before exposure with UV light, the gel was rinsed briefly in $\mathrm{H}_{2} \mathrm{O}$ to reduce background staining. The detection of DNA was done with an UV-transilluminator and Gel 
documentation device. The sizes and amount of the DNA fragments were determined using DNA standards.

The elution of DNA fragments from agarose gel was done using the QIAquick or Nucleospin Extract II Gel Extraction kit following the manufacturer's instructions. The eluted fragments were verified by electrophoresis as described above.

\subsubsection{Restriction digestion of DNA}

Type II endonucleases were used to digest a double stranded DNA molecule for analytical and cloning purposes. The enzymes cut the DNA either as 5' or 3' "sticky" overhangs or as blunt ends. The digestion reactions were incubated in a buffer system optimized for the used enzyme (see chapter 3.1.11; buffer $\mathrm{B}+$; $\mathrm{G}+$; $\mathrm{O}+; \mathrm{R}+$; $\mathrm{Y}+$, MBI-Fermentas). In the case of a double digestion, a universal buffer system $(1 x$ or $2 x Y+)$ was chosen. The activity of the restriction enzymes was determined in "units" $(U)$, where $1 \mathrm{U}$ was defined as the amount of enzyme cutting completely $1 \mu \mathrm{g}$ of $\lambda$ DNA ( $48.5 \mathrm{~kb}$ ) in 60 minutes at optimal conditions. The minimal amount of enzyme necessary for each restriction was determined according to the following formula:

$U=(b p[\lambda] \times$ No. of restriction sites in target DNA $) /($ No. of restriction sites in $[\lambda] \times b p$ of target DNA)

The incubation temperature was $37^{\circ} \mathrm{C}$ unless otherwise indicated for special restriction enzymes. Due to the adverse effect of high glycerol concentration on enzyme activity, the total volume of restriction enzymes should not extend more than $10 \%$ in the restriction mix.

\subsubsection{Isolation of genomic DNA from Arabidopsis thaliana leaves for genotyping}

This qick and dirty method was used for PCR based genotyping of the F2 generation after crossing of different mutants. A leaf disc was cut out with the help of the lid of a microcentrifuge tube avoiding cross-contamination with foreign plant material. $100 \mu \mathrm{l}$ extraction buffer was added ( $200 \mathrm{mM}$ Tris- $\mathrm{HCl}, \mathrm{pH} 7.5 ; 250 \mathrm{mM} \mathrm{NaCl} ; 25 \mathrm{mM}$ EDTA; 0.5\% SDS) to grind the tissue with a pistil fitting in a $1.5 \mathrm{ml}$ microcentrifuge tube. $300 \mu \mathrm{l}$ extraction buffer was added and the tubes inverted before a centrifugation step (15000 $\mathrm{rpm}, 5 \mathrm{~min}, 4^{\circ} \mathrm{C}$ ) occurs. $300 \mu \mathrm{l}$ of the supernatant was transferred to a new microcentrifuge tube and supplemented with $300 \mu \mathrm{l}$ 2-propanol. After inverting the tube several times the samples were centrifuged ( $13000 \mathrm{rpm}, 5 \mathrm{~min}, \mathrm{RT})$. The supernatant has to be removed before the resulting pellet could be washed with $200 \mu \mathrm{l}$ of $70 \% \mathrm{EtOH}$. After removing the supernatant the pellet should dry at $37^{\circ} \mathrm{C}$ for $10 \mathrm{~min}$ to be resolved in $100 \mu \mathrm{l}$ water (ultra pure) for $10 \mathrm{~min}$ at $65^{\circ} \mathrm{C}$. After a last centrifugation ( $13000 \mathrm{rpm}, 5 \mathrm{~min}, \mathrm{RT}$ ), the supernatant containing the isolated genomic DNA was transferred to a new microcentrifugation tube and can be stored at $-20^{\circ} \mathrm{C}$.

\subsubsection{Preparation of DNA-free CDNA for qRT-PCR}

To analyse gene expression by PCR it is necessary to synthesize cDNA from RNA. DNasel restriction was done before cDNA synthesis. $1 \mu \mathrm{g}$ RNA template together with $1 \mu \mathrm{L}$ of $10 \mathrm{x}$ DNasel-reaction buffer and $1 \mu \mathrm{l}$ DNasel, RNase-free was added with water to a final reaction volume of $10 \mu \mathrm{L}$. The mixture was incubated at $37^{\circ} \mathrm{C}$ for 30 minutes. To deactivate the DNasel enzyme1 $\mu \mathrm{L} 25 \mathrm{mM}$ EDTA was added and incubated at $65^{\circ} \mathrm{C}$ for 10 minutes. cDNA synthesis was performed with $1 \mu \mathrm{g}$ total RNA (DNA-free), 20 pmol of oligo-dT primer and $200 \mathrm{pmol}$ of random nonamer oligonucleotides. Water was added to a final reaction 
volume of $12.5 \mu \mathrm{L}$. For annealing of the primers, the mixture was heated to $70^{\circ} \mathrm{C}$ for $10 \mathrm{~min}$ and immediately cooled down on ice. Subsequently $20 \mathrm{nmol}$ dNTPs, $4 \mu \mathrm{L}$ RT - $5 x$ first strand reaction buffer and $60 \mathrm{u}$ reverse transcriptase $\mathrm{H}$ - and competed with $\mathrm{H}_{2} \mathrm{O}$ to a final volume of $20 \mu \mathrm{l}$. The mixture was incubated at $42^{\circ} \mathrm{C}$ for $70 \mathrm{~min}$ and then heated to $70^{\circ} \mathrm{C}$ for $10 \mathrm{~min}$.

\subsubsection{Quantitative real time RT-PCR}

This high sensitive method was used to investigate gene expression on RNA level. Prepaired cDNA-was diluted 1:10 with sterile water. The amplification mix consisted of $1 \mathrm{x} \mathrm{NH}_{4}$ reaction buffer; $2 \mathrm{mM} \mathrm{MgCl}$; $100 \mu \mathrm{M}$ dNTPs; $0.4 \mu \mathrm{M}$ primers, 0.25 u BIOTaq DNA polymerase; $10 \mathrm{nM}$ Fluoresceine; 100,000 times diluted SYBR Green I solution; $1 \mu \mathrm{L}$ of the diluted cDNA as template and water (ultra pure) added to a total volume of $25 \mu \mathrm{L}$. PCR consisted of a 6 min initial denaturation step at $95^{\circ} \mathrm{C}$ followed by 40 cycles of $20 \mathrm{~s}$ at $95^{\circ} \mathrm{C}$, $20 \mathrm{~s}$ at $55^{\circ} \mathrm{C}$ (annealing) and $40 \mathrm{~s}$ at $72^{\circ} \mathrm{C}$ (elongation). A final elongation step was done for $4 \mathrm{~min}$ at $72^{\circ} \mathrm{C}$ followed by a melt curve analysis. During the elongation and annealing phase measurement of the fluorescence occurs. As housekeeping gene UBQ5 (At3G62250) was used. The data analysis was done with the help of the $2^{-\triangle \Delta C T}$ method (Schmittgen and Livak, 2008) to quantify the relative expression levels.

\subsubsection{RNA extraction}

The extraction method based on TRIZOL extraction can be used to extract RNA, DNA and proteins from plants (Chomczynski, 1993). This method uses a Phenol/ Chloroform (dichloromethane) extraction to solve RNA in the aqueous phase while other parts like proteins solved in the hydrophobic chloroform phase. The two thiocyanates in the extraction buffer inhibit RNAses. After grinding of the plant material under liquid nitrogen $1.3 \mathrm{~mL}$ extraction buffer ( $380 \mathrm{ml} / \mathrm{l}$ Phenol saturated with $0.1 \mathrm{M}$ citrate buffer $\mathrm{pH} 4.3 ; 0.8 \mathrm{M}$ guanidiniumthiocyanate; $0.4 \mathrm{M}$ ammoniumthiocyanate; $33.4 \mathrm{ml} \mathrm{Na}$-acetate, $3 \mathrm{M}, \mathrm{pH}$ 5.2; $5 \%$ glycerol) was added to $150 \mathrm{mg}$ plant material. After shaking for $15 \mathrm{~min}$ at RT, chloroform $(260 \mu \mathrm{L}$ ) was added to each sample. After an additional shaking step (15 min, RT) and centrifugation (12000 rpm, 30-60 min, $\left.4^{\circ} \mathrm{C}\right)$ the supernatant $(900 \mu \mathrm{L})$ was transferred to new microcentrifuge tubes. Precipitation buffer (HSPB, 1.2 M NaCl1, 0.8 M $\mathrm{Na}$-citrate) and 2-propanol (each $325 \mu \mathrm{L}$ ) were added, the tubes inverted several times and the samples were incubated for $10 \mathrm{~min}$ at RT and centrifuged (12000 rpm, $20 \mathrm{~min}, 4^{\circ} \mathrm{C}$ ) followed by a washing step with $70 \%$ ethanol. After removing the supernatant, samples were dried and afterwards resolved in $50-100 \mu \mathrm{L}$ water (ultra pure). Concentration was measured as described in 3.2.11.4.

\subsubsection{Northern blot analysis}

Total RNA was extracted from $100 \mathrm{mg}$ plant tissue using the trizol method (chapter 3.2.10.12) and analyzed by Northern blot analysis (Heinekamp et al., 2002). A fragment representing the CDNA of FRK1 was amplified by PCR using the primers FRK1CDNA forw and FRK1CDNA rev. After separation on an agarose gel, the fragment was gel-eluated with the Nucleo Spin ${ }^{\circledR}$ Extract II kit. 50 ng PCR fragment was used as template for the northern probe. Probes were radioactively labeled using the random-priming method with the Megaprime DNA labeling system. Aliquots of total RNA were fractionated on denaturing agarose gels and transferred to nylon membranes. Hybridization was performed over night. Membranes were washed with $2 x$ SSC / $0.1 \%$ SDS at $65^{\circ} \mathrm{C}$ for $1 \mathrm{~h}$ and with $1 \mathrm{xSSC} / 0.1 \%$ SDS at $65^{\circ} \mathrm{C}$ for $1 \mathrm{~h}$. Quantification of RNA levels was performed using Bio-imager analysis. 


\subsubsection{Biochemical methods}

\subsubsection{Measurement of free SA}

The measurement of free SA was done in collaboration with Ivo Feussner (Georg-AugustUniversity, Göttingen) as previously described in (Ochsenbein et al., 2006).

\subsubsection{Whole cell protein extracts}

The extractions of proteins were performed under denaturing conditions and on whole cell extract level. Extraction buffer containing urea (4 M urea, $16.6 \%$ glycerol, $5 \%$ SDS, $0.5 \%$ ßmercaptoethanol) was used to extract the proteins. After grinding the plant material in liquid nitrogen, extraction buffer $(450 \mu \mathrm{L})$ was added to $\sim 150 \mathrm{mg}$ plant material. The samples were incubated at $65^{\circ} \mathrm{C}$ for $10 \mathrm{~min}$ and centrifuged (13000 rpm, $20 \mathrm{~min}, \mathrm{RT}$ ). The supernatant was transferred to new microcentrifuge tubes and used for SDS-PAGE.

\subsubsection{Determination of concentrations of proteins}

Protein concentration was estimated by two different methods. A colorimetric assay was used to determine the concentration from proteins extracted without detergent usage according to (Bradford and Williams, 1976). The assay was conducted by pipetting equal amounts of protein extract into a microtiter plate containing $200 \mu \mathrm{L}$ of 5 -fold diluted Bradford reagent and the $O D_{595}$ was measured with a plate reader. Protein concentrations were calculated with the help of a standard curve derived from different BSA protein amounts $(1,3$ and $6 \mu \mathrm{g})$ on the same plate. Proteins isolated using buffers containing detergents were either defined to equal amounts in a coomassie stained SDS gel (scanned and analysed with TINA2.0).

\subsubsection{SDS-PAGE}

In sodium dodecyl sulphate-polyacrylamide gel electrophoresis (SDS-PAGE), proteins are separated mostly on the basis of polypeptide length. The electrophoresis was done using a discontinuous buffer system, in which a non-restrictive large pore gel, called a stacking gel, is layered on top of a separating gel called a resolving gel. The recipe for the resolving gel was consisting of: 7-8 \% (w/v) acrylamide/ bisacrylamide (37.5:1), $400 \mathrm{mM}$ Tris- $\mathrm{HCl} \mathrm{pH} \mathrm{8.8,}$ $0.1 \%(\mathrm{w} / \mathrm{v})$ SDS, $0.1 \%(\mathrm{w} / \mathrm{v})$ TEMED and $0.1 \%(\mathrm{w} / \mathrm{v})$ APS. The stacking gel was consisting of: $5 \%$ (w/v) acrylamide/bisacrylamide (37.5:1), $125 \mathrm{mM}$ Tris-HCl pH 6.8, $0.1 \%$ (w/v) SDS, 0.2 $\%(w / v)$ TEMED and $0.1 \%(w / v)$ APS. The denatured protein extract samples (each $\sim 10 \mu \mathrm{L}$, or defined equal amounts after a first coomassie stained gel) were boiled with $15 \mu \mathrm{L} 2 \mathrm{x}$ SDS sample buffer (0.09 M Tris, $20 \%$ glycerol, $2 \%$ SDS, $0.02 \%$ bromophenol blue, $0.1 \mathrm{M}$ DTT) at $95^{\circ} \mathrm{C}$ for 5 minutes and cooled on ice. The electrophoresis was performed at $120 \mathrm{~V}$ with $1 \mathrm{x}$ SDS running buffer (250 mM Tris, 2 M Glycine, $1 \%$ SDS) until the bromophenol blue band reached the lower end of the gel. $6 \mu \mathrm{L}$ pre-stained protein ladder were used for the estimation of the size of the separated proteins. 


\subsubsection{Coomassie staining of SDS gels}

The Coomassie Brilliant Blue G-250 dye was used to detect proteins separated on SDSPAGE. The gels were incubated with coomassie staining solution (colloidal coomassie) o/n. The gels were destained in water $\mathrm{o} / \mathrm{n}$.

Colloidal coomassie consists of $400 \mathrm{~mL}$ solution A (40 g ammonium sulphate and $8 \mathrm{~mL}$ phosphoric acid) and $10 \mathrm{~mL}$ solution $B$ ( $0.5 \mathrm{~g}$ coomassie brilliant blue $\mathrm{G} 250$, this has to be solved shaking at least for $0.5 \mathrm{~h}$ ). Each gel was stained in $40 \mathrm{~mL}$ colloidal coomassie complemented with $10 \mathrm{~mL}$ methanol.

\subsubsection{Western blot}

The proteins separated in the SDS-PAGE were blotted onto a PVDF membrane using semidry blotting method in an electric field between two graphite plates. The PVDF membrane was activated before blotting using $\mathrm{MeOH}$. For the transfer of proteins from the gel to the membrane, the gel on top of the membrane was sandwiched between two times 3-layers of Whatman papers (pre-soaked with transfer buffer). The whole arrangement was placed within a blot apparatus and transfer was performed under amperage of one $\mathrm{mA} / \mathrm{cm}^{2}$ for 1.4 hours. (Optional: Ponceau S staining was done to observe the success of the transfer. Destaining was done using $1 \times$ PBS.) After blotting the membrane was dried between two layers of Whatman paper. The standard was marked on the membrane with an iMark (pen containing pre-immune serum from rabbit) for later detection of standard bands with the second antibody and ECL kit to visualize them on the film. After 5 min the membrane was reactivated in $\mathrm{MeOH}$ and non-specific binding to the proteins on the membrane was prevented by blocking the membrane with non-fat dried milk powder ( $5 \%$ in $1 x$ PBST) o/n at $4^{\circ} \mathrm{C}$ on a shaking platform. The detection of specific proteins on the membrane was performed using an antiserum directed against the protein of interest in a 1:1000 dilution in $1 \mathrm{x}$ PBST (with $0.5 \%$ milk powder). The membrane was therefore incubated with the respective antiserum for $2 \mathrm{~h}$ at RT on a shaking platform. The incubation with the second antibody (anti-rabbit 1:25000 in 1x PBST) was performed for $1 \mathrm{~h}$ at RT on a shaking platform. This second antibody is conjugated to horseradish peroxidase (HRP). The HRP can utilize the enhanced chemi-luminescent substrate (ECL, GE Healthcare, incubation of the membrane in ECL mix for 5 min) emitting luminescence, which allows visualization of the membrane bound proteins on autoradiography films. The films were exposed to the membrane in detection cassettes for $30 \mathrm{~s}$ up to $10 \mathrm{~min}$ depending upon the strength of chemi-luminescence signal generated by the respective amounts of bound protein.

\subsubsection{Chromatin immunoprecipitation (ChIP)}

ChIP allows the analysis of the in vivo binding status of transcription factors or other DNAassociated proteins to certain DNA sequences. Intact cells are treated with formaldehyde to crosslink promoter-associated proteins to the DNA. After isolation and shearing of the chromatin, protein-DNA complexes are immunoprecipitated with specific antibodies against the protein of interest. The precipitated DNA fragments are subsequently purified and analysed by PCR using primers flanking the (putative) binding site of the protein. The amount of PCR product obtained is indicative for the relative amount of protein bound to the DNA when the tissue was harvested. The procedure allows detecting of quantitative differences in the relative amount of protein-DNA complexes, so that stimulus-induced binding can be detected. Chromatin immunoprecipitations and subsequent real-time PCR analysis were done as specified by Fode et al., 2008. 


\subsection{Crosslinking}

3-5 g of leaf material from plants grown for 6 weeks under short day conditions was placed into a plastic basket ( $15 \mathrm{~cm}$ diameter) that was put into $500 \mathrm{ml}$ of $1 \%$ formaldehyde in 50 $\mathrm{mM} \mathrm{KH_{2 }} \mathrm{PO}_{4} / \mathrm{K}_{2} \mathrm{HPO}_{4}, \mathrm{pH}$ 5.8. Vacuum was applied twice for $5 \mathrm{~min}$ and samples were afterwards left for another $20 \mathrm{~min}$ in this buffer. Subsequently, the leaf material was placed

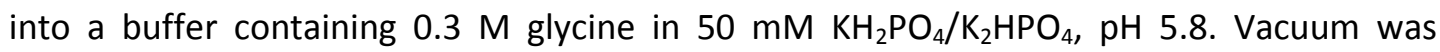
applied twice for $5 \mathrm{~min}$ with subsequent incubation for $5 \mathrm{~min}$. Leaves were washed twice in water, dried with paper towels, frozen and stored in liquid nitrogen till further processing.

\subsection{Isolation of nuclei}

Nuclei were isolated according to a modified protocol (Folta and Kaufman, 2000). Briefly, the frozen tissue was ground with a pistil under liquid nitrogen, resuspended in $20 \mathrm{ml}$ extraction buffer (1 M hexylene glycol, $50 \mathrm{mM}$ PIPES KOH, pH 7.2, $10 \mathrm{mM} \mathrm{MgCl} 2,5 \mathrm{mM}$ ßmercaptoethanol) and homogenized for 5 min using a Miccra-D8 homogenizer (14000 rpm). The homogenate was passed through a double layer of Miracloth. Triton X-100 (25\%) was added dropwise to the resulting liquid fraction with constant stirring to a final concentration of $1 \%$ to lyse organelle membranes. The lysate was gently layered on top of a $6 \mathrm{ml} 35 \%$ percoll cushion in gradient buffer $(0.5 \mathrm{M}$ hexylene glycol, $50 \mathrm{mM}$ PIPES KOH pH 7.2, $10 \mathrm{mM} \mathrm{MgCl}_{2}, 5 \mathrm{mM}$ 2-mercaptoethanol, 1\% Triton X-100). After centrifugation at 2100 $\mathrm{x} g$ for $30 \mathrm{~min}$ in a swinging bucket rotor, the nuclei were found as a pellet at the bottom of the tube. Nuclei were resuspended in $21 \mathrm{ml}$ of gradient buffer and again gently layered on

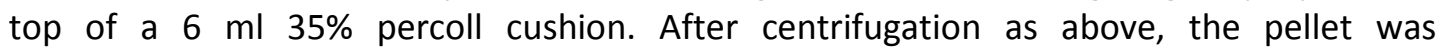
resuspended in $1 \mathrm{ml}$ of gradient buffer and centrifuged at $2100 \mathrm{xg}$ for $10 \mathrm{~min}$.

\subsection{Chromatin extraction and immunoprecipitation}

Chromatin extraction and chromatin immunoprecipitation (ChIP) was performed as described previously (Turck et al., 2004) with slight modifications. Nuclei from 3-5 g of formaldehyde cross-linked leaf material were first resuspended in $1 \mathrm{ml}$ sonication buffer (10 mM HEPES/ $\mathrm{maOH}, \mathrm{pH} 7.4,1 \mathrm{mM}$ EDTA, 0.5\% SDS and diluted with $1 \mathrm{ml}$ sonication buffer without SDS. Chromatin was sheared to an average size of 500-1000 base pairs by repetitive sonication (4 times $20 \mathrm{~s}$ in an ethanol/ice bath, interrupted by $1 \mathrm{~min}$ cooling steps) at 12 amplitude microns. The final centrifugation was performed at $11200 \times \mathrm{g}$ for 20 $\min$ at $4^{\circ} \mathrm{C}$. To normalize different samples for equal DNA content, the DNA concentration was measured after the following purification steps: $50 \mu \mathrm{l}$ of the chromatin were brought to a volume of $450 \mu \mathrm{l}$ with sonication buffer containing $0.25 \%$ SDS, incubated first in the presence of $10 \mu \mathrm{g}$ of Proteinase $\mathrm{K}$ for $1 \mathrm{~h}$ at $37^{\circ} \mathrm{C}$ and subsequently at $65^{\circ} \mathrm{C}$ for $16 \mathrm{~h}$ for decrosslinking. Free DNA was purified from the solution by phenol/chloroform/isoamylalcohol (25:24:1) extraction followed by chloroform/isoamylalcohol (24:1) extraction. DNA was precipitated by the addition of $10 \mu \mathrm{g}$ glycogen, one-tenth volume of $3 \mathrm{M}$ sodium acetate and 2.5 volumes of ethanol at $-80^{\circ} \mathrm{C}$ for at least $3 \mathrm{~h}$. After centrifugation, DNA was resuspended and used for $\mathrm{OD}_{260}$ measurements.

Equal amounts of chromatin as measured by DNA content $(15 \mu \mathrm{g})$ were brought to a total volume of $200 \mu \mathrm{l}$ with sonication buffer (10 mM HEPES/ $\mathrm{NaOH}, \mathrm{pH} 7.4,1 \mathrm{mM}$ EDTA, $0.25 \%$ SDS). After adding $300 \mu \mathrm{l}$ RIPA buffer (50 mM HEPES/ $\mathrm{NaOH}, \mathrm{pH} 7.4,140 \mathrm{mM} \mathrm{NaCl}, 1 \mathrm{mM}$ EDTA, $1 \%$ Triton $X-100,0.1 \%$ deoxycholate), samples were incubated in the presence of preimmune serum $(5 \mu \mathrm{l})$ for $1 \mathrm{~h}$ at $4^{\circ} \mathrm{C}$ on a rotary shaker. Next, $50 \mu \mathrm{l}$ Protein A agarose beads ( $50 \%$ slurry in RIPA buffer supplemented with $0.1 \%$ SDS) were added and incubated for additional $1 \mathrm{~h}$. Beads were pelleted and $50 \mu \mathrm{l}$ of the supernatant was removed for the 
input control (see below). The residual supernatant was incubated with $5 \mu$ of the immune serum for $4 \mathrm{~h}$ at $4^{\circ} \mathrm{C}$ on a rotary shaker. Subsequently, $50 \mu \mathrm{l}$ Protein A agarose beads $(50 \%$ slurry in RIPA with $0.1 \%$ SDS) were added. After incubation for $2 \mathrm{~h}$ on a rotary shaker at $4^{\circ} \mathrm{C}$, immunoprecipitates were washed three times in $1 \mathrm{ml}$ of RIPA buffer with $0.1 \%$ SDS, followed by an additional wash with $800 \mu \mathrm{l}$ and a transfer into a fresh tube. Immunocomplexes were then eluted from the beads by two sequential incubations in 150 $\mu \mathrm{l}$ of elution buffer $(0.1 \mathrm{M}$ glycine, $0.5 \mathrm{M} \mathrm{NaCl}$, and $0.05 \%$ Tween $20, \mathrm{pH} 2.5)$ followed by centrifugation and addition of $150 \mu \mathrm{l} 1 \mathrm{M} \mathrm{Tris} / \mathrm{HCl}, \mathrm{pH} 8.0$ to the combined eluates. As input control, $50 \mu \mathrm{l}$ of the supernatant from preimmune incubations ( $10 \%$ of the sample) was brought to a volume of $450 \mu$ l with sonication buffer ( $10 \mathrm{mM} \mathrm{HEPES} / \mathrm{NaOH}, \mathrm{pH} 7.4,1 \mathrm{mM}$ EDTA, $0.25 \%$ SDS). Eluted DNA and DNA of the input control were treated with Proteinase $\mathrm{K}$, heat treated and purified as described above. Precipitation of the DNA was done at $80^{\circ} \mathrm{C}$ for at least $3 \mathrm{~h}$. DNA was resuspended in $35 \mu \mathrm{l}$ (ChIP-DNA) or $175 \mu \mathrm{l}$ (input control) of water for PCR analysis. Comparison of the amounts of PCR products yielded with immunoprecipitated and input DNA, respectively, allowed us to estimate that roughly $0.8 \%$ of the input promoters are precipitated.

\subsection{Analysis by ChIP-on-chip array}

The analysis of ChIP samples by the ChIP-on chip array was done in collaboration with Christopher Town (Institute for Genomic Research, Rockwille, USA).The experimental procedures are described in principle by Thibaud-Nissen et al., 2006. The used custommade array contained the initial $\sim 200$ promoter targets (including $P R-1$ and GST6) selected on the basis of their published association with SAR, plus 50 new targets identified from the first NimbleGen ChIP data (Thibaud-Nissen, 2006) and 67 targets identified based upon their co-expression with $P R-1$ in analysis of ATH1 microarray expression data. In addition the array contains 89 sets of control spots that consist of a pool of 7 non-target amplicons for normalization purposes. Immunoprecipitated and control (raw chromatin) samples are labeled by incorporation of amino allyl nucleotides during PCR amplification, conjugated with Cydyes and hybridized as a flip dye pair.

The signal intensities of the IP samples were normalized to the signal intensities of raw chromatin. Probes with a values $\geq 1.0$ were considered as enriched

\subsection{Analysis by real-time PCR}

The analysis of ChIP experiments by real-time PCR (qPCR, chapter 3.2.10.11) is recommended. The conditions for the PCR depend on the primers that are used for amplification of the promoter DNA sequence. It is recommended to use primers that amplify a fragment of about $250 \mathrm{bp}$. As template, use $2.5 \mu \mathrm{L}$ of the purified IP-DNA and the input DNA, each. Calculation was done according to the $2^{-\triangle \Delta C T}$ method (Schmittgen et al., 2008), taking ACTIN8 reference sequences for normalization. 


\section{$4 \quad$ Results}

\subsection{The growth inhibition effect of flg22 is strongly increased in the tga2,5,6 mutant}

The addition of the flagellin-derived peptide flg22 to the liquid medium of young $A$. thaliana seedlings causes a strong reduction in growth (Gómez-Gómez et al., 1999). Tsuda et al. (2008) demonstrated that an interplay between PAMP-triggered and SA-mediated defense responses exist. Therefore, mutants of the SA biosynthesis or signaling pathway were tested for an altered response to flg22 in a root growth assay. Arabidopsis seedlings were grown for 14 days on vertical axenic plates containing $100 \mathrm{nM}$ flg22 peptide. Seedlings grown on plates without flg22 show no difference in root growth, but all of the tested mutants show increased flg22-induced root growth inhibition in comparison to the wildtype Col-0 plants (Figure 4-1).

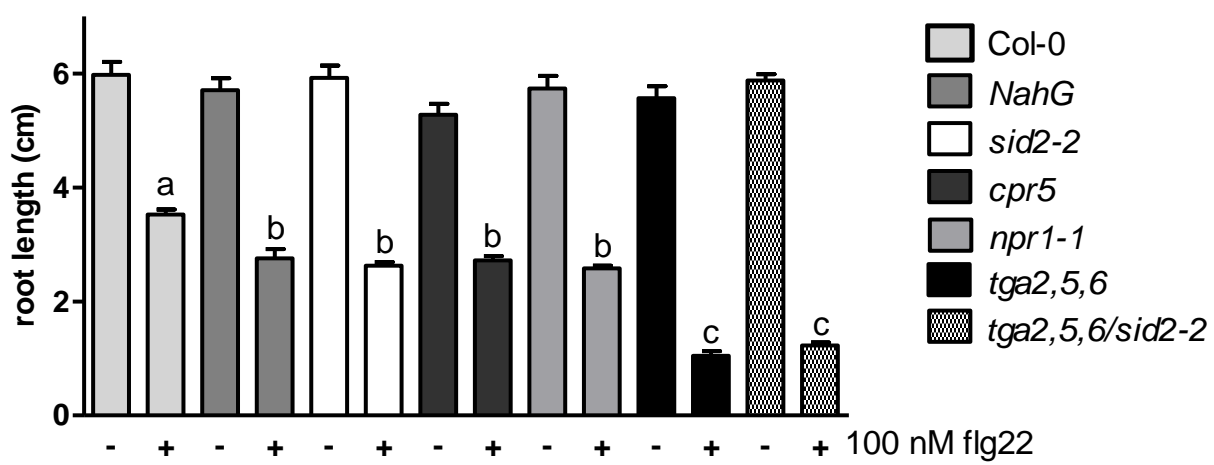

Figure 4-1| Growth inhibition caused by flg22 in mutants impaired in SA biosynthesis and signaling.

A. thaliana seedlings of ecotype Col-0, NahG, sid2-2, cpr5, npr1-1, tga2,5,6 and tga2,5,6/sid2-2 were grown vertically for 10 days on 1MS-MES medium containing $100 \mathrm{nM}$ flg22. For quantification, root length of 30 seedlings per genotype was determined with ImageJ. Each bar represents the average \pm SEM. Different letters indicate significant differences between genotypes within a treatment (1wayAnova, $\mathrm{P}<$ $0,05)$.

The roots of NahG, sid2-2, cpr5 and npr1-1 mutants grown in the presence of flg22 are about $25 \%$ shorter than the roots of Col-0 seedlings. NahG and sid2-2 mutants are impaired in SA accumulation. sid2-2 contains a point mutation in the ISOCHORISMATE SYNTHASE 1 (ICS1) gene, whereas salicylate hydroxylase converts SA to catechol in plants carrying the 
NahG transgene (Delaney et al., 1994). cpr5 mutations show pleiotropic phenotypes including enhanced constitutive expression of $P R$-genes and elevated $S A$ and JA levels (Bowling et al., 1997). NPR1 together with the class-II TGA factors TGA2, TGA5 and TGA6 are important key regulators of SAR (Cao et al., 1997; Zhang et al., 2003).

The strongest flg22-induced growth inhibition was observed in the tga2,5,6 mutant with over $70 \%$ shorter roots than the wild type. Hyper-induction of flg22-induced root growth inhibition still occurs in the tga2,5,6/sid2-2 mutant. Thus, TGA factors enhance PAMPtriggered immune responses in an SA-independent way.

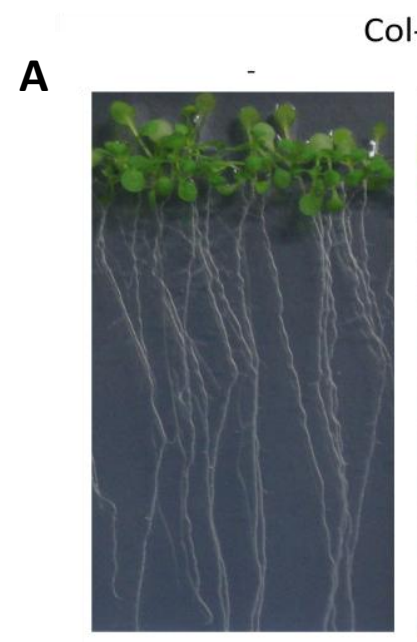

B

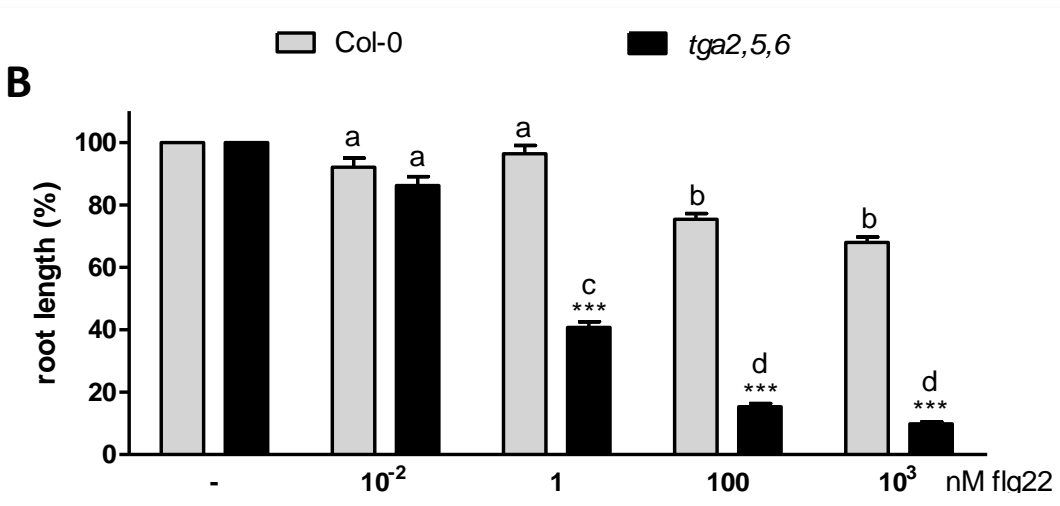

$\operatorname{tga} 2,5,6$
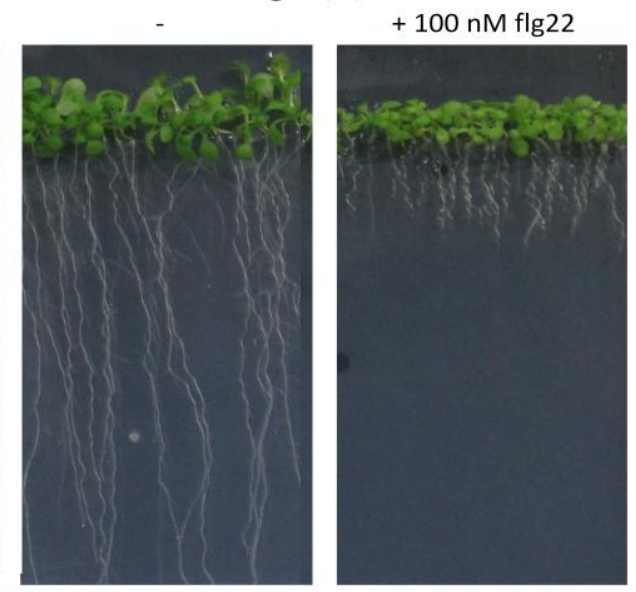

$\operatorname{tga2,5,6}$

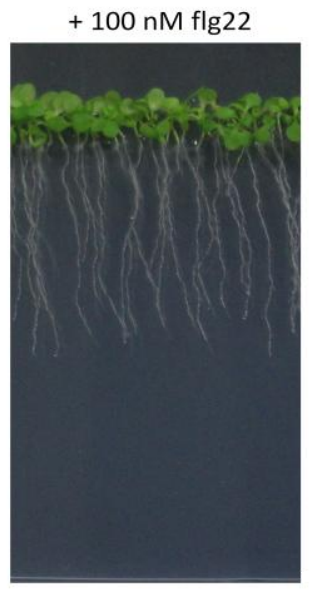

Figure 4-2| tga2,5,6 mutants show enhanced sensitivity to flg22 in root growth assay.

(A) Representative pictures of ten-days-old wild-type (Col-0) and tga2,5,6 seedlings grown vertically on 1MS-MES medium with or without $100 \mathrm{nM}$ flg22 peptide.

(B) Dose-dependence of growth inhibition caused by flg22. Bars represent the average and SEM of $n=30$ seedlings. The root length of each phenotype grown on control plates without flg22 was set to $100 \%$. Asterisks represent significant differences between wild-type and mutant plants (2wayAnova; $\left.{ }^{* * *} \mathrm{P}<0.001\right)$. Different letters indicate significant differences between treatments within a genotype (1wayAnova; $P<0.01$ ).

Flg22 not only has an inhibitory effect on roots. In addition, the aerial parts stay smaller on flg22-containing medium. This effect is more pronounced in the tga2,5,6 mutant (Figure 42A). Next, the effect of different flg22-concentrations on root growth was tested in Col-0 and tga2,5,6 seedlings (Figure 4-2B). The roots of wild-type Col-0 plants show a growth 
reduction of about $30 \%$ at a concentration of $100 \mathrm{nM}$. The inhibition in the tga2,5,6 mutant is much stronger; about $80 \%$ in the presence of $100 \mathrm{nM}$ flg22. This effect already occurs at very low nanomolar concentrations of flg22. The tga2,5,6 mutant is much more sensitive to flg22 than the wild-type. For further investigations an flg22 concentration of $100 \mathrm{nM}$ was used based on the finding that this concentration is sufficient to induce a maximized root length inhibition.

To investigate whether other TGA transcription factors act as suppressors of flg22-induced root growth, several tga single and multiple mutants were tested (Figure 4-3). The quadruple mutant of $\operatorname{tga} 2, \operatorname{tg} a 3, \operatorname{tg} a 5$ and $\operatorname{tg} a 6(\operatorname{tga} 2,3,5,6)$ shows the same phenotype as the triple tga2,5,6 mutant. The observation that the tga3 single mutant shows also an increased root growth inhibition, leads to the assumption that the root growth inhibition in the tga2,5,6 mutant reaches its maximum and is not further increased by a mutation of TGA3. The tga6 single mutant shows no altered root growth. The increased root growth inhibition observed in the double tga2,5 is not as severe as in the tga2,5,6 mutant, indicating that TGA6 partially complement the root growth phenotype. These results point out that the class II TGA factors TGA2, TGA5 and TGA6 may operate together as negative regulators of PAMP triggered immunity. Mutants of other TGA factors show an increased root growth inhibition indicating an overlapping function of different members of this transcription factor family.

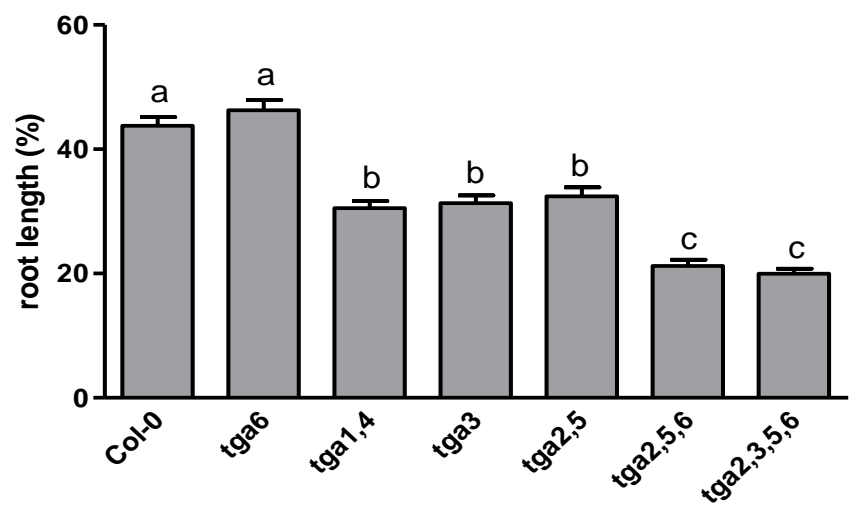

Figure 4-3| Growth inhibition caused by flg22 in different tga mutants.

Ten-days-old $A$. thaliana seedlings of ecotype Col-0 and different tga mutants were grown vertically on $1 \mathrm{MS}-\mathrm{MES}$ medium containing $100 \mathrm{nM}$ flg22. Bars represent the average and SEM of $n=30$ seedlings. The root-length of each genotype grown on control plates without flg22 was set to $100 \%$. Different letters indicate significant differences between genotypes (1wayAnova, $\mathrm{P}<0,05)$. 
To determine whether TGA2, TGA5 or TGA6 can complement the mutant phenotypes of

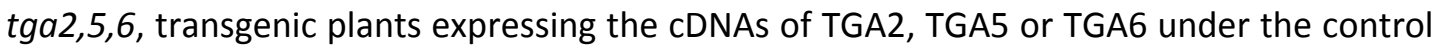
of the Cauliflower mosaic virus (CaMV) 35S promoter in the tga2,5,6 background were used for root growth inhibition analysis (Figure 4-4A). Western blot analysis was done to verify the protein levels in roots and shoots (Figure 4-4B). The used serum, generated against the C-termini of TGA2 and TGA5, also detects TGA6 protein in roots and shoots. Roots contain higher class-II TGA-protein levels than shoots. The transgenic protein levels in the two lines tested for each construct are similar in roots, but differ in shoots of TGA5OE and TGA6OE transgenic lines.

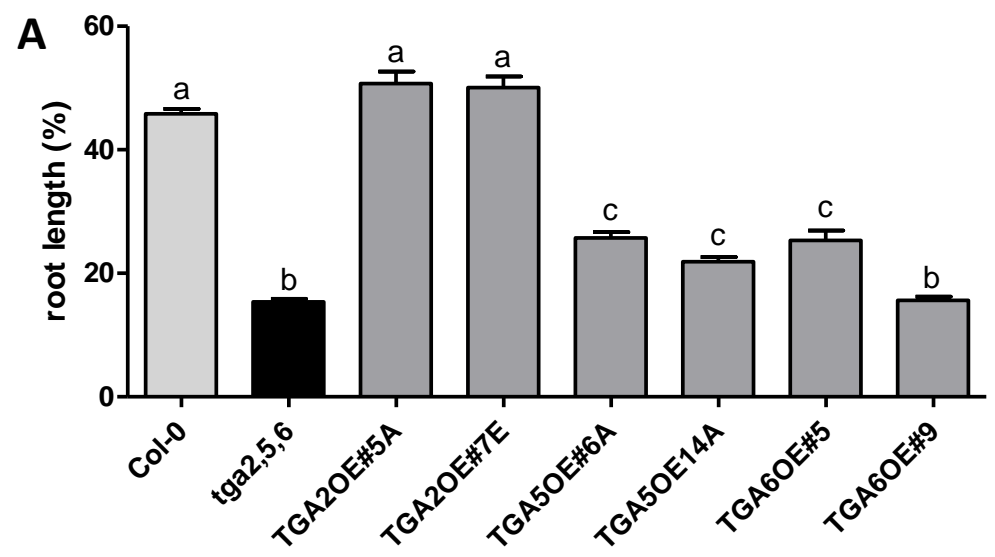

B

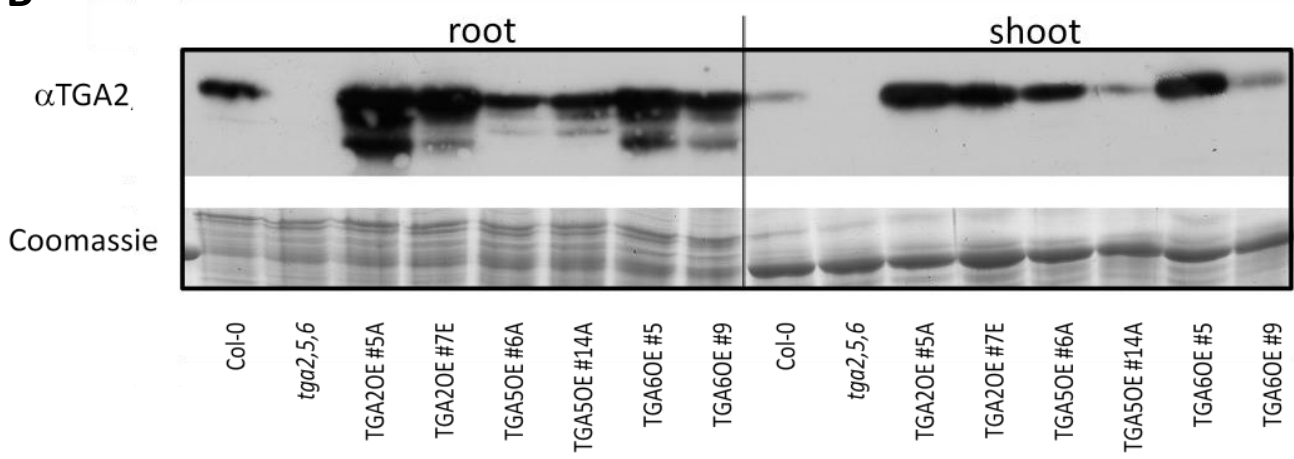

Figure 4-4| Complementation of the growth phenoptype of tga2,5,6 mutants on flg22.

(A) Ten-days-old $A$. thaliana seedlings of ecotype Col-0, tga2,5,6 or transgenic lines ectopically expressing TGA2, TGA5 or TGA6 in the tga2,5,6 mutant background grown vertically on 1MS-MES medium containing $100 \mathrm{nM}$ flg22. Bars represent the average and SEM of $n=30$ seedlings. The rootlength of seedlings grown on control plates without flg22 was set to $100 \%$. Different letters indicate significant differences between genotypes (1wayAnova, $\mathrm{P}<0,05$ ).

(B) Western blot analysis of the transgenic lines analyzed in (a) using an antiserum (1:1000 dilution) generated against the $C$ termini of TGA2 and TGA5 (Fode et al 2008). The samples for protein extraction were taken from untreated seedlings grown in the same experiment as for root-length measurement shown in (A). Crude protein extracts $(10 \mu \mathrm{g})$ were separated by SDS-PAGE. Coomassie staining is shown as loading control. 
The hyper-susceptibility of tga2,5,6 roots to flg22 was only restored to wild-type levels in the tga2,5,6 mutant plants overexpressing TGA2. The TGA5 transgene is able to partially rescue the root growth phenotype. Transgenic plants containing TGA6 show a nonconsistent result. Only TGA6OE\#5, containing higher protein levels than TGA6OE\#9 is able to rescue the root growth phenotype partially. Obviously, TGA2 is sufficient to rescue this phenotype and TGA5 and TGA6 play a more marginal role in regulating these flg22mediated response. Based on the intermediate root growth phenotype in the tga2,5 double mutant and a wild-type like phenotype in the tga6 single mutant (Figure 4-3), TGA6 seems to be involved in regulation of the signaling cascade leading to growth inhibition only if TGA2 and TGA5 are not present in the cell. TGA6 is not sufficient to completely replace TGA2 and TGA5, indicated by the intermediate phenotype of the tga2,5 mutant and the fact that ectopic expression of TGA6 only partially rescues the root growth phenotype of the tga2,5,6 mutant.

\subsection{Roots of the tga2,5,6 mutant contain higher ROS levels than the wild-type}

It is widely accepted that ROS play a central role in many signaling pathways during stress perception, regulation of photosynthesis, pathogen response, hormonal action, and plant growth and development (Mittler et al., 2004; Apel and Hirt, 2004). ROS perception is also involved in root growth. The NADPH oxidase RHD2 regulates root development by producing ROS that stimulate plant cell expansion through the activation of $\mathrm{Ca}^{2+}$ channels, and the inhibition of ROS formation leads to short root hairs and stunted roots (Foreman et al. 2003). In contrast, high intracellular concentrations of ROS lead to cell damage or cell death. Therefore the level of ROS needs to be tightly regulated (Mittler et al., 2004). To determine whether TGAs restrain growth via a ROS-dependent mechanism, the contribution of ROS to flg22-mediated root growth inhibition was analyzed.

To visualize the generation of ROS, an assay based on 5-(and-6)-carboxy-2', 7'dichlorodihydrofluorescein diacetate (carboxy- $\mathrm{H}_{2}$ DCFDA), a ROS-sensitive dye with good intracellular retention in growing roots, was used (Jiang et al., 2003). The non-fluorescent carboxy- $\mathrm{H}_{2}$ DCFDA permeates living cells and is deacetylated by nonspecific intracellular esterases. In the presence of nonspecific ROS (produced throughout the cell, particularly 
during oxidative stress) the reduced fluoresceine compound is oxidized and emits bright green fluorescence. Seedlings of Col-0 and tga2,5,6 plants were pretreated with flg22 or SA (positive control (Boursiac et al., 2008)) for $30 \mathrm{~min}$, before the seedlings were transferred to the staining solution. As shown in Figure 4-5, roots of the tga2,5,6 mutant exhibit higher levels of ROS than roots from wild-type seedlings. It was not possible to induce a ROS burst by flg22 or SA due to the fact that roots of mock treated plants show the same fluorescence signal as roots treated with flg22 or SA.

A

Col-0
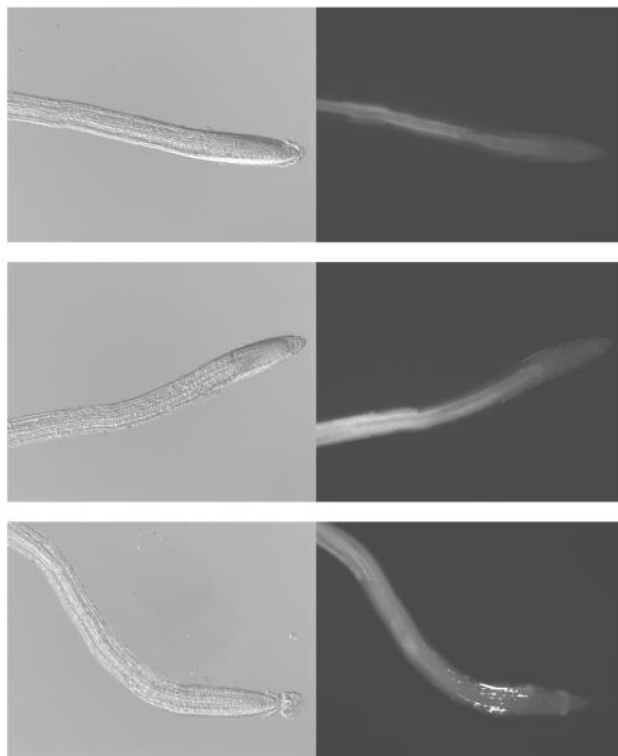

B
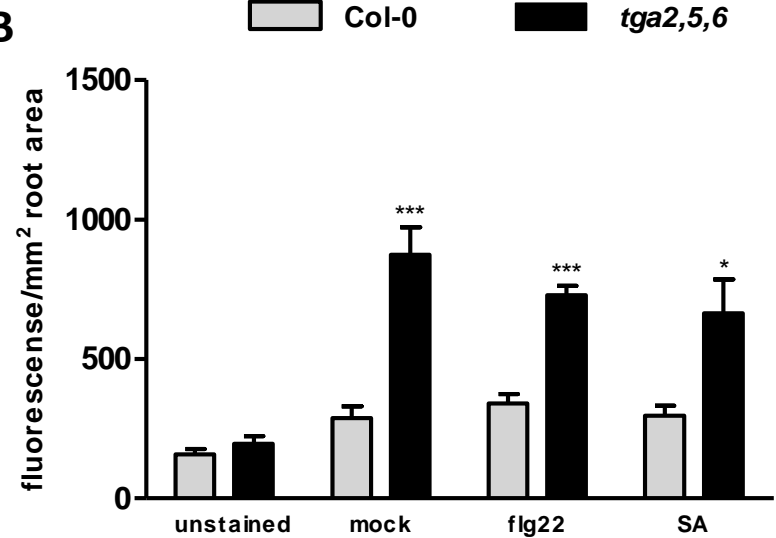

$\operatorname{tga} 2,5,6$

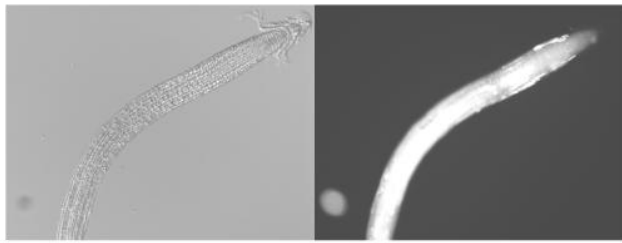

mock

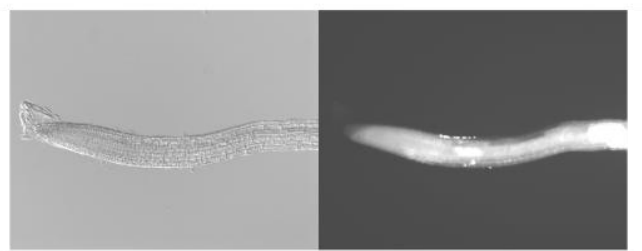

flg22

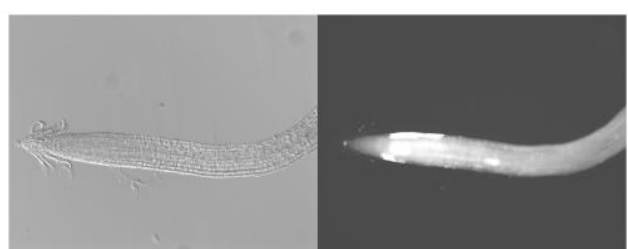

SA

Figure 4-5| ROS accumulation in Arabidopsis roots.

(A) ROS accumulation ( $\mathrm{H}_{2}$ DCFDA imaging) of WT (Col-0) and tga2,5,6 mutant seedling roots after mock, flg22 or SA treatment. A. thaliana seedlings were grown vertically on 1MS+MES medium for 7 days. Seedlings were spray-treated with $\mathrm{H}_{2} \mathrm{O}$ (mock), $1 \mu \mathrm{M}$ flg22 and $1 \mathrm{mM}$ SA for 30 min before transfer to staining solution or DMSO (unstained) for additional 30 min was performed. After a washing step, images of root tips were captured with a fluorescence microscope (GFP filter) and 100x magnification.

(B) Quantification of $\mathrm{H}_{2}$ DCFDA staining. Bars represent the average and SEM of at least $n=8$ roots. Asterisks represent significant differences between wild-type and mutant plants (1wayAnova, $* * * p<0.001 ; * p<0.05)$. 
Different chemical compounds are known to inhibit ROS production. Butylated hydroxyanisole (BHA) is a synthetic phenol which can scavenge reactive oxygen species by donating labile hydrogen to oxygen radicals. This lipophilic compound is generally used as antioxidant in food industries. Dimethylthiourea (DMTU) is a powerful scavenger of hydroxyl radicals $(. \mathrm{OH})$ and diphenyleneiodonium chloride (DPI) is an inhibitor of nitric oxide synthases and NADPH oxidases like the ROS-producing Rboh enzymes. The root growth of ga1-3 seedlings, which accumulate lower basal levels of ROS than the WT, was more resistant to the inhibitory effect of DPI than that of the WT (Achard et al., 2008).

These three inhibitors were used in a root growth assay to investigate, whether increased ROS levels in the roots of the tga2,5,6 mutant lead to a higher sensitivity to ROS scavengers.

A

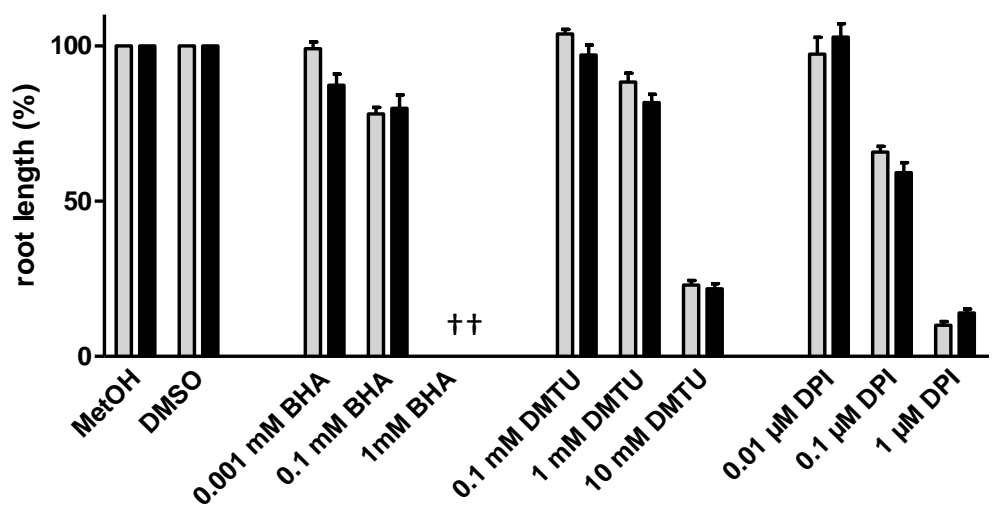

B

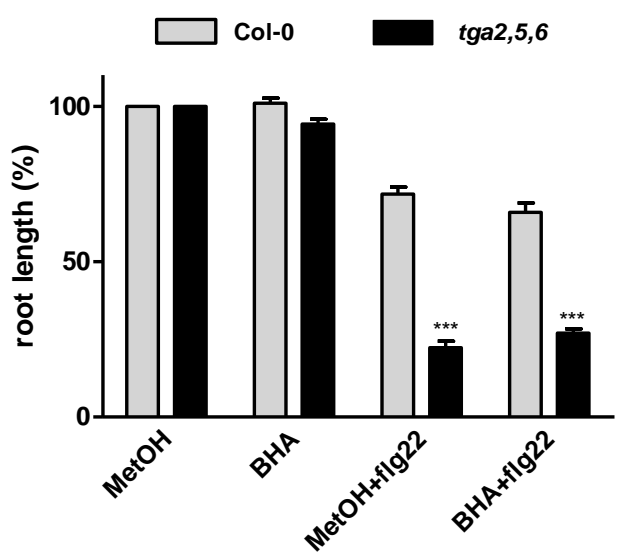

Figure 4-6| Influence of different ROS inhibitors on root growth.

(A) Two-days-old Col-0 and tga2,5,6 seedlings were transferred to vertical plates containing 1 MS-MES and different concentrations of the ROS inhibitors BHA, DMTU and DPI or the organic solvents MetOH and DMSO. Five days after transfer, the root length was measured.

(B) Influence of BHA on flg22 induced root growth inhibition. Two-days-old Col-0 and tga2,5,6 seedlings were transferred to vertical plates containing MetOH, $100 \mathrm{nM}$ flg22, 0,1 mM BHA or a combination of both. Five days after transfer, the root length was measured.

Bars represent the average and SEM of $n=15$ seedlings. The root-length of seedlings grown on control plates (MetOH for BHA and DMTU; DMSO for DPI) was set to $100 \%$. Crosses indicate no plant survived. Asterisks represent significant differences between wild-type and tga2,5,6 plants (1wayAnova, ${ }^{* * *} \mathrm{P}<0.001$ ). 
In an initial experiment it was tested, how seedlings grow on media containing different concentrations of the used inhibitors. Increasing concentrations lead to a reduction of root growth with every tested inhibitor (Figure 4-6A). A concentration of $1 \mathrm{mM} \mathrm{BHA}$ is sufficient to inhibit the root growth completely.

Col-0 and tga2,5,6 seedlings show no significant differences in the sensitivity to the different inhibitors. A concentration of $0.1 \mathrm{mM}$ BHA leads only to a weak decrease in root elongation. This BHA concentration was used to investigate the root growth in presence of flg22 together with a ROS inhibitor. The presence of the ROS inhibitor has no influence on the growth inhibitory effect of flg22 (Figure 4-6B).

\subsection{PAMP-induced ROS burst is not influenced in the tga2,5,6 mutant}

Few minutes after PAMP-perception, a transient ROS burst is initiated and displays one of the earliest responses of the plant. A luminol based chemiluminescence assay was used to detect the oxidative burst after treatment of leaf slices with different elicitors. Horseradish peroxidase catalyses the ROS-mediated oxidation of luminol to 3-aminophthalate via several intermediates. The reaction is accompanied by emission of low intensity light at 428 $\mathrm{nm}$ and the emitted chemiluminescence is proportional to the amount of accumulated ROS. Like flg22, elf18 is a peptide derived from a bacterial elicitor, called EF-Tu. EF-Tu is highly conserved in all bacteria and the $\mathrm{N}$-acetylated peptide elf18 comprising the first 18 amino acids of the protein is fully active to induce defense responses (Kunze et al., 2004). It was possible to trigger a rapid release of ROS with both elicitors flg22 and elf18. In comparison to Col-0 plants, the tga2,5,6 mutant shows slightly increased ROS burst after flg22 perception (Figure 4-7A). A treatment with elf18 has the opposite effect: the tga2,5,6 mutant is less sensitive to elf18 as the wild-type (Figure 4-7B). These differences are not statistical significant and probably are due to the big variances between the samples.

Chitin and chitosan are fungal elicitors. Chitosan is a hydrophilic biopolymer and is obtained by $\mathrm{N}$-deacetylation of chitin. It could be shown that chitosan induces various defense reactions in plants (Iriti and Faoro, 2009). For Arabidopsis it is only known that chitosan stimulates a NADPH-dependent, hyperpolarization-activated $\mathrm{Ca}^{2+}$ influx current in guard cells, necessary for stomata closure (Klüsener et al., 2002). 
Chitin and chitosan induce only a very weak ROS burst in comparison to the treatments with flg22 and elf18 (Figure 4-7C+D). Like for flg22 and elf18 perception, no significant differences between Col-0 and tga2,5,6 were detectable. Remarkably, the ROS burst released by chitosan is much stronger than the burst triggered by chitin.
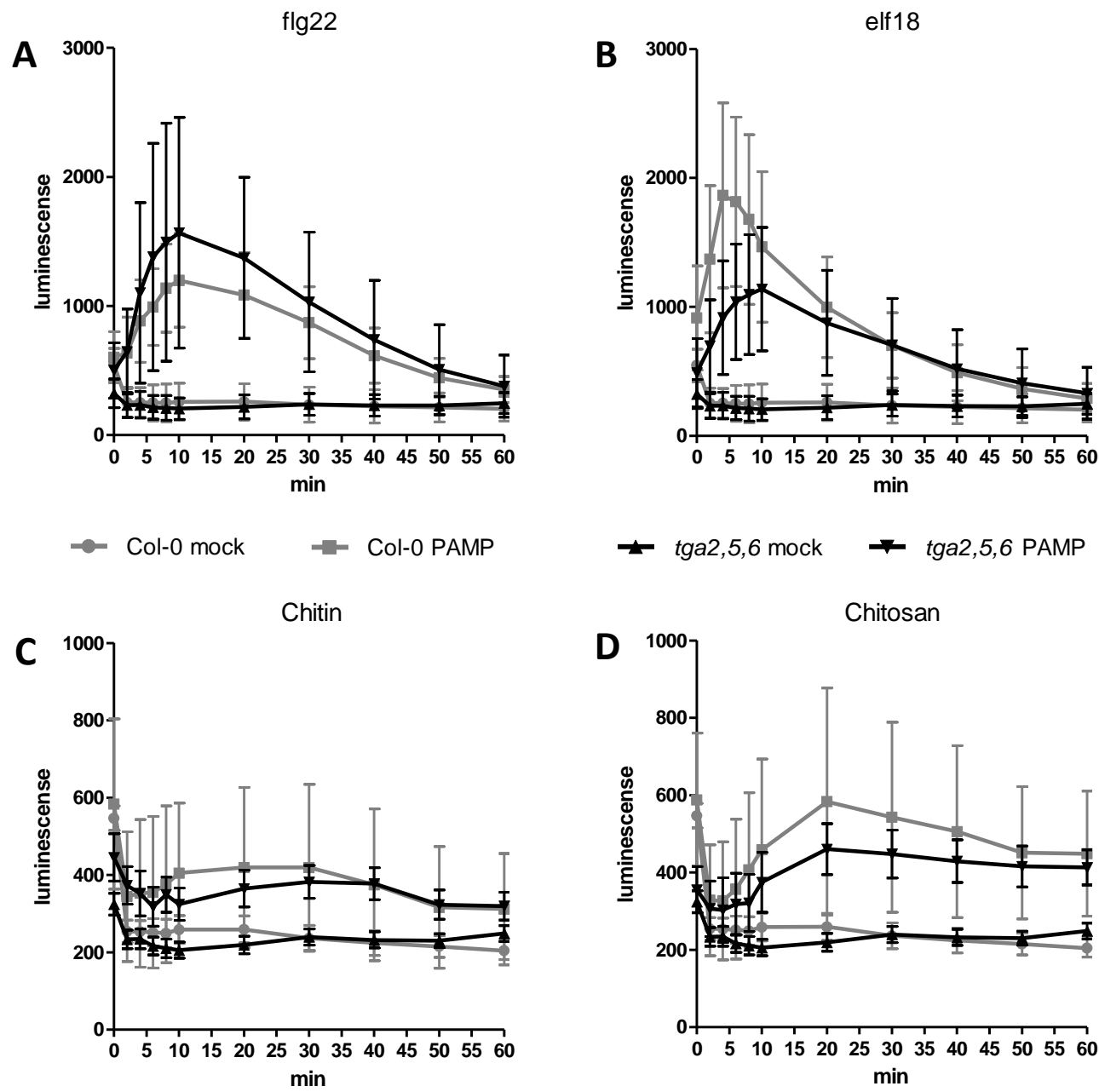

Figure 4-7| Oxidative burst in the leaf tissues of Col-0 and tga2,5,6.

Luminescence of $A$. thaliana leaf discs in a solution with luminol and peroxidase after treatment with different PAMPs and after control treatment (mock), as indicated. Light emission at the very beginning of the experiments is caused by phosphorescence of the green tissue. Every data point represents the average and SD of $n=12$ leaf discs. Statistical analysis with 1wayAnova does not point out significant differences between Col-0 and tga2,5,6 plants. This experiment was repeated once with similar results.

(A) $1 \mu \mathrm{M}$ flg22 (B) $1 \mu \mathrm{M}$ elf18 (C) $100 \mathrm{mg} / \mathrm{L}$ chitin (D) $100 \mathrm{mg} / \mathrm{L}$ chitosan 


\subsection{Gene expression analysis shows an enhanced activation of early flg22-inducible genes in the tga2,5,6 mutant}

Flg22 induces numerous defense related genes in Arabidopsis thaliana. Very early induced genes (after $60 \mathrm{~min}$ ) mostly encode signaling components, such as transcription factors, protein kinases/phosphatases, and proteins that regulate protein turnover. Approximately $80 \%$ of these genes were also up-regulated by treatment with cycloheximide. This suggests that many early flg22-induced genes are negatively regulated by rapidly turned-over repressor proteins (Navarro et al., 2004). For TGA2 it is described that this transcription factor can act as a repressor for $P R$-gene expression (Kesarwani et al., 2007). The tga2,5,6 mutant shows enhanced root growth inhibition after treatment with flg22 (e.g. Figure 4-1). In order to investigate, if the class-II TGA factors TGA2, TGA5 and TGA6 also act as negative regulators for early flg22-induced genes, a quantitative PCR (qRT-PCR) expression analysis was used.

A

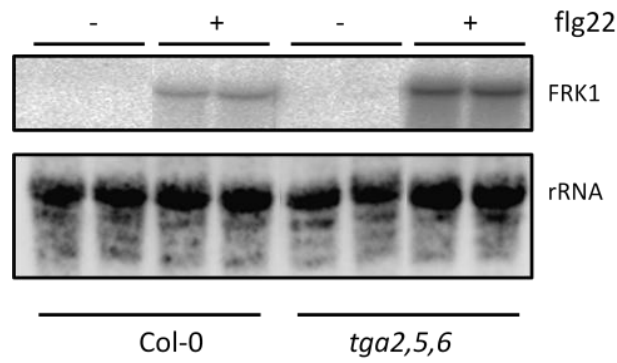

B

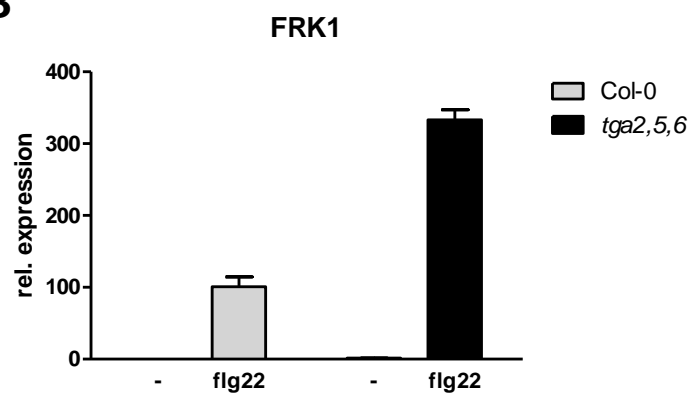

Figure 4-8| Comparison of FRK1 expression analyzed by northern blot and qRT-PCR.

10-14-days-old wild-type and tga2,5,6 mutant seedlings grown on 1MS+MES medium were spraytreated with $\mathrm{H}_{2} \mathrm{O}(-)$ or $1 \mu \mathrm{M}$ flg22. After 2 hours of treatment, approximately 50 seedlings were harvested for RNA extraction.

(A) Northern blot. 10 ng RNA per lane was loaded. The hybridization occurs with a specific probe against FRK1.

(B) qRT-PCR with specific primer against FRK1. The transcript levels are normalized to the house keeping gene UBQ5. The expression level in flg22-treated Col-0 seedlings was set to $100 \%$. The average \pm SEM of $n=2$ samples is shown.

The analysis of FRK1 expression was selected because FRK1 is well described as early transcriptional activated after flg22 perception (Asai et al., 2002) and serves as a marker gene for flg22 signaling. Total RNA of 14 days old seedlings spray-inoculated for two hours with $1 \mu \mathrm{M}$ flg22 peptide was isolated and simultaneously analyzed by a northern blot or by qRT-PCR (Figure 4-8). 
For northern blot analysis, a radioactive-labeled probe comprising the cDNA of FRK1 was used. The northern blot analysis revealed that the FRK1 expression was induced by flg22 in Col-0 and tga2,5,6 seedlings, albeit with different intensities (Figure 4-8A). The tga2,5,6 seedlings are much more sensitive to the flg22 stimulus as the wild-type. The same result could be obtained from the qRT-PCR (Figure 4-8B). This method is much faster and more sensitive than a northern blot and it is possible to analyze many genes with the same RNA preparation, so qRT-PCR was selected for further expression analysis.

To elucidate, if other tga mutants beside the tga2,5,6 mutant show altered expression levels of FRK1 after flg22 treatment, the same mutants as those used in the root growth assay were used for gene expression analysis (Figure 4-9). FRK1 expression is not affected in flg22-treated tga2,5 double mutant plants. The single mutants tga 3 and tga 6 as well as the double mutant tga1,4 show only slightly increased expression levels of $F R K 1$, which does not significantly differ from the wild-type expression. In turn, the tga2,3,5,6 quadruple mutant shows the same elevated induction as the triple mutant tga2,5,6 does.

Root growth assays showed that an ectopic expression of TGA2 is sufficient to rescue the phenotype of enhanced root growth inhibition in the tga2,5,6 mutant (Figure 4-4A). The transgenic line TGA2OE\#7 was used for qRT-PCR analysis of FRK1 expression (Figure 4-10). TGA2 is sufficient to repress the expression of FRK1 to wild-type levels, indicating that TGA2 is an important regulator of early defense genes.

\section{FRK1}

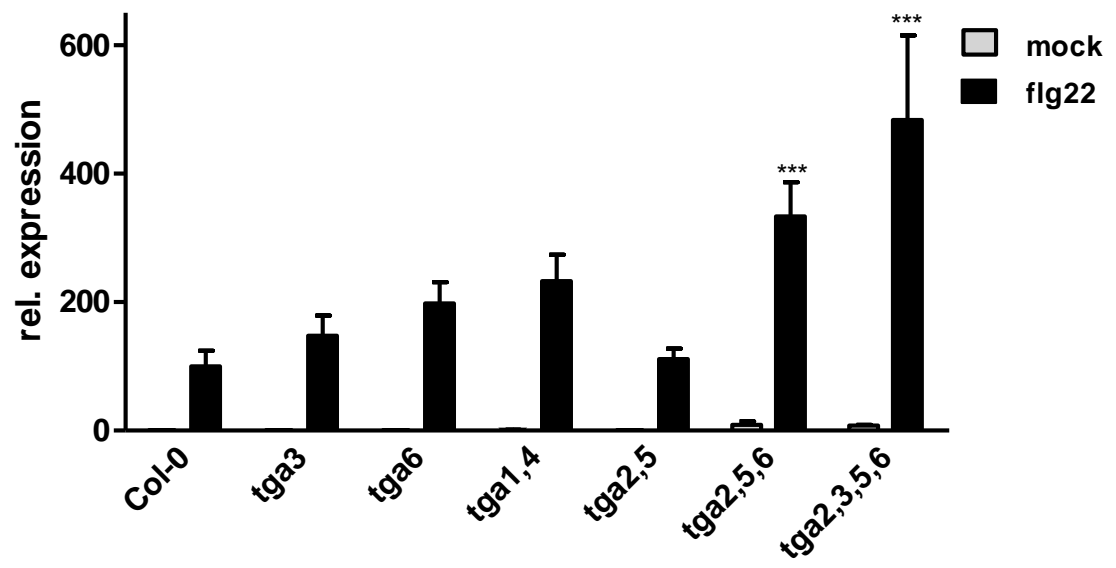

Figure 4-9| flg22-induced $F R K 1$ expression in Col-0 and different tga mutants.

10-14-days-old $A$. thaliana seedlings grown on $1 \mathrm{MS}+\mathrm{MES}$ medium were spray treated with $\mathrm{H}_{2} \mathrm{O}$ (mock) or $100 \mathrm{nM}$ flg22. Two hours after treatment approximately 50 seedlings were harvested for RNA extraction. Transcript levels were quantified by qRT-PCR with specific primers against FRK1 and normalized to relative expression in comparison to the house keeping gene UBQ5. The expression level in flg22-treated Col-0 seedlings was set to $100 \%$. The average \pm SEM of $n=3$ samples is shown. Asterisks represent significant differences between wild-type and tga mutant plants within a treatment (Student's t-test, ${ }^{* * *} \mathrm{P}<0.001$ ). 
FRK1

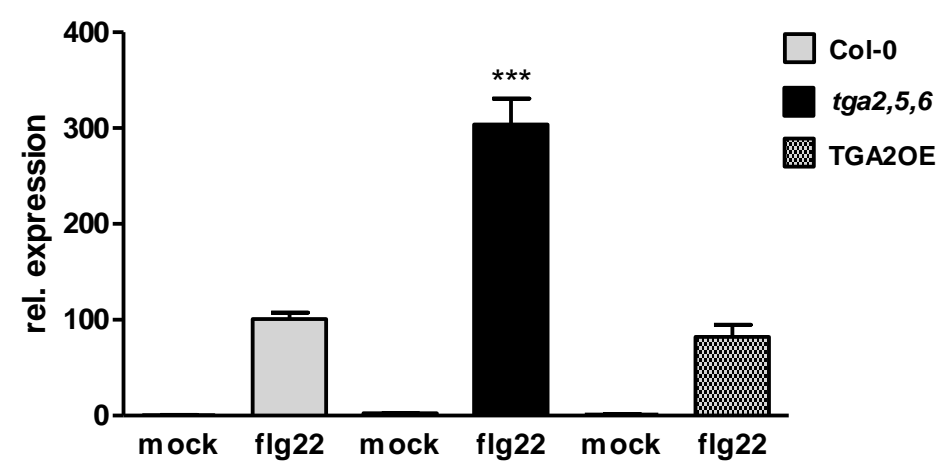

Figure 4-10| flg22-induced $F R K 1$ expression in Col-0, tga2,5,6 and plants ectopically expressing TGA2.

10-14-days-old $A$. thaliana seedlings (Col-0, tga2,5,6 and transgenic line TGA2OE\#7E ectopically expressing TGA2 in tga2,5,6 background) grown on 1MS+MES medium were spray treated with $\mathrm{H}_{2} \mathrm{O}$ (mock) or $100 \mathrm{nM}$ flg22. Two hours after treatment approximately 50 seedlings were harvested for RNA extraction. Transcript levels were quantified by qRT-PCR with specific primers against FRK1 and normalized to relative expression in comparison to the house keeping gene UBQ5. The expression level in flg22-treated Col-0 seedlings was set to $100 \%$. The average \pm SEM of $\mathrm{n}=3$ samples is shown. Asterisks represent significant differences between wild-type, tga 2,5,6 and TGA2OE plants within a treatment (Student's t-test, $* * * P<0.001$ ).

For further expression analysis, 10 days old seedlings were treated with $100 \mathrm{nM}$ flg22 for $15,30,60,90$ and 120 minutes or 2,12 and 24 hours in two separate time course experiments. RbohD, WRKY22, WRKY29 and FRK1, which are known to be transcriptionally activated by flg22, were chosen for the analysis. The Arabidopsis NADPH-oxidases RbohD and RbohF are known to produce ROS after pathogen attack (Torres et al., 2002). WRKY22 and WRKY29, members of the same subgroup of the WRKY transcription factor family are direct targets of the flg22 activated MAP kinase pathway regulating the expression of FRK1 in protoplasts (Asai et al., 2002).

The $R b o h D$ gene is very fast inducible by flg22 (Figure $4-11 A+B$ ). 15 min after flg22 treatment, the expression of RbohD was strongly induced in Col-0 and tga2,5,6 seedlings. The maximal expression was detected after $30 \mathrm{~min}$ and declines to almost background levels after one hour. No significant differences could be detected between the RbohD expression of wild-type and tga2,5,6 mutant seedlings. The induction of WRKY22 shows a similar kinetic as the expression of $R b o h D$, with the difference that the maximal expression was detected after 60 min (Figure 4-11C+D). Furthermore, at early time points, WRKY22 is significantly stronger expressed in the tga2,5,6 mutant than in the wild-type. The closely related WRKY22 and WRKY29 are functionally redundant (Asai et al., 2002), but the expression kinetic differs. 
RbohD

A

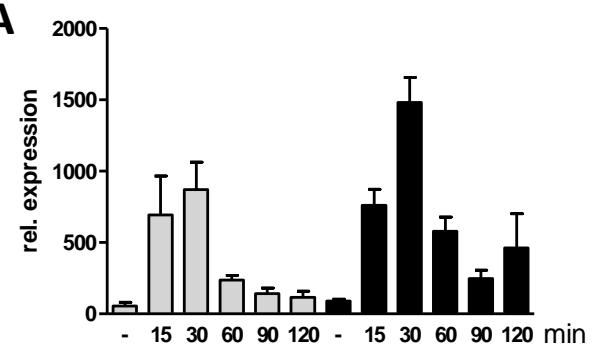

WRKY22
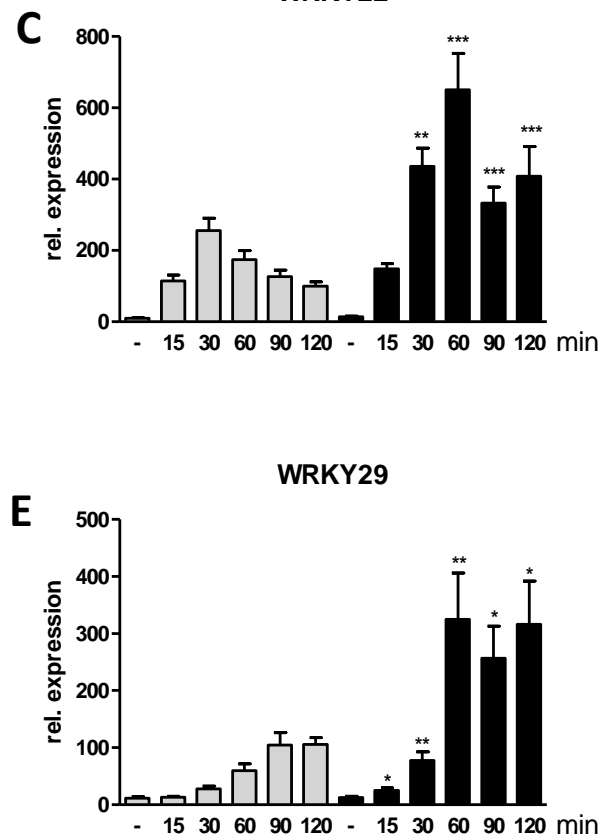

FRK1

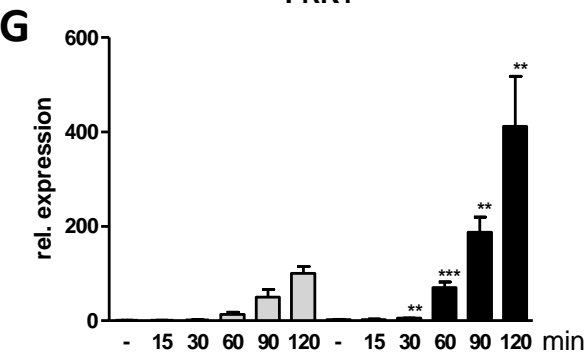

B

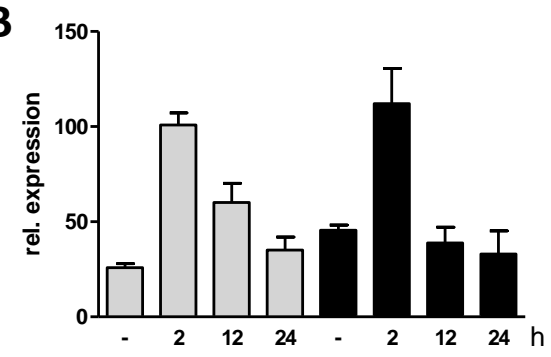

WRKY22

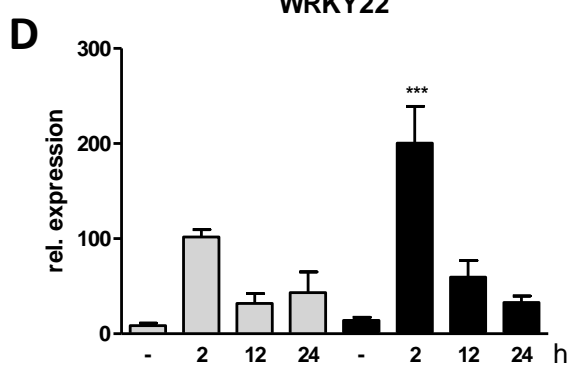

WRKY29

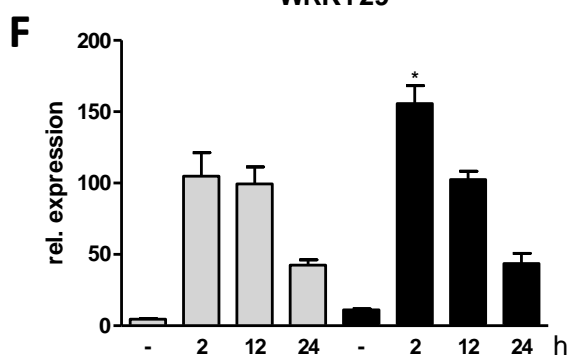

FRK1

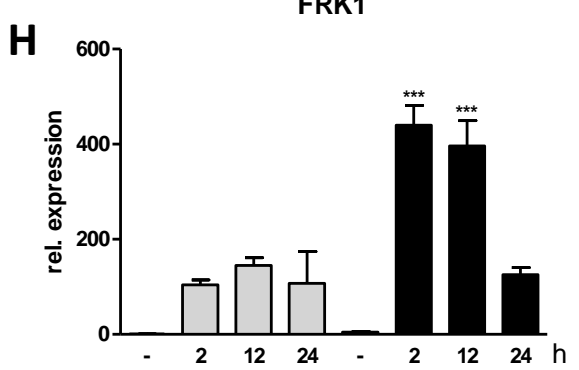

Figure 4-11| Expression analysis of early flg22-inducible genes in Col-0 and tga2,5,6 seedlings. 10-14-days-old Col-0 (gray bars) and tga2,5,6 (black bars) $A$. thaliana seedlings grown on $1 \mathrm{MS}+\mathrm{MES}$ medium were spray treated with $\mathrm{H}_{2} \mathrm{O}$ (mock) or $100 \mathrm{nM}$ flg22 in two different time course experiments. Approximately 50 seedlings were harvested for RNA extraction after the indicated time points. Transcript levels were quantified by qRT-PCR with specific primers against RbohD, WRKY22, WRKY29 and FRK1 and normalized to the house keeping gene UBQ5. The expression level in Col-0 seedlings treated with flg22 for $2 \mathrm{~h}$ was set to $100 \%$. Every bar represents the average \pm SEM of

(A), (C), (E), (G) $n=9$ samples derived from three independent experiments

$(B),(D),(F),(H) n=6$ samples derived from two independent experiments

Asterisks represent significant differences between Col-0 and tga2,5,6 plants within a treatment

(Student's t-test, $* * * \mathrm{P}<0.001 ;{ }^{* *} \mathrm{P}<0.01 ;{ }^{*} \mathrm{P}<0.05$ ) 
The activation of WRKY22 proceeds in a transient manner, whereas the expression of WRKY29 is a more long lasting effect (Figure 4-11E+F). WRKY29 is also hyper-inducible in the tga2,5,6 mutant and reaches wild-type levels after 12 hours. WRKY22 and WRKY29 are able to activate the FRK1 promoter directly (Asai et al., 2002). The expression data confirms with this situation, since the transcriptional activation of FRK1 starts after 60 min (Figure 4$11 \mathrm{G}+\mathrm{H})$ at a time point where WRKY22 and WRKY29 are still expressed. In the tga2,5,6 mutant the FRK1 expression is not only stronger than in Col-0 plants, in addition the expression starts earlier (after $30 \mathrm{~min}$ instead of $60 \mathrm{~min}$ in Col-0).

To investigate, wether other PAMPs induce an increased expression of flg22-induced genes in the tga2,5,6 mutant, seedlings were treated with the bacterial PAMP elf18 and the fungal elicitor chitosan to analyze FRK1 expression after $2 \mathrm{~h}$ of treatment (Figure 4-12). Indeed, a treatment with each of the PAMPs tested induced a hyper-activation of FRK1expression. Elf18 induces FRK1-expression to a level comparable with flg22-induction. A slightly enhanced response to chitosan was detected in tga2,5,6 plants, while the FRK1expression in Col-0 plants is close to background levels. This result corresponds to the weak ROS burst induced by chitosan (4-7D).

\section{FRK1}

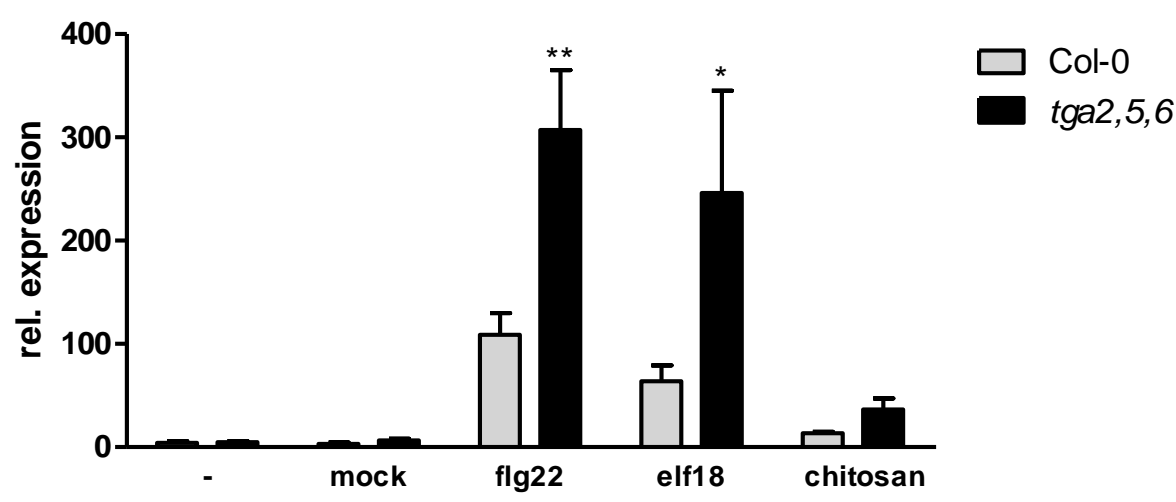

Figure 4-12| Expression analysis of FRK1 in Col-0 and tga2,5,6 seedlings after PAMP treatment. 10-14-days-old Col-0 (gray bars) and tga2,5,6 (black bars) A. thaliana seedlings grown on $1 \mathrm{MS}+\mathrm{MES}$ medium were spray treated with $\mathrm{H}_{2} \mathrm{O}$ (mock), $1 \mu \mathrm{M}$ flg22, $1 \mu \mathrm{M}$ elf18 or $100 \mathrm{mg} / \mathrm{L}$ chitosan. After two hours of treatment, approximately 50 seedlings were harvested for RNA extraction. Transcript levels were quantified by qRT-PCR with specific primers against FRK1 and normalized to relative expression in comparison to the house keeping gene UBQ5. The expression level in flg22-treated Col-0 seedlings was set to $100 \%$. The average \pm SEM of $n=5$ samples is shown. The experiment was replicated once with similar results. Asterisks represent significant differences between Col-0 and tga2,5,6 plants within a treatment ( 2 wayAnova, $* * \mathrm{P}<$ $0.01 ; * P<0.05)$ 


\subsection{The effect of flg22 on late cell wall-based defense responses is fortified in the tga2,5,6 mutant}

Another typical PAMP response is callose deposition. Flg22-induced callose responses were monitored in Arabidopsis Col-0 and tga2,5,6 seedlings grown under the same conditions as described for the root growth assay. Callose is a $ß(1,3)$ glucan polymer which is deposited at sites of fungal or bacterial entry and is described as a comparatively late defense-associated response. Staining with aniline blue was used to visualize callose (Figure 4-13). Fluorescent deposits on the cotyledons of Col-0 seedlings treated with $1 \mu \mathrm{M}$ flg22 were observed that were absent in water treated plants. A mutant of the callose synthase encoded by the PMR4 gene did not respond to flg22 treatment, demonstrating that the appearance of these fluorescent deposits depends on PMR4. In comparison to wild-type seedlings, the tga2,5,6 mutant shows a much stronger callose deposition after flg22 treatment. Furthermore, non-induced tga2,5,6 cotyledons exhibit significantly more callose spots. The pmr4-1/tga2,5,6 quadruple mutant behaves like the pmr4-1 single mutant, indicating that the enhanced callose deposition in the tga2,5,6 mutant depends exclusively on PMR4.

QRT-PCR was performed, to test whether PMR4, CYP81F2 and CYP79B2 genes, involved in flg22-induced callose deposition, are transcriptionally hyper-activated like the early defense genes FRK1, WRKY22 and WRKY29. Early expression of PMR4 is not altered in the tga2,5,6 mutant (Figure 4-14A). However, no clear results could be obtained for the two hours time point. Together with the significantly enhanced transcript levels 24 hours after flg22treatment a slight hype-ractivation of PMR4 in the tga2,5,6 mutant could be observed (Figure 4-14B). The flg22-triggered callose response in Arabidopsis seedlings requires ETand MYB51-dependent I3G biosynthesis by cytochrome CYP79B2 and CYP81F2-dependent 4-methoxylation of IGS (Clay et al., 2009). The transcript levels of CYP79B2 and CYP81F2 are elevated in the tga2,5,6 mutant but display different kinetics. Whereas CYP81F2 expression is most activated after one hour (Figure $4-14 C+D$ ), the expression of CYP79B2 starts later with a maximum after 12 hours and is a more long lasting effect (Figure 4-14E+F). In conclusion, the fortified callose deposition might be due to transcriptional hyper-activation of CYP81F2 and CYP79B2. 
A
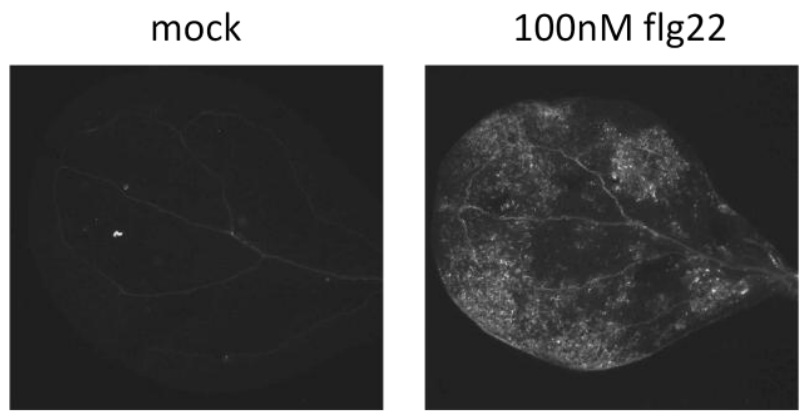

Col-0
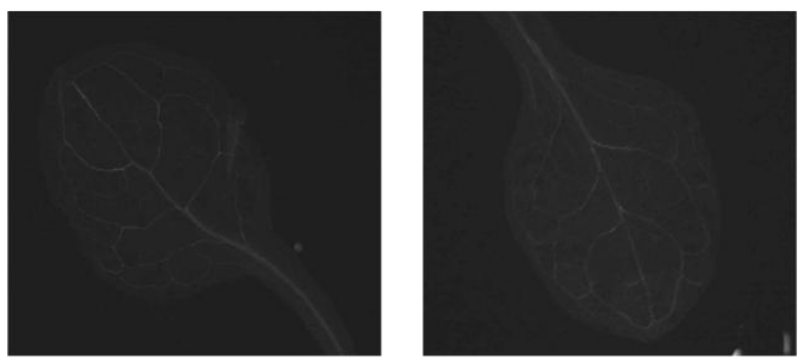

pmr4-1
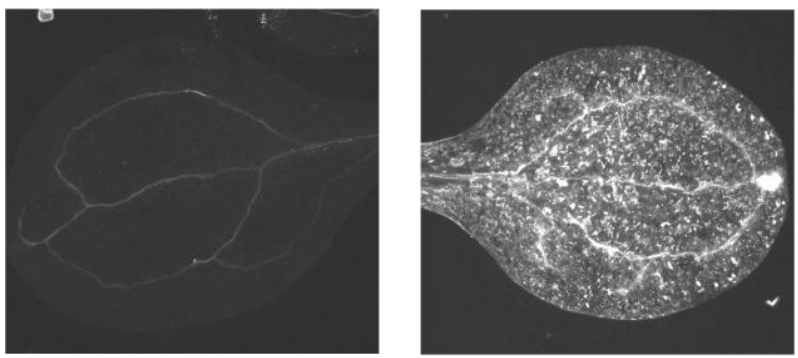

$\operatorname{tga} 2,5,6$
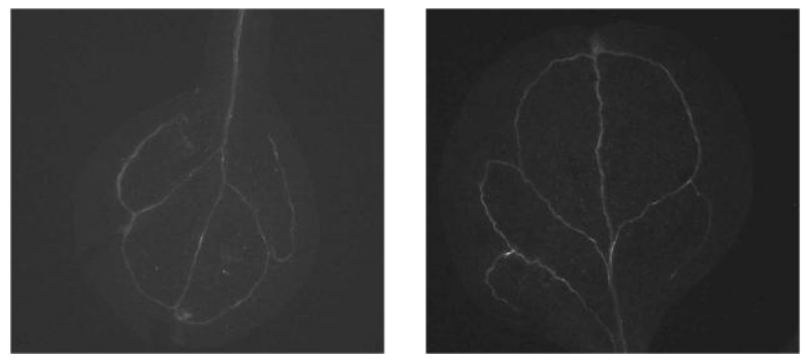

$\operatorname{tga} 2,5,6 /$

pmr4-1

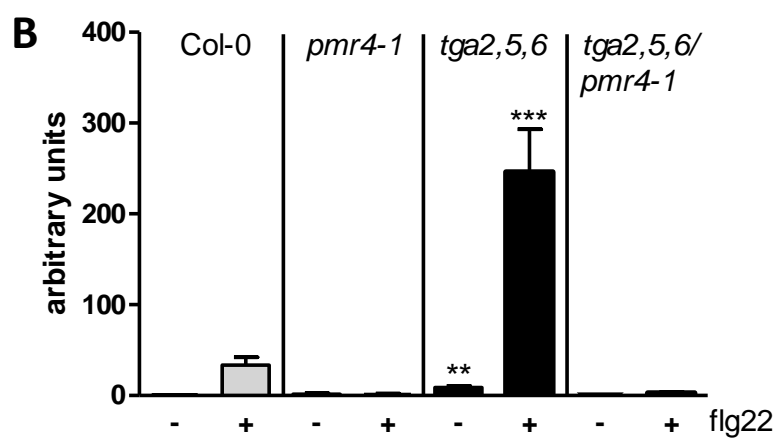

Figure 4-13| Callose deposition in Col-0, pmr4-1, tga2,5,6 and tga2,5,6/pmr4-1 seedlings.

(A) Aniline blue staining of cotyledons from 14 days old seedlings treated with $1 \mu \mathrm{M}$ flg22. After $24 \mathrm{~h}$, leaves were stained for callose by aniline blue and fluorescence was detected under UV light (filtercube $A ; 25 x$ magnification).

(B) Quantification of callose deposition. The average \pm SEM of callose deposits from $n=10$ independent cotyledons is shown. Asterisks represent significant differences between wild-type and tga256 plants within a treatment (Student's t-test, $* * * P<0.001 ; * * P<0.01$ ). 

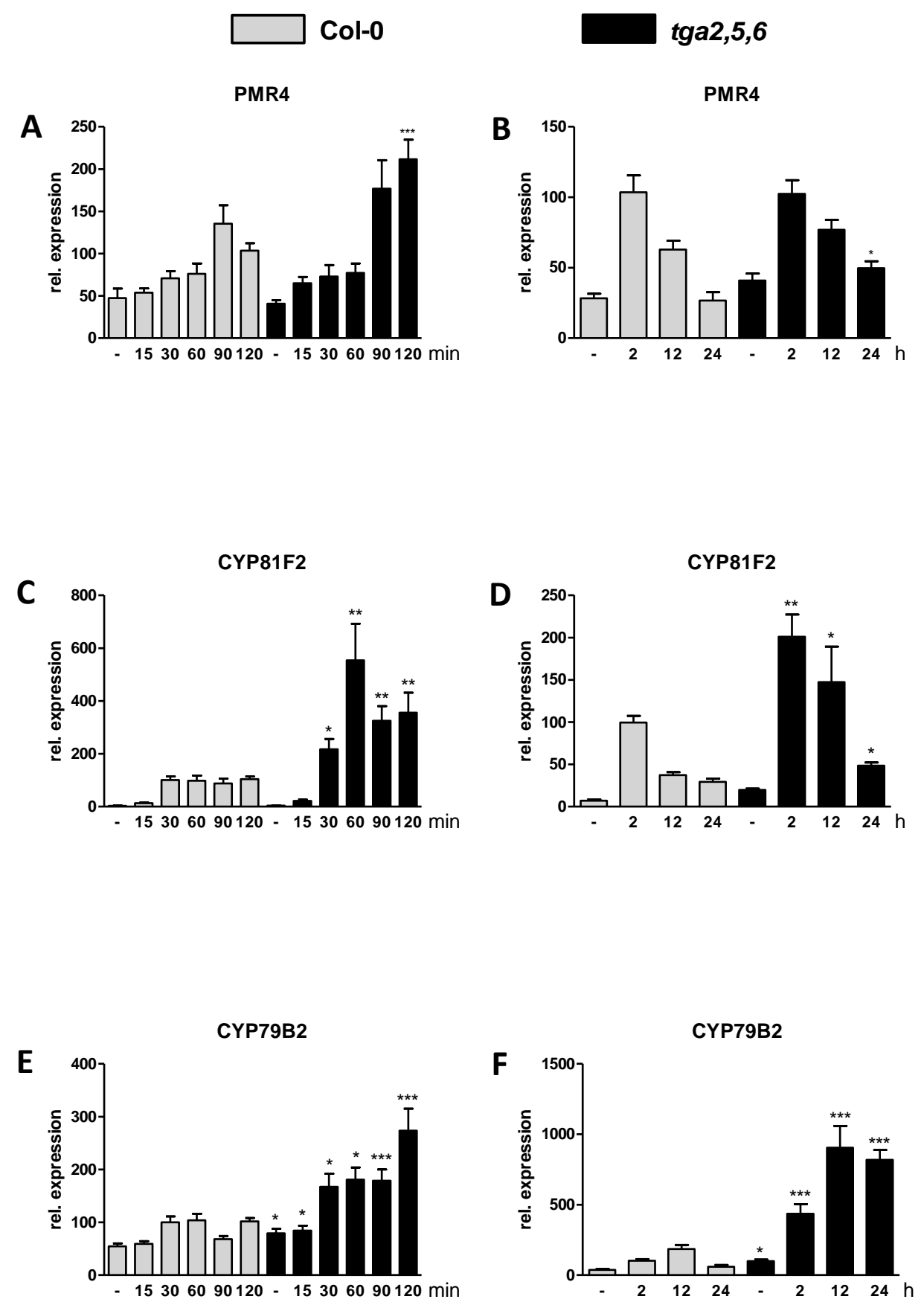

Figure 4-14| Expression analysis of genes involved in flg22-induced callose deposition in Col-0 and tga2,5,6 seedlings.

10-14-days-old Col-0 (gray bars) and tga2,5,6 (black bars) $A$. thaliana seedlings grown on $1 \mathrm{MS}+$ MES medium were spray treated with $\mathrm{H}_{2} \mathrm{O}$ (mock) or $100 \mathrm{nM}$ flg22 in two different time course experiments. Approximately 50 seedlings were harvested for RNA extraction after the indicated time points. Transcript levels were quantified by qRT-PCR with specific primers against $P M R 4, C Y P 81 F 2$ and CYP79B2 and normalized to the house keeping gene UBQ5. The expression level in Col-0 seedlings treated for $2 \mathrm{~h}$ with flg22 was set to $100 \%$.

Every bar represents the average \pm SEM of

(A), (C), (E) $n=9$ samples derived from three independent experiments

(B), (D), (F) $n=6$ samples derived from two independent experiments

Asterisks represent significant differences between Col-0 and tga2,5,6 plants within a treatment (Student's t-test, ${ }^{* * * P}<0.001 ;{ }^{* * P}<0.01 ;{ }^{*} \mathrm{P}<0.05$ ) 


\subsection{The tga2,5,6 mutant fails to develop callose deposition after wounding}

To exclude that the increased callose deposition in the tga2,5,6 mutant is an unspecific effect, callose deposition was stimulated by wounding the leaves with a syringe or forceps in seedlings or soil grown plants (Figure 4-15). In wild type leaves, callose deposition develops around the wounding sites. In the tga2,5,6 mutant, callose deposition after wounding is hardly detectable. The signal measured by the quantification with AIDA ${ }^{\odot}$ (Figure $4-15 C+D$ ) shows callose deposition predominantly next to leaf veins. This result not only indicates that an increase of callose deposition in the tga2,5,6 mutant is specific for PAMP induction, moreover the tga2,5,6 mutant fails to develop callose deposits after wounding.

A

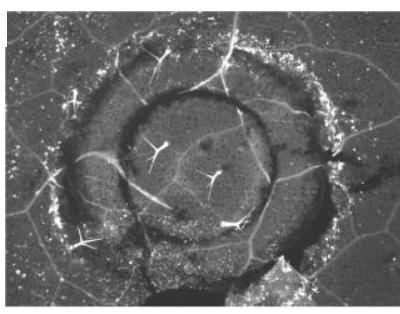

Col-0

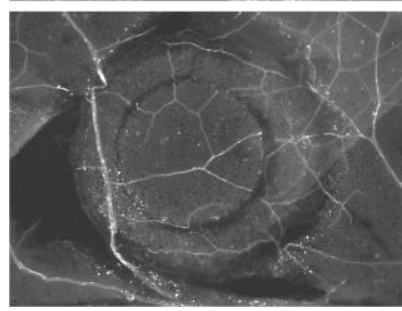

C

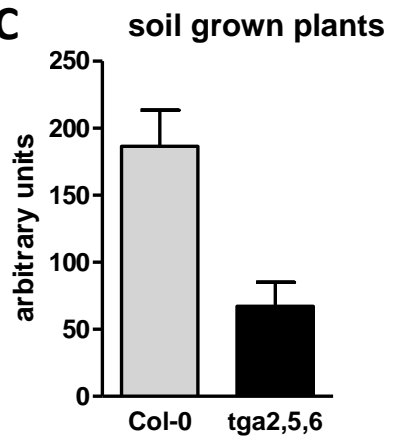

B
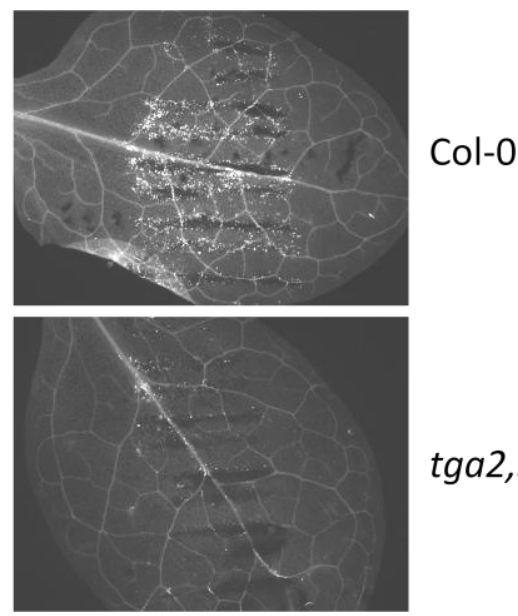

$\operatorname{tga} 2,5,6$

$\operatorname{tga} 2,5,6$

D

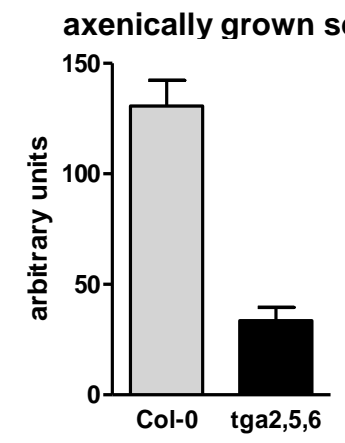

Figure 4-15| Callose deposition in Col-0 and tga2,5,6 leaves after wounding.

(A) 4 week old soil grown plants were wounded by forceps or stamping with a syringe without needle or (B) 14 days old, axenically grown seedlings. After 24h, leaves were stained for callose by aniline blue and fluorescence was photographed under UV light (filtercube $A ; 25 x$ magnification). (C) + (D) Quantification of callose deposition. The average \pm SEM of fluorescence from $n=12$ leaves is shown. The experiment was repeated twice with similar results. 


\section{7 tga2,5,6 mutants show no altered callose deposition after bacterial infection}

Bacterial plant pathogens do not only present PAMPs that are recognized by the host plant, furthermore, they secrete many effectors with different outcomes. In order to assess whether the increased callose deposition in the tga2,5,6 mutant occurs after bacterial infection, soil grown plants were syringe infiltrated with different Pseudomonas syringae strains. The virulent Pst DC3000 strain and the COR-strain (missing the bacterial phytotoxin coronatine) induce a weak callose deposition (Figure 4-16). The hrpA-strain, impaired in TTSS induce a strong callose deposition in Col-0 and tga2,5,6 leaves. This result fits the observation that elicitors secreted by the TTSS suppress callose deposition (Underwood et al., 2007). No significant difference could be observed between Col-0 and the tga2,5,6 mutant.

\section{A}
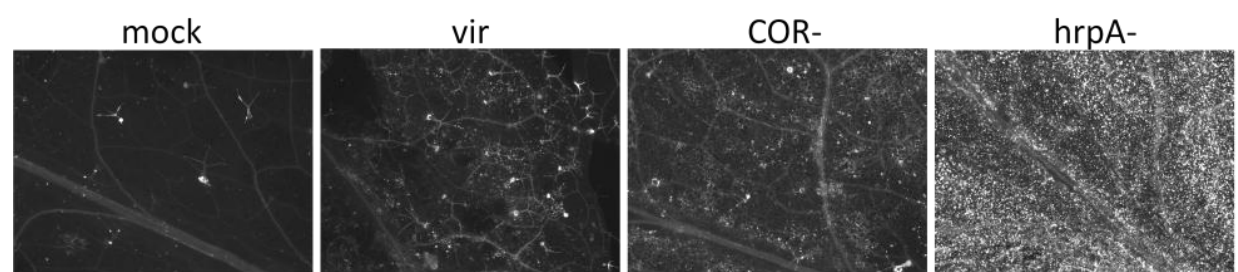

Col-0
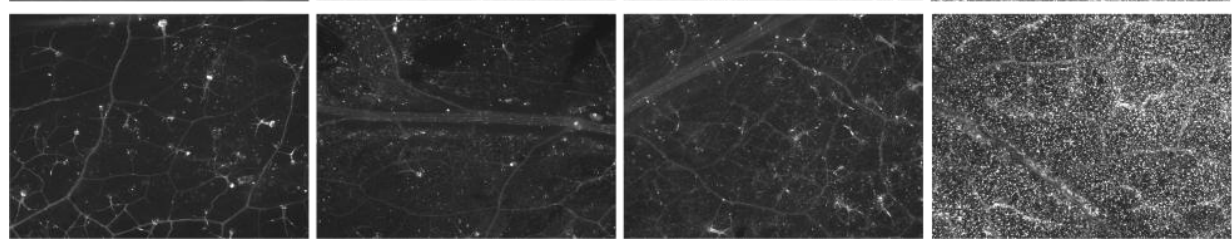

$\operatorname{tg} a 2,5,6$

B

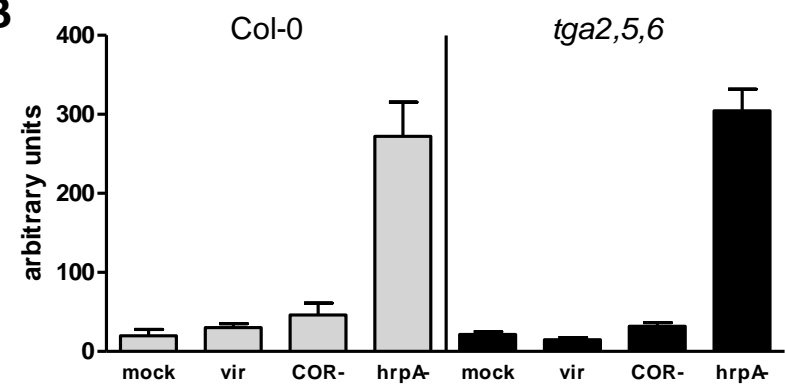

Figure 4-16| Callose deposition in Col-0, pmr4-1, tga2,5,6 and tga2,5,6/pmr4-1 leaves after infection with different Pseudomonas syringae strains.

(A) The leaf lower surface of 4-weeks-old soil grown plants were infiltrated with Pst DC3000 (vir) or Pst DC3000 COR (cor-) or Pst DC3000 hrpA- (hrpA-) $\left(\mathrm{OD}_{600}=0,02\right)$ using a syringe. After $24 \mathrm{~h}$, leaves were stained for callose by aniline blue and fluorescence was photographed under UV light (filtercube A; 25x magnification).

(B) Quantification of callose deposition. The average \pm SEM of fluorescence from at least $n=6$ leaves is shown. 


\section{8 tga2,5,6 mutant plants are insensitive to coronatine (COR) triggered stomatal closure}

During infection, stomata can serve as passive openings for bacterial entry. It was shown that stomatal guard cells are able to perceive bacterial PAMPs like flg22 leading to stomatal closure as a defense response (Melotto et al., 2006). In turn, the phytotoxin coronatine produced by several bacteria like $P$. syringae, is able to circumvent this innate immune response (Melotto et al., 2006). Also, MeJA-treatment completely suppresses the flg22induced callose response (Clay et al., 2009). One hypothesis, considering the antagonism between JA and SA pathways, is that COR promotes susceptibility to $P$. syringae infection by stimulating JA signaling in plants, thereby inhibiting SA-mediated defenses that normally limit growth of $P$. syringae within host tissues. Class-II TGA factors are not only necessary for the establishment of SAR (Zhang et al., 2003); moreover they are important activators of JA/ET-induced responses (Zander et al., 2009).

To determine whether stomata of the tga2,5,6 mutant show altered response to flg22 and COR, leaf slices of adult soil grown plant were incubated with flg22 and COR. After 3 hours, the stomatal apertures of epidermal peals were measured. Whereas in control treated leaves most stomata are open, a marked reduction of stomatal aperture can be observed after 3 hours of flg22-incubation (Figure 4-17). If COR was added to the incubation solution, no stomatal closure can be observed any more in wild-type plants. The stomata of tga2,5,6 plants are insensitive to COR. Stomata from leaf slices incubated in a solution containing flg22 and COR are predominantly closed, similar to treatment with flg22 alone. 
Col-0
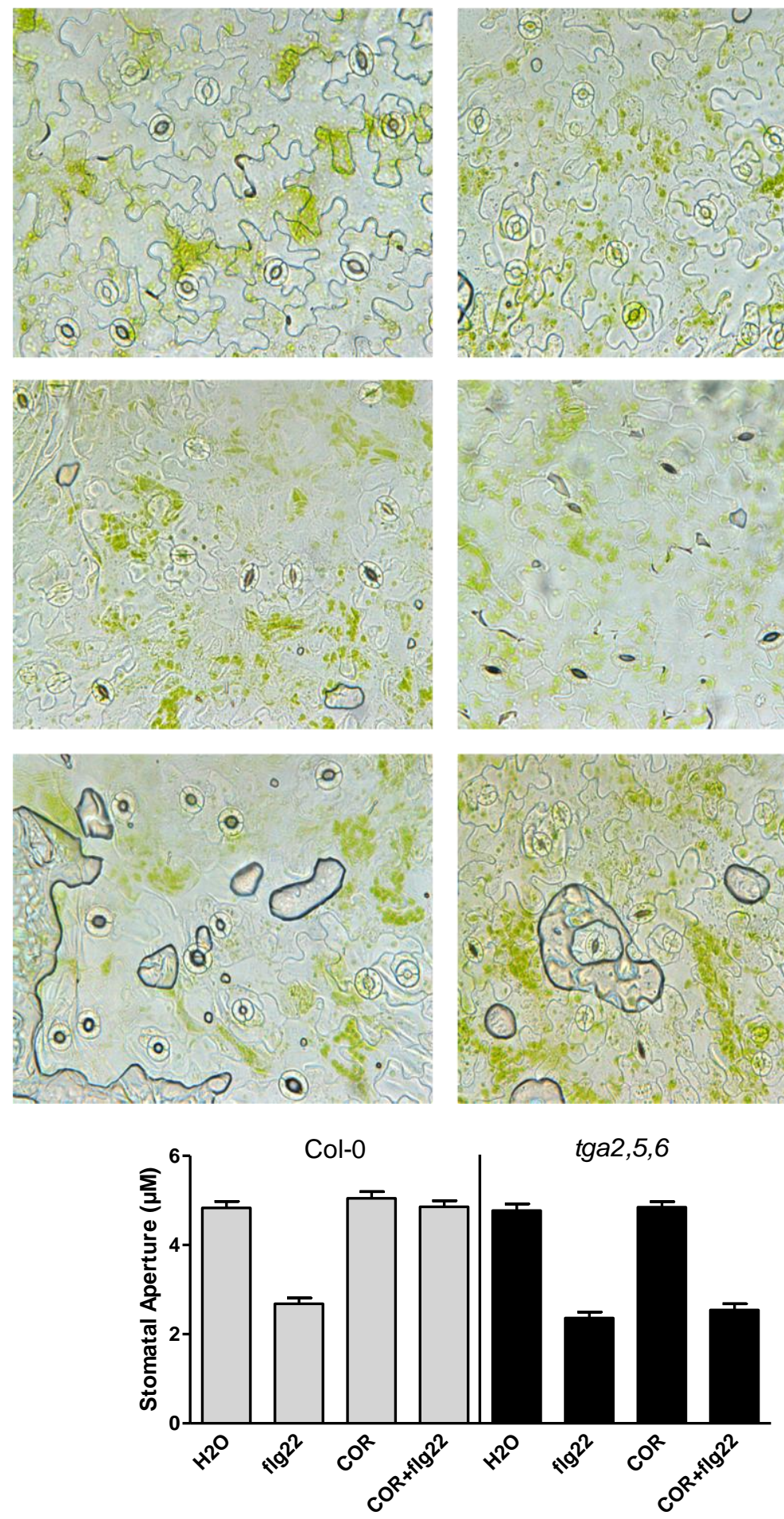

$\operatorname{tg} a 2,5,6$
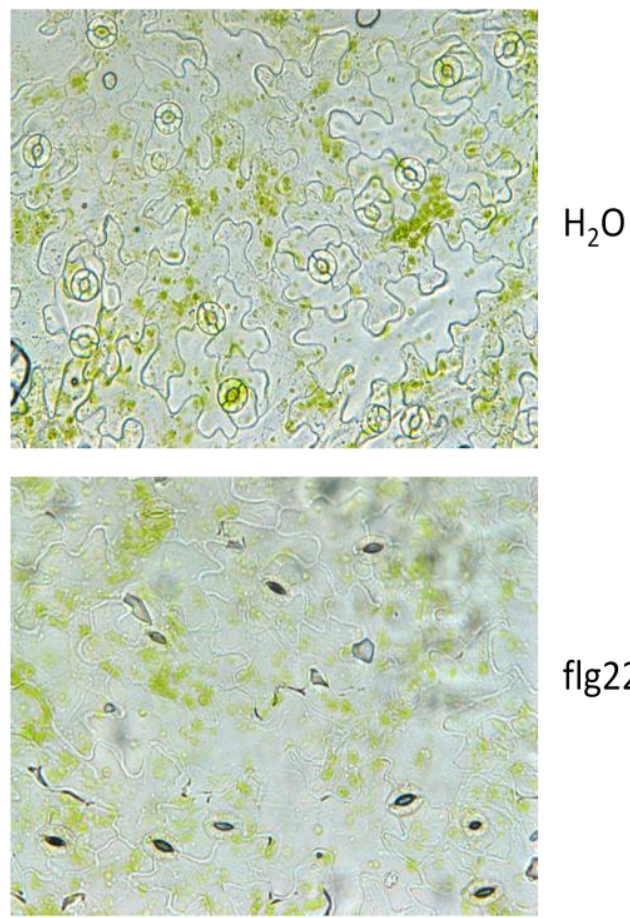

flg22

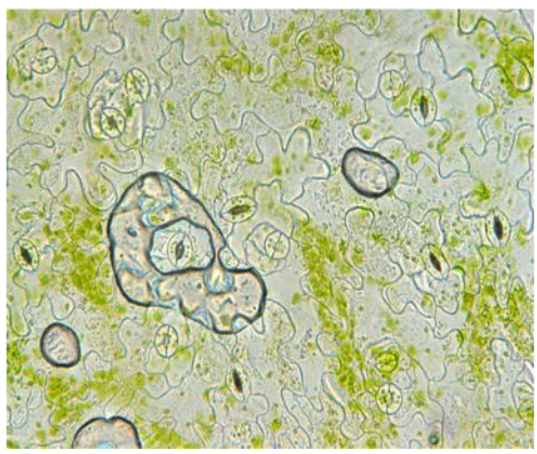

flg $22+C O R$

Figure 4-17| Stomatal closure after treatment with flg22 and flg22/ COR in Col-0 and tga2,5,6 plants.

(A) Leaf slices of 6 week old soil grown plants were floated with $\mathrm{H}_{2} \mathrm{O}, 5 \mu \mathrm{M}$ flg22 or flg22 in combination with $0,5 \mathrm{ng} / \mu \mathrm{l}$ COR. After $3 \mathrm{~h}$, epidermis was fixed by applying the leaf lower surface on ultra clear adhesive tape and observed under a microscope (bright field; 400x magnification). (B) Quantification of stomatal aperture shown in (A). The average \pm SEM from $n=100$ stomata derived from two independent experiments is shown. 
To investigate, wether the stomatal closure also occurs in response to virulent bacteria, leaf slices were incubated with the virulent Psm ES4326. After one hour of incubation with Psm ES4326 a stomatal closure occurs in Col-0 and tga2,5,6 plants to the same degree as after flg22 incubation (Figure 4-18). Interestingly, after three hours of incubation, when the bacteria had time to release COR, the stomata of wild-type plants are re-opened, whereas the stomata of tga2,5,6 plants are still closed. The inhibitory effect of COR on PAMP induced stomatal closure is abolished in both experimental set ups, after treatment with the isolated substances or in the more biological system by infection with bacteria.

$1 \mathrm{~h}$

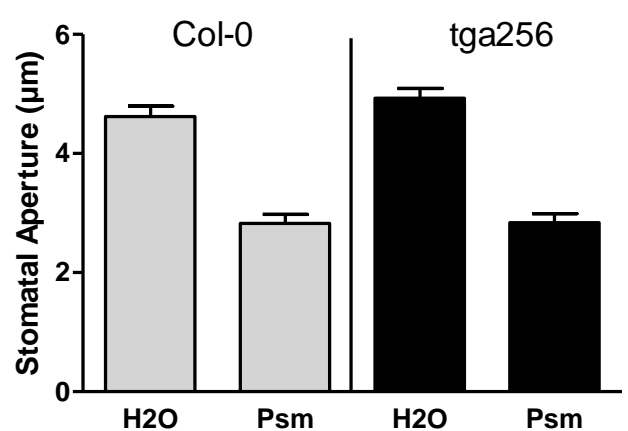

$3 \mathbf{h}$

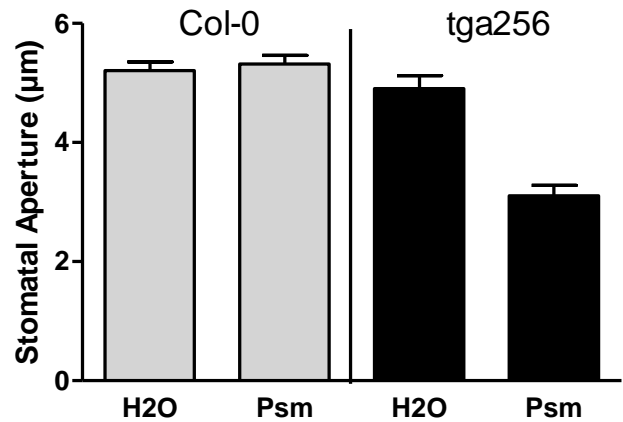

Figure 4-18| Stomatal closure after treatment with Psm ES4326 in Col-0 and tga2,5,6 plants. Leaf slices were exposed to water or virulent Psm ES4326 $\left(\mathrm{OD}_{600}=0.2\right)$. After $1 \mathrm{~h}$ and $3 \mathrm{~h}$, epidermis was fixed by applying the leaf lower surface on ultra clear adhesive tape and observed under a microscope (bright field; 400x magnification). The average \pm SEM from $n=100$ stomata derived from two independent experiments is shown.

Next, it was tested if the ectopic expression of one TGA transcription factor is sufficient to restore the wildtype-like stomatal response to flg22 and COR or exposition to virulent $P$. syringae. All plants accomplish a stomatal closure reaction $3 \mathrm{~h}$ after treatment with flg22 or 1h after incubation in the presence of Psm ES4326 (Figure 4-19). Ectopic expression of TGA2 under the control of the 355 promoter in the tga2,5,6 mutant (here shown for line TGA2OE\#7) leads to a wildtype-like response to COR+flg22 regarding stomatal re-opening (Figure 4-19A), demonstrating that TGA2 is sufficient to complement the phenotype in the tga2,5,6 mutant. However, plants ectopically expressing TGA5 show only a partial complementation of the phenotype.

As shown for the pharmacological assay, ectopic expression of TGA2 is also sufficient to rescue the wild-type like stomatal re-opening 3h after treatment with Psm ES4326, while TGA5 is not able to fulfill this function (Figure 4-19B). 


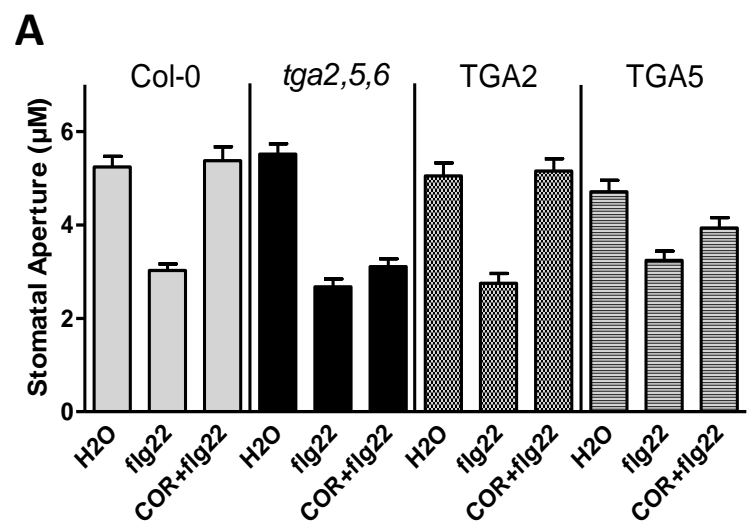

B

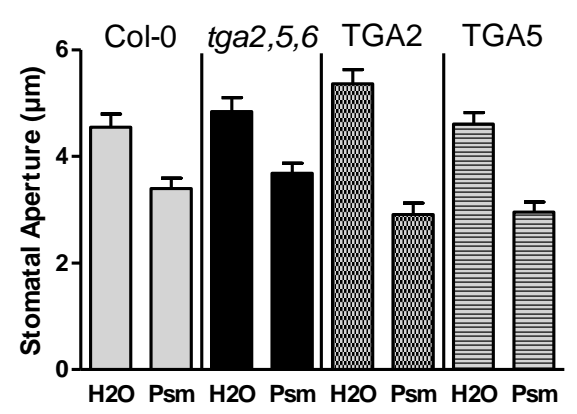

$3 \mathrm{~h}$

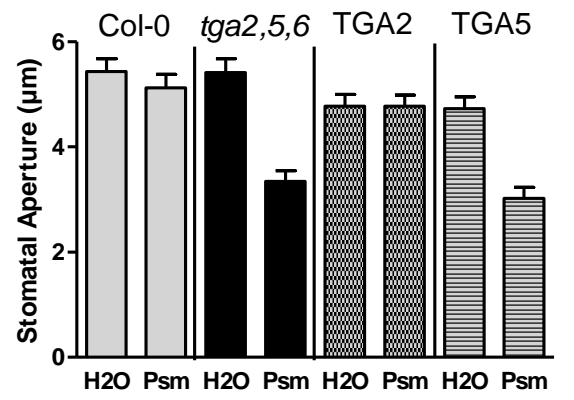

Figure 4-19 Stomatal closure in Col-0, tga2,5,6, TGA2OE and TGA5OE plants.

(A) Leaf slices of 6-weeks-old soil grown plants were floated with $\mathrm{H}_{2} \mathrm{O}$ and $5 \mu \mathrm{M}$ flg22 or flg22 in combination with $0,5 \mathrm{ng} / \mu \mathrm{l}$ COR. After $3 \mathrm{~h}$, epidermis was fixed by applying the leaf lower surface on ultra clear adhesive tape and observed under a microscope (bright field; 400x magnification).

(B) Leaf slices of 6-weeks-old soil grown plants were floated with $\mathrm{H}_{2} \mathrm{O}$ and virulent Psm ES4326 $\left(O D_{600}=0.2\right)$. After $1 \mathrm{~h}$ and $3 \mathrm{~h}$, epidermis was fixed by applying the leaf lower surface on ultra clear adhesive tape and observed under a microscope (bright field; 400x magnification). The average \pm SEM from $n=50$ stomata is shown.

\subsection{Class-II TGA factors are involved in flg22-triggered defense against Pst DC3000}

In this thesis, it could be pointed out that class-II TGA transcription factors act as negative regulators of PAMP-triggered responses. Furthermore, they are important positive regulators in SA-signaling leading to SAR. It was shown that interplay between PAMPtriggered and SA-mediated defense responses exists (Tsuda et al., 2008). Pre-treatment with flg22 induces an SAR-like defense in Arabidopsis (Zipfel et al., 2004) with SA accumulation in local and systemic leaves (Mishina and Zeier, 2007). Due to this fact, the bacterial titers in tga2,5,6 and tga2,5,6/sid2-2 mutants were determined. The use of the quadruple mutant tga2,5,6/sid2-2 in comparison to sid2-2 is necessary to investigate the 
function of class-II TGA factors independently of SA to distinguish between PAMP- or SAdependent effects.

The bacterial growth assay was performed in collaboration with Jane Glazebrook, (University of Minnesota). To induce PAMP-triggered defense, 5 week old plants were infiltrated with $1 \mu \mathrm{M}$ flg22. Control plants were treated with water. After 1 day, leaves were infiltrated with a suspension of Pst DC3000 bacteria $\left(\mathrm{OD}_{600}=0.0001\right)$. The bacterial titer was measured at 0 and 2 days after inoculation (dpi) (Figure 4-20). Comparison of bacterial growth between mock pre-treated and flg22 pre-treated wild-type plants at $2 \mathrm{dpi}$ confirmed the previous observation that pre-treatment with flg22 confers resistance to Pst DC3000 (Zipfel et al., 2004). Bacterial titers in mock pre-treated tga2,5,6 plants are similar to the wild type. sid2-2 and tga2,5,6/sid2-2 plants were slightly different from mock pretreated Col-0 at $2 \mathrm{dpi}$, illustrating the enhanced susceptibility phenotypes of these mutants, founded in the absence of SA-dependent defense responses. The bacterial titers in flg22 pre-treated tga2,5,6, sid2-2 and tga2,5,6/sid2-2 plants were clearly higher than flg22 pretreated Col-0 at $2 \mathrm{dpi}$. Importantly, sid2-2 displays the most pronounced susceptibility to Pst DC3000, significantly higher than tga2,5,6 and tga2,5,6/sid2-2 plants. If SA biosynthesis and class-II TGA factors are absent, the plants become more resistant to Pst DC3000, confirming the hypothesis that in the absence of SA, class-II TGA factors negatively regulate PAMP-triggered response. However, there was still a large difference between mock and flg22 pre-treated plants $2 \mathrm{dpi}$, indicating that the effects of flg22 pre-treatment on resistance to Pst DC3000 are only partially dependent on SA signaling and class-II TGA factors.

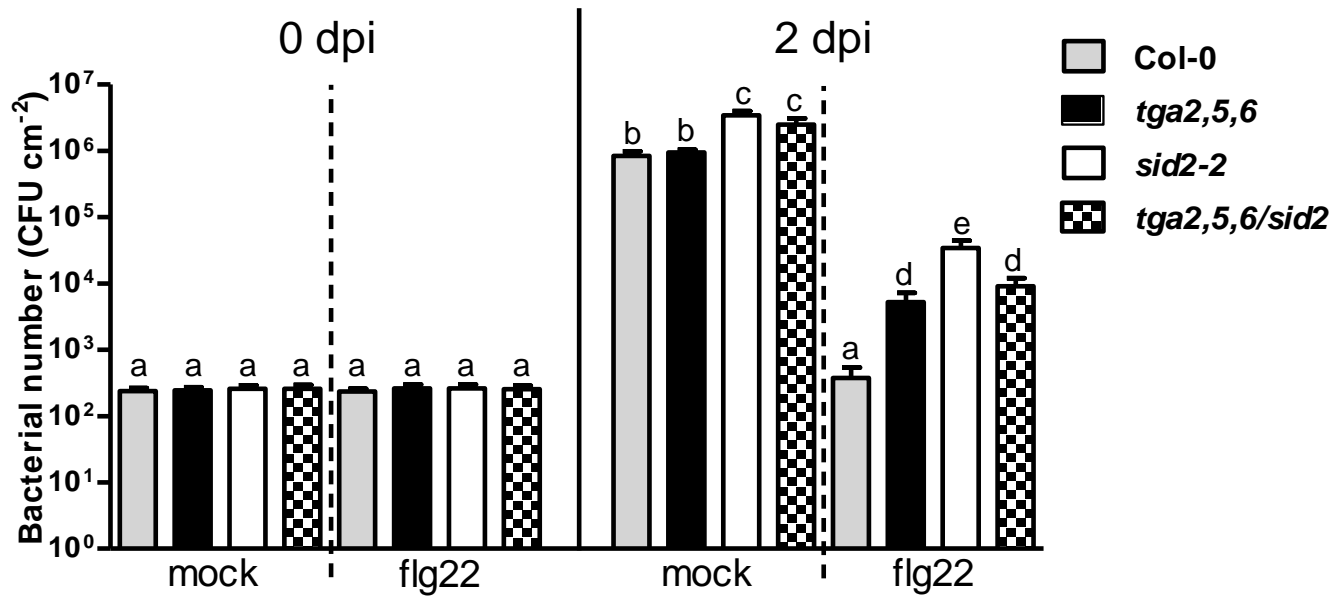

Figure 4-20| Influence of flg22 on bacterial growth.

Pst DC3000 bacterial suspension $\left(\mathrm{OD}_{600}=0.0001\right)$ was infiltrated into Col-0, tga2,5,6, sid2-2 and tga2,5,6/sid2-2 plants 1 day after treatment with water (mock) or $1 \mu \mathrm{M}$ flg22 (flg22). The average \pm SEM from three independent experiments is shown. Significant differences are indicated by different letters (Student's t-test, $\mathrm{P}<0.05$ ). 


\subsection{COR suppresses flg22-induced FRK1 expression in Col-0 and tga2,5,6 mutant}

As COR is not able to suppress flg22-induced stomatal closure in the tga2,5,6 mutant, it was important to know, if COR has an inhibitory effect on PAMP induced expression of defense genes and if this effect takes place in the tga2,5,6 mutant. To prove this hypothesis, seedlings were spray-induced with COR, flg22 and flg22/COR for 2 hours. The isolated RNA was used for qRT-PCR to analyze the expression levels of FRK1 after the different treatments (Figure 4-21). COR alone is not able to induce FRK1. In comparison to flg22 treatment alone, simultaneous application of flg22 together with COR leads to a weaker FRK1 expression in wild-type and tga2,5,6 plants. This reduction of FRK1 transcript levels by COR is eminently pronounced in the tga2,5,6 mutant, only reaching flg22-induced wild-type expression levels.

\section{FRK1}

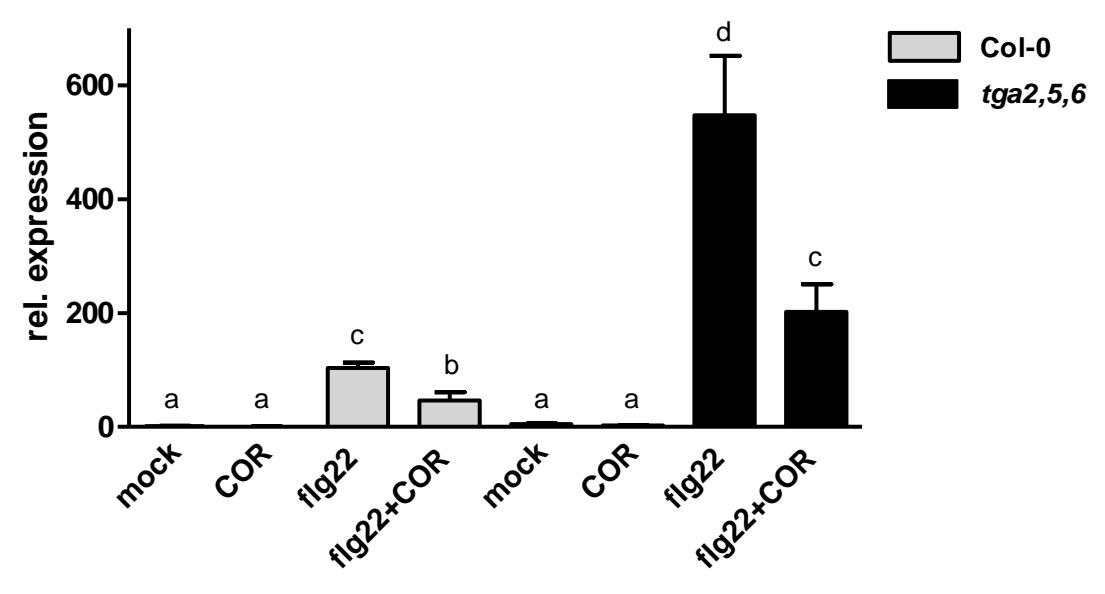

Figure 4-21| Expression analysis of $F R K 1$ in Col-0 and tga2,5,6 seedlings after treatment with flg22 and COR.

RNA was extracted from Col-0 (gray bars) and tga2,5,6 (black bars) seedlings harvested $2 \mathrm{~h}$ after treatment with $1 \mu \mathrm{M}$ flg22, $5 \mu \mathrm{M}$ COR or a combination of both as indicated. Transcript levels were quantified by qRT-PCR with specific primer against FRK1 and normalized to the house keeping gene UBQ5. Expression in Col-0 seedlings that were flg22-treated for $2 \mathrm{~h}$ was set to $100 \%$. The average \pm SEM of $n=12$ samples derived from four independent experiments is shown. Asterisks represent significant differences between two treatments in comparison to the wild-type (Student's t-test, $\mathrm{P}^{* * *}<0,001$ ) 


\subsection{SA and flg22 act synergistically on FRK1-expression in Col-0 seedlings}

To prove wether application of SA has an opposite effect on FRK1 expression as described for COR, a similar experimental setup was chosen as used for the COR+flg22 treatments. The only remarkable difference is the application of SA 24 hours before flg22 treatment, to ensure that SA-dependent responses are activated, like it is the case in primed plants. SA alone activates FRK1 expression only very slightly (Figure 4-22). However, a pre-treatment with SA in combination with flg22 leads to an enhanced expression level of FRK1 in Col-0 seedlings. This difference is significant but transcript levels are not as high as in the tga2,5,6 mutant. No effect of SA on FRK1 expression was detectable in the mutant seedlings, assuming a constitutive primed status of the tga2,5,6 mutant.

\section{FRK1}

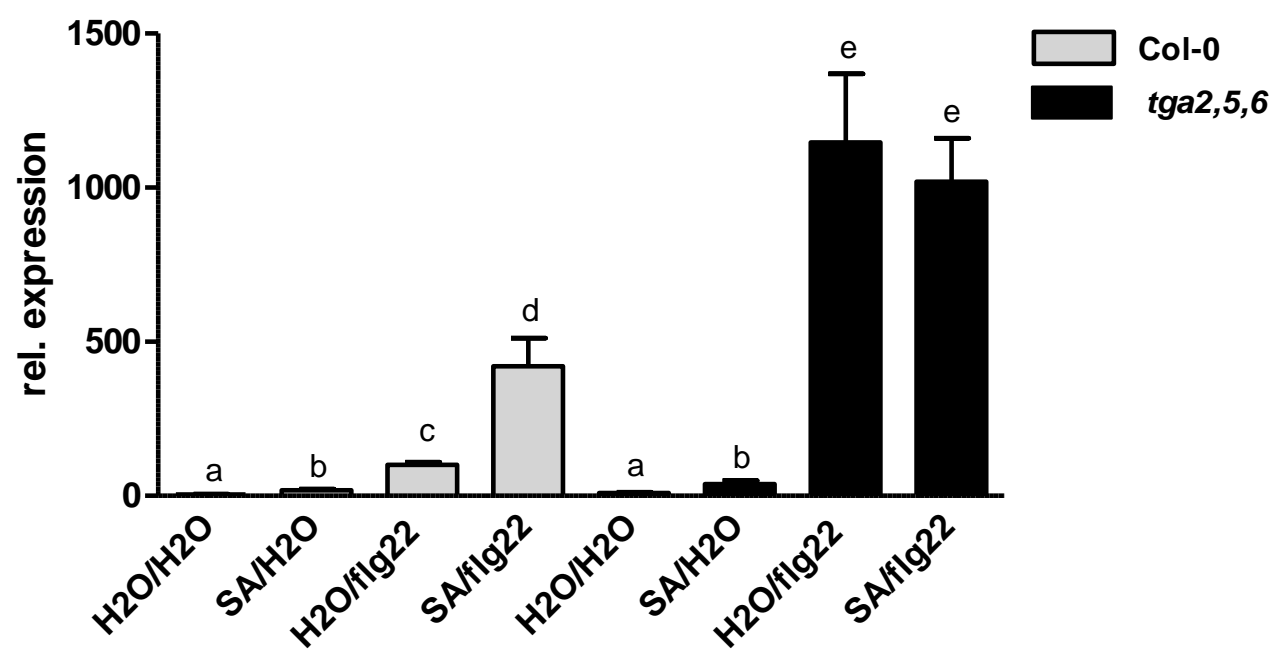

Figure 4-22| Expression analysis of $F R K 1$ in Col-0 and tga2,5,6 seedlings after treatment with SA and flg22.

10-14-days-old Col-0 (gray bars) and tga2,5,6 (black bars) seedlings were spray-inoculated with $\mathrm{H}_{2} \mathrm{O}$ or $1 \mathrm{mM} \mathrm{SA}$. After $24 \mathrm{~h}$, a second spray-inoculation with $\mathrm{H}_{2} \mathrm{O}$ or $1 \mu \mathrm{M}$ flg22 occurs. RNA was isolated two hours after the second treatment. Transcript levels were quantified by qRT-PCR with specific primer against FRK1 and normalized to the house keeping gene UBQ5. Expression in Col-0 seedlings flg22-treated for $2 \mathrm{~h}$ was set to $100 \%$. The average $\pm \mathrm{SEM}$ of $\mathrm{n}=$ 8 samples derived from three independent experiments is shown. Similar letters indicate significant differences between treatments or genotypes (Student's t-test, $P<0,01$ ). 
Recently, it was demonstrated that PAMPs induce SA accumulation within $6 \mathrm{~h}$ in a SID2dependent manner (Tsuda et al., 2008). SA levels were measured in Col-0 and tga2,5,6 seedlings with and without flg22-treatment (Figure 4-23). Flg22 treatment leads to slightly enhanced SA levels. Treated and untreated tga2,5,6 seedlings contain higher levels of SA as the wild-type, but no significant differences could be observed.

\section{SA}

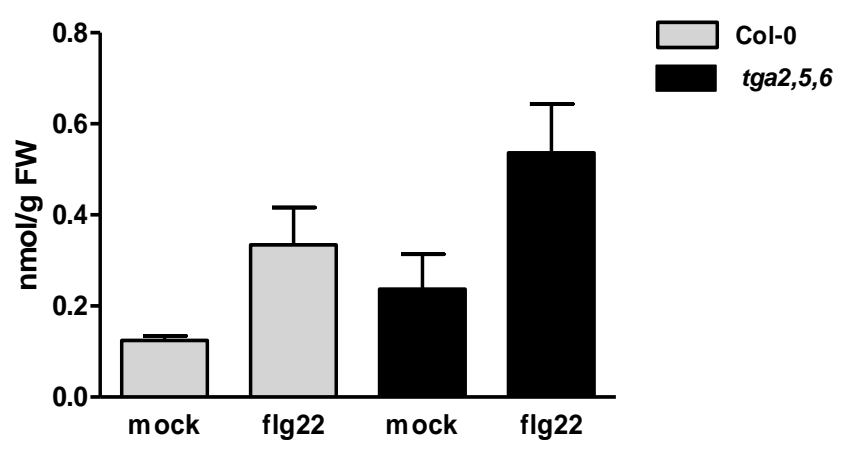

Figure 4-23| Measurement of SA levels by HPLC.

Col-0 (gray bars) and tga2,5,6 (black bars) seedlings were spray-inoculated with $1 \mu \mathrm{M}$ flg22 for $2 \mathrm{~h}$. Every bar represents the average \pm SEM of $n=6$ samples derived from two independent experiments.

In the tga2,5,6 mutant, increased basal transcript levels of the SA-inducible $P R-1$ gene were known from the literature (Zhang et al., 2003; Blanco et al., 2009). To elucidate whether the tga2,5,6 mutant also shows enhanced basal expression of ICS1, which is responsible for pathogen-induced SA biosynthesis, the expression levels of ICS1 and PR-1 were analyzed by qRT-PCR (Figure 4-24). The basal transcript levels of ICS1 are 1.5 times enhanced, and after flg22-treatment, the ICS1-expression is hyperactivated in the tga2,5,6 mutant (Figure 424A). The same result, but much more pronounced could be observed for PR-1 (Figure 424B). The basal $P R-1$ expression in tga2,5,6 plants is 100 -fold higher than in wild-type plants. Treatment with flg22 leads to an even stronger expression of $P R-1$ up to around 700-fold higher than the wild type 24 hours after treatment suggesting that SA-dependent basal defense responses might also be enhanced in the tga2,5,6 mutant. 
$\square$ Col-0

A

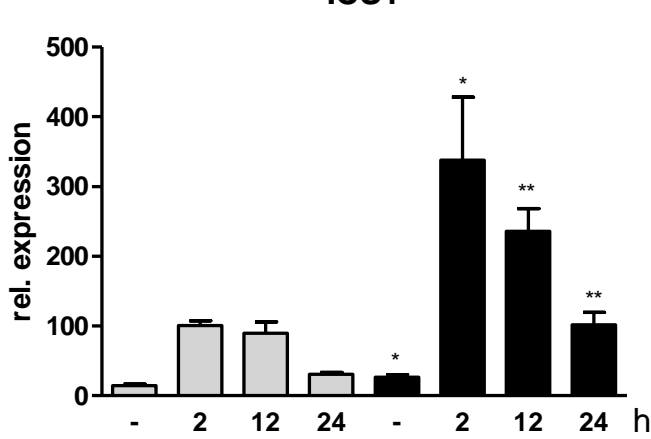

$\operatorname{tga} 2,5,6$

B

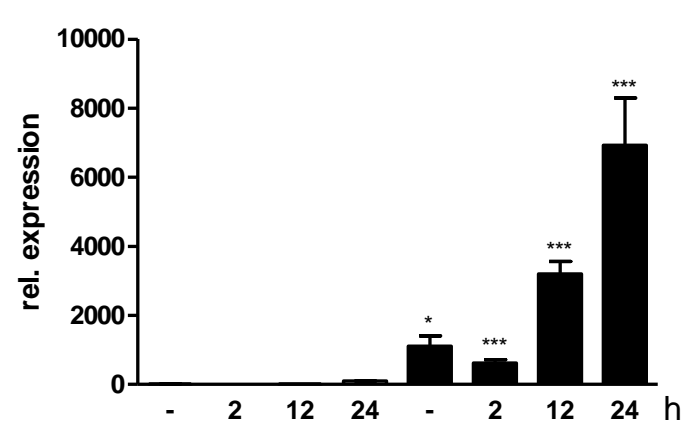

Figure 4-24| Expression analysis of ICS1 and PR-1 in Col-0 and tga2,5,6 seedlings.

10-14-days-old Col-0 (gray bars) and tga2,5,6 (black bars) A. thaliana seedlings grown on $1 \mathrm{MS}+\mathrm{MES}$ medium were spray treated with $\mathrm{H}_{2} \mathrm{O}$ (mock) or $100 \mathrm{nM}$ flg22 in a time course experiment. Approximately 50 seedlings were harvested for RNA extraction after the indicated time points. Transcript levels were quantified by qRT-PCR with specific primers against ICS1 (A) and $P R-1(B)$ and normalized to the house keeping gene UBQ5.

(A) ICS1 expression. Col-0 $2 \mathrm{~h}$ flg22 was set to $100 \%$

(B) $P R-1$ expression. Col-0 24h flg22 was set to $100 \%$.

Every bar represents the average \pm SEM of $n=6$ samples derived from two independent experiments. Asterisks represent significant differences between Col-0 and tga2,5,6 plants within a treatment (Student's t-test, $* * * P<0.001 ; * * P<0.01 ; * P<0.05$ ).

\subsection{Expression of $F R K 1$ is not influenced in mutants of the SA or JA pathway}

To investigate if an imbalance of the phytohormones SA or JA is the reason for the enhanced basal defense responses in the tga2,5,6 mutant, qRT-PCR analysis were done with mutants impaired in SA-biosynthesis (sid2-2), JA-biosynthesis (aos) or SA signaling and SA/JA cross-talk (npr1-1) (Figure 4-25). None of the tested mutants show altered FRK1 transcript levels. 
FRK1

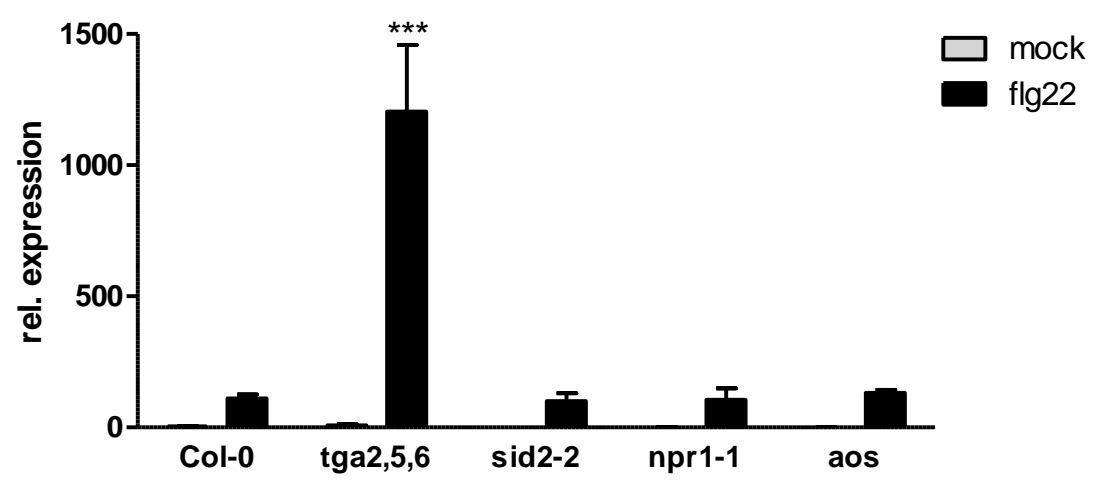

Figure 4-25| flg22-induced FRK1 expression in Col-0 and different mutants of the SA or JA pathways.

10-14-days-old A. thaliana seedlings of ecotype Col-0, tga2,5,6, sid2-2, npr1-1 and aos grown on 1MS-MES medium were spray inoculated with $1 \mu \mathrm{M}$ flg22. Two hours after treatment the seedlings were harvested for RNA extraction. Transcript levels were quantified by qRT-PCR with specific primers against FRK1 and normalized to the house keeping gene UBQ5. Every bar represents the average \pm SEM of $n=6$ samples derived from two independent experiments. Asterisks represent significant differences between Col-0 and mutant within a treatment (Student's t-test, ${ }^{* * *} \mathrm{P}<0.001$ ).

\subsection{TGA-dependent suppression of early flg22-induced genes occurs indirectly}

To investigate whether TGA2 or TGA5 are recruited directly to the promoter regions of the flg22-induced genes up-regulated in the tga2,5,6 mutant, chromatin-immunoprecipitation (ChIP) analyses were done. ChIP is a powerful method to study the in vivo binding of transcription factors to target motives in the genome. For this, leaf tissue of Col-0 and tga2,5,6 mutant plants was treated with formaldehyde to crosslink promoter-associated proteins to the DNA. After isolation and shearing of the chromatin, protein-DNA complexes were immunoprecipitated with antiserum generated against TGA2 and TGA5 (Fode et al., 2008).

In collaboration with Christopher Town it was possible to analyse Col-0 ChIP-DNA (untreated and treated with SA for 2 hours) with a mini array spotted with 200 putative target promoters for TGA2. From the flg22-inducible and in the tga2,5,6 mutant upregulated genes, only PR-1, WRKY22 and WRKY29 were spotted on the array (Table 4-1 and supplemental data). PR-1 and GSTU7 are depicted as positive controls, because it was shown previously that TGA2 and TGA5 bind to the related promoter regions (Fode et al., 2008). In comparison to raw chromatin, no increased binding of class-II TGAs to the analyzed promoter regions of WRKY22 and WRKY29 is detectable. A sequence analysis of 
the promoter regions (2000 bps upstream of the translation start) reveals no putative as-1like element but some TGACGTCA-motives. It was shown that members of the TGA family are able to bind to a single TGACGTCA motive in vitro but TGA2 is not included (Lam and Lam, 1995). Remarkably, several other WRKY transcription factors could be identified as putative targets for class-II TGA factors (Table 4-2).

Table 4-1| Promoter analysis of WRKY22 and WRKY29 for putative TGA binding sites and signals from the ChIP-on-chip array.

\begin{tabular}{|l|l|l|l|l|l|} 
Gene & AGI code & as-1 like \\
element
\end{tabular}

Chromatin immunoprecipitated with antiserum against TGA2,5 was hybridized to a mini array representing 200 putative target promoters for TGA2 (cooperation with C. Town, Institute for Genomic Research, Rockwille, USA). The average \pm SD from three independent experiments, normalized to the signal derived from raw-chromatin, is shown. A detailed array analysis of putative target of class-II TGAs is listed in supplemental data.

Table 4-2| Promoter analysis of WRKY factors for TGA binding sites enriched in the ChIP-on-chip array.

\begin{tabular}{|c|c|c|c|c|}
\hline Gene & AGI code & $\begin{array}{l}\text { as-1 like } \\
\text { element }\end{array}$ & TGACGTCA motive & $\begin{array}{l}\text { IP/RAW } \\
\text { (avg) }\end{array}$ \\
\hline WRKY62 & At5g01900 & + & 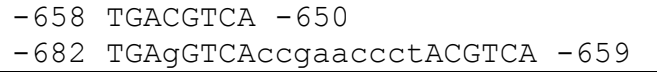 & 2.88 \\
\hline WRKY54 & At2g40750 & - & -1419 TGaCGTCA -1411 & 2.30 \\
\hline WRKY51 & At5g64810 & + & -286 TGACGTCAtaacagaTGACGTCA -263 & 2.01 \\
\hline WRKY66 & At1g80590 & - & - & 1.64 \\
\hline WRKY28 & At4g18170 & + & -1398 ctACGTCA -1390 & 1.64 \\
\hline WRKY47 & At4g01720 & + & 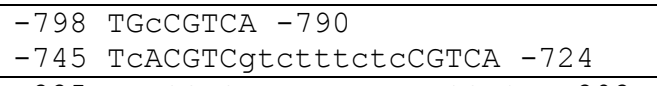 & 1.64 \\
\hline WRKY70 & At3g56400 & + & -225 ctACGTCAtttgagcTtACGTCA -202 & 1.55 \\
\hline WRKY67 & At1g66550 & - & -640 TGACGatA -632 & 1.27 \\
\hline WRKYG & At1g62300 & + & -153 TGACGcaggatcTGACGTaA -133 & 1.25 \\
\hline WRKY59 & At2g21900 & - & - & 1.21 \\
\hline WRKY48 & At5g49520 & - & $\begin{array}{l}-1519 \text { ttACGTCA }-1511 \\
-850 \text { TGACGTaA }-842 \\
\end{array}$ & 1.16 \\
\hline WRKY11 & At4g31550 & - & - & 1.15 \\
\hline WRKY38 & At5g22570 & + & $\begin{array}{lll}-1250 & \text { TGACGTCA } & -1242 \\
-1213 & \text { ctACGTCAtggggCTGACGTCg } & -1191 \\
\end{array}$ & 1.09 \\
\hline WRKY4 & At1g13960 & - & - & 1.06 \\
\hline WRKY42 & At4g04450 & + & -568 TGACGTCgacacTGACGaaA -548 & 1.03 \\
\hline WRKY75 & At5g13080 & - & $\begin{array}{lll}-1913 & \text { TGACGTCg } & -1905 \\
-1220 & \text { gGACGTCA } & -1212 \\
\end{array}$ & 1.02 \\
\hline
\end{tabular}


To verify the results of the ChIP-on-chip-array, the ChIP-DNA was analysed with real-time PCR (Figure 4-26). The template ChIP-DNA used for the PCR derived from two independent experiments. The DNA-template derived from the first experiment was shown to be suitable for IP in PCR analysis against PR-1 and GSTU7 described in Fode et al. (2008). The second DNA-template derived from an independent ChIP. The chromatin preparation used in this experiment was also positively tested for TGA2,5-binding to the PR-1 and GSTU7 promoter. The amount of PCR product is indicative for the relative amount of protein bound to the DNA. For WRKY22, primers flanking the first both TGACGTCA-motives (-317, 380) were used. A second primer pair includes the third motive (-779). For normalization, a PCR was performed using primers against the coding region of ACTIN8, which does not contain putative TGA binding motives. Chromatin including the amplified regions of the WRKY22 promoter isolated from tga2,5,6 plants was precipitated with the same efficiency as from Col-0 plants. This confirms the result from the ChIP-on-chip array, suggesting that TGA factors indirectly regulate the expression of early flg22-inducible genes.

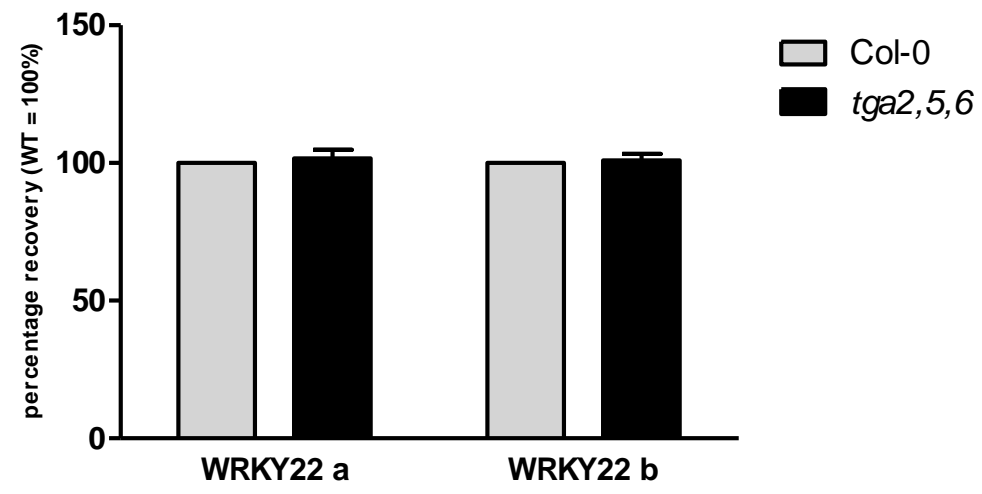

Figure 4-26| In vivo TGA factor binding to the WRKY22 promoter region revealed by ChIP analysis

Leaves from five-weeks-old (short-day) Col-0 plants and tga2,5,6 mutants were incubated in $1 \%$ formaldehyde before chromatin preparation. Chromatin samples were subjected to immunoprecipitation using $5 \mu \mathrm{l}$ of the $\alpha \mathrm{TGA} 2,5$ antiserum. The DNA was recovered after reversal of the cross-links and analyzed for the enrichment of promoter sequences by quantitative real-time PCR using two different primer pairs including three putative TGA binding sites. ACTIN8 was taken as reference for normalization. Bars represent the results from two independent experiments. Statistical analysis revealed no significant differences. 


\section{Discussion}

TGA transcription factors TGA2, TGA5 and TGA6 are essential regulators of the SAdependent defense response SAR (Zhang et al., 2003). Moreover, they are crucial for the activation of detoxification pathways upon chemical stress (Fode et al., 2008; Mueller et al., 2008) and indispensible for the induction of JA-inducible genes like PDF1.2 and $b$-Chi under conditions of increased ET levels, and finally contribute to the defense against the necrotrophic pathogen B. cinerea (Zander et al., 2009). In this study, a combination of molecular, pharmacological, physiological and microscopic assays were used to determine a new role of class-II TGA transcription factors as negative regulators during plant basal defense responses. They act as important regulators for PTI responses like root growth inhibition, gene expression, callose deposition and stomatal closure. Furthermore, the tga2,5,6 mutant is more resistant to Pst DC3000 in a sid2-2 background.

\section{1 flg22-induced growth inhibition is damped by class-II TGA factors}

The effect of flg22 as a plant defense-activating elicitor was first described by Felix et al., 1999, who used alkalinization of tomato cell culture medium as a quantifiable defense response. The alkalinization response occurs also in other plant species, including Arabidopsis thaliana (Felix et al., 1999). Further studies revealed a negative effect of flg22 on plant growth. This growth inhibition depends on the presence of the FLS2 receptor indicating that it is due to the activation of the defense signaling cascade. Incubation of seedlings in the presence of flg22 resulted in dwarf plants, but the seedlings remained green and did not show necrosis (Gómez-Gómez et al., 1999).

Using root growth assays, a strong enhancement of flg22-mediated growth inhibition took place in the tga2,5,6 triple mutant (e.g. Figure 4-2). This result establishes a so far unknown role for TGA factors in PAMP-mediated defense responses.

Little is known about mechanisms which are responsible for flg22-mediated growth inhibition. Previously, several mutants impaired in hormone signaling or biosynthesis were tested for their involvement in flg22-induced growth inhibition (Navarro et al., 2008). The signaling mutants tir1-1 (auxin), ein3-1 (ET) and coi1-16 (JA) as well as the SA-biosynthesis 
mutant sid2-1 showed a wild type like growth inhibition. Exclusively, mutants involved in GA biosynthesis or signaling showed an altered growth inhibition (Navarro et al., 2008). In Arabidopsis, GA is perceived by AtGID1a/b/c GA receptors. Binding of GA to these receptors promotes AtGID1-DELLA protein-protein interactions, which in turn lead to polyubiquitination (through the $\mathrm{E} 3$ ubiquitin ligase $\mathrm{SCF}^{\mathrm{SLY1}}$ ) and subsequent degradation of DELLAs by the $26 \mathrm{~S}$ proteasome (Jiang and Fu, 2007). Mutants that stabilize one or more DELLAs, including sly1-10, the dominant gai, and the GA-deficient ga1-3, showed a more pronounced flg22-induced growth inhibition, thus exhibiting the same phenotype as the $\operatorname{tga2,5,6}$ mutant. The loss of function mutant gai-t6/rga-t2/rg/1-1/rg/2-1 (quadruple-DELLA mutant, deficient in GAI, RGA, RGL1, and RGL2 protein), was slightly less inhibited in growth by flg22 than the wild type controls (Navarro et al., 2008). Further, it was shown that flg22 treatment delayed GA-mediated degradation of a GFP-RGA fusion protein in roots. These results suggest that flg22-induced DELLA stabilization contributes to growth inhibition.

Interestingly, the GA deficient mutant ga1-3 exhibits constitutively elevated transcript levels of defense related genes that are induced in the wild type only upon flg22 treatment (Navarro et al., 2008). This was shown by a comparison of microarray datasets generated from untreated ga1-3 mutant (Cao et al., 2006) and wild-type Arabidopsis seedlings treated with flg22 (Zipfel et al., 2004). Approximately $30 \%$ of the transcripts were more elevated in the ga1-3 mutant, as compared to La-er, were also upregulated by flg22 (Navarro et al., 2008).

To find out, if some of the putative downstream target genes of DELLAs in flg22-response are also putative target genes of TGA2, the genes identified by Navarro et al., 2008 were compared with microarray datasets generated from the tga2,5,6 mutant seedlings (Mueller et al., 2008). Though it has to be taken account of the fact that different ecotypes were used for the microarrays, the picture emerges that TGA factors and DELLA proteins operate through distinct mechanisms, because WRKY7O (At3g56400) and WRKY53 (At4g23810) display the only genes fulfilling the requested conditions. WRKY7O was shown to act as an activator of SA-responsive genes and a repressor of JA-inducible genes, thereby functioning as a molecular switch between both pathways (Li et al., 2004). WRKY53 plays a regulatory role in the early events of leaf senescence (Miao et al., 2004) and is also involved in basal resistance against Pseudomonas syringae (Murray et al., 2007). In future work, it would be interesting to investigate, if TGAs together with DELLAs bind to the promoter region of WRKY70 or WRKY53 to negatively regulate PAMP-induced defense responses.

As reduced ROS inhibit root growth (Achard et al., 2008), we tested whether an altered flg22-induced ROS accumulation in the tga2,5,6 mutant is responsible for the enhanced 
root growth inhibition. Increased ROS levels were detected in the tga2,5,6 mutant already in the absence of flg22 (Figure 4-5). Most likely, the known function of TGA factors in detoxification processes (Mueller et al., 2008; Fode et al., 2008) is responsible for the increased levels. However, in our hands, ROS levels were independent from SA- or flg22 treatment and thus cannot account for the increased flg22-responsiveness of the mutant. Consistently, the root growth of tga2,5,6 shows no altered sensitivity to different ROS inhibitors (Figure 4-6).

\subsection{Class-II TGA factors are not involved in PAMP-induced ROS burst}

The ROS burst in leaves after treatment with different PAMPs was not influenced in the tga2,5,6 mutant (Figure 4-7). It is not unlikely that very early defense responses, like the ROS burst, which occurs within the first minutes after PAMP perception, are regulated by protein destabilization, whereas later defense responses are regulated on the transcriptional level. Examples for negative regulators of PAMP-triggered immunity are the three homologous E3 ubiquitin ligases PUB22, PUB23 and PUB24. The triple mutant pub22/pub23/pub24 is de-repressed in basal immune responses resulting in enhanced resistance against bacterial and oomycete pathogens (Trujillo et al., 2008). The mechanism, how the E3 ligases suppresses basal defense seems to be independent of TGA2, TGA5 and TGA6, because in the pub22/pub23/pub24 mutant the oxidative burst is strongly enhanced and prolonged after treatment with different PAMPs, whereas the tga2,5,6 mutant shows only a slightly fortified ROS burst after flg22 in comparison to the wild type. Furthermore, the set of marker genes with enhanced expression is different. In the pub22/pub23/pub24 mutant, transcript levels of genes related to oxidative stress signaling (RhbohD and OXIDATIVE SIGNAL-INDUCIBLE1 (OXI1)) are elevated, which is not the case in the tga2,5,6 mutant. Moreover, FRK1 and WRKY22, which show the strongest de-regulation in the tga2,5,6 mutant are not up-regulated in the pub22/pub23/pub24 mutant (Trujillo et al., 2008). 


\subsection{The tga2,5,6 mutant shows enhanced sensitivity to many early defense responses}

\subsubsection{Gene expression}

In qRT-PCR, it was shown that transcript levels of early flg22-inducible genes are elevated in the tga2,5,6 mutant (Figure 4-11). The activation of $R b o h D$ in the flg22-mediated signaling cascade is independent of class-II TGA factors, because the transcript levels of this NADPH oxidase are not significantly enhanced in the tga2,5,6 mutant. This conforms to the results obtained by the ROS burst assay (Figure 4-7). Genes (WRKY22, WRKY29, FRK1), which are located downstream of $R b o h D$, have an increased expression in the tga2,5,6 mutant.

Most of the TGA-regulated genes did not display constitutive changes but rather earlier or stronger induction by flg22, indicating that TGAs rather sensitize plants to PAMPs than function as a repressor of PAMP-mediated signaling. To proof this hypothesis, microarray datasets generated from untreated tga2,5,6 mutant (Mueller et al., 2008) and flg22induced (1h and 3h) Col-0 seedlings (Denoux et al., 2008) were compared, similar to the analysis done by Navarro et al., 2008. Whereas in the stabilized DELLA mutant ga1-3 about over 100 genes were elevated compared with flg22-treated wild type plants, the transcript levels of only six genes are elevated in tga2,5,6 mutants as well as flg22-treated Col-0 (Supplemental data; Table 6-3). Interestingly, three of them are members of the WRKY transcription factor family, all involved in defense responses. As mentioned before, WRKY53 was described as putative DELLA target. WRKY75 has been described to be involved in regulation of phosphate starvation responses (Devaiah et al., 2007). Furthermore, a role for WRKY75 in the activation of basal and $R$-mediated resistance against $P$. syringae in Arabidopsis could be demonstrated (Encinas-Villarejo et al., 2009). WRKY40 is structurally related to WRKY18 and WRKY60. All together, they have partially redundant roles as negative regulators in plant resistance against bacterial as well as fungal pathogens (Xu et al. 2006; Shen et al. 2007). WRKY75, WRKY53 and WRKY4O were spotted on a ChIP-on-chip array and binding of TGA2 to the related promoter regions was shown, at least after SA-treatment. TAT3 transcripts are JA and wound-inducible (Titarenko et al., 1997), whereas RLP35 and BGLU17 are not further characterized. Thus, TGAs constitutively repress only a few plant defense related-genes, which in turn may act as upstream regulators of flg22-hyperinduced genes like WRKY22, WRKY29 or FRK1. 


\subsubsection{Callose deposition}

Pathogen attack, wounding and other stresses induce callose deposition. The tga2,5,6 mutant showed an increased callose deposition after flg22, which is abolished in the tga2,5,6/pmr4 quadruple mutant (Figure 4-13). In Arabidopsis, 12 callose synthase genes are known, which are expressed specifically in different tissues during plant development (Dong et al., 2008). Transcript levels of callose synthase PMR4, which is responsible for callose synthesis after pathogen attack, are inducible $6 \mathrm{~h}$ after SA treatment or $4 \mathrm{dpi}$ with the pathogen Hyaloperonospora arabidopsis. Five other callose synthases are also inducible by SA treatment and pathogen infection, whereas PMR4 and CalS1 are the only ones, which show an NPR1-dependent induction by SA (Dong et al., 2008). However, the expression of PMR4 is only slightly inducible by flg22 and transcript levels are little elevated in the tga2,5,6 mutant (Figure 4-14A+B). Some branches of PAMP-triggered callose deposition are SA dependent. Mutants impaired in SA biosynthesis or signaling show normal callose deposition (Clay et al., 2009; Adams-Phillips et al., 2010), but interestingly, SA is able to rescue flg22-induced callose deposition in pen2, pcs 1 and vtc1 mutants impaired in glucosinolate hydrolysis (Clay et al., 2009). More recently, it was shown that inhibition of poly(ADP-ribosyl)ation, a posttranslational protein modification, blocks basal defense responses including callose deposition and again, pre-treatment with SA is able to rescue callose deposition (Adams-Phillips et al., 2010). Surprisingly, the pmr4 mutant became more resistant to pathogens, rather than more susceptible (Jacobs et al., 2003; Nishimura et al., 2003; Flors et al., 2008). This resistance is based on an enhanced SA response, indicating a negative cross-talk between the callose response and SA signaling (Nishimura et al., 2003). These results indicate a kind of negative feedback loop for the regulation of PMR4. Perception of PAMPs induces SA biosynthesis that activates transcription of PMR4, which in turn suppresses the SA pathway. flg22 itself is only a very weak elicitor for transcriptional activation of PMR4 leading to the presumption, that flg22-mediated callose deposition is induced by posttranslational modification independent of class-II TGA factors.

The PMR4 callose synthase is also responsible for wound-induced callose synthesis (Jacobs et al., 2003; Nishimura et al., 2003). In contrast to PAMP perception, the tga2,5,6 mutant failed to develop callose deposition after wounding (Figure 4-15). Wound-induced responses depend on JA-signaling. This result indicates a role of class-II TGA factors as positive regulators not only involved in JA/ET signaling (Zander et al., 2009), but also for wound induced JA signaling. 
Recently, it was shown that glucosinolate metabolites are involved in callose synthesis after PAMP treatment upstream of PMR4 (Clay et al., 2009). Mutants in the glucosinolate biosynthetic pathway, including cytochrome P450 monooxygenases CYP81F2 and CYP79B2, failed in PAMP-triggered callose deposition. Interestingly, both genes are up-regulated in the tga2,5,6 mutant (Figure 4-14), and may display a target for transcriptional regulation by class-II TGA factors.

If an infection with $P$. syringae was used instead of the synthetic peptide flg22, no differences between wild type and tga2,5,6 mutant could be observed (Figure 4-16). It seems likely that $P$. syringae present additional PAMPs, such as LPS or harpin (Livaja et al., 2008), which may act independently of class-II TGA factors to induce callose deposition. Another explanation is founded in differences in experimental setups. The flg22-mediated callose deposition was induced by spray-treatment on axenically grown seedlings, similar to the procedure to induce gene expression. The bacterial inoculation takes place by syringe infiltration of adult soil grown plants according to the infection for the bacterial growth assay.

\subsubsection{Stomatal closure}

Stomata serve as natural openings to provide bacterial pathogens entry into the apoplast. Stomatal closure occurs through changes in turgor pressure within the guard cells, a very specific cell type embedded in the epidermis of the leaf. Stimuli activating stomatal function exist in a large number. Hence, it is not surprising that beside the indispensable key regulator $\mathrm{ABA}$ also other phytohormones contribute to stomatal aperture regulation. The ethylene receptor ETR1 mediates $\mathrm{H}_{2} \mathrm{O}_{2}$ signaling in stomatal guard cells. Consequently, stomata in the loss-of-function etr1-7 mutant do not close in response to $\mathrm{H}_{2} \mathrm{O}_{2}$ (Desikan et al., 2005). Independent of $A B A$, MeJA induces stomatal closure and promotes $\mathrm{H}_{2} \mathrm{O}_{2}$ production in guard cells (Suhita et al., 2004). Stomatal closure in response to bacterial pathogens is compromised in NahG plants and the SA biosynthetic mutant eds16-2, indicating that SA is required for stomatal defense (Melotto et al., 2006). Interestingly, the JA signaling mutant coi1-20 is not impaired in stomatal defense against bacteria (Melotto et al., 2006) and is able to respond to $A B A$, but not to MeJA-induced stomatal closure (Munemasa et al., 2007). The JA mimic COR is able to inhibit PAMP-induced stomatal closure in a COI1 dependent manner (Melotto et al., 2006). Several studies have shown strong antagonistic interactions between JA signaling and SA- or ABA-mediated signaling 
(e. g. Laurie-Berry et al., 2006; Anderson et al., 2004). Therefore, an attractive hypothesis is that COR exploits the endogenous antagonistic interactions between JA, SA, and ABA hormone signaling pathways in plants to affect stomatal response after pathogen attack. It could be shown that under abiotic stresses like drought or UV light, an accumulation of JA occurs in soybean and tobacco leaves (Creelman and Mullet, 1995; Demkura et al., 2009). These results suggest a potentially bimodal effect of JA and COR on stomatal response, depending on the trigger. Due to the fact that the tga2,5,6 mutant is insensitive to CORinduced stomatal re-opening (Figure 4-17), class-II TGA factors function as regulators for this mechanism.

Recently, a novel function of the bimodal defense regulator RIN4 in stomata closure was elucidated. Whereas class-II TGAs act as negative regulators for PTI and positive regulators for $P R$ gene expression, RIN4 acts as negative regulator for PTI and ETI. rin4 knockout lines exhibit increased callose deposition after PAMP treatment and decreased Pst growth, consistent with enhanced PTI signaling (Kim et al., 2005). In addition, two R proteins, RPM1 and RPS2 monitor RIN4. In the absence of pathogen perception, RIN4 acts as a negative regulator of RPM1 and RPS2. When the $P$. syringae effectors AvrRpm1 or AvrB are delivered to the plant cell, RIN4 is hyper-phosphorylated, which in turn leads to the activation of RPM1-mediated resistance (Mackey et al., 2002). Another P. syringae effector, AvrRpt2, is a protease that directly targets RIN4, leading to the activation of RPS2-mediated resistance (Mackey et al., 2003).

Similar to the tga2,5,6 mutant, stomata of the rin4 knock out could not be re-opened by virulent Pst. RIN4 interacts with AHA1 and AHA2, two plasma membrane $\mathrm{H}^{+}$-ATPases to regulate stomatal apertures during pathogen attack (Liu et al., 2009). RIN4 has no motifs predictive of enzyme function. So, it is supposed that it acts as an adaptor protein involved in negatively regulating PAMP signal transduction or ETI (Kim et al., 2005). It is supposable that class-II TGA factors may act together with RIN4 to negatively regulate PAMP-triggered responses. It would be of big interest to determine, if RIN4 expression in mesophyll or guard cells is regulated by class-II TGA factors. 


\subsection{Ectopic expression of TGA2 is sufficient to restore the wild- type situation}

Overexpression of TGA2 in the tga2,5,6 mutant is sufficient to rescue the wild type phenotype of root growth, gene expression and stomatal closure. To investigate the function of single class-II TGA factors, an expression system driven by the CaMV 355 promoter was used. With this system, the creation of transgenic plants with a very high global expression of the transgene in all tissues is possible but also could cause pleiotropic effects. Gene regulation also occurs by tissue-specific expression of transcription factors. The main tissues involved in defense responses against pathogens are mesophyll and guard cells. Using the endogenous promoter instead of the CaMV 355 promoter would restore a more physiological situation and may lead to other results. Tissue specific promoters can be used to elucidate the tissue-specific function of TGA factors. For example, under the control of a promoter specifically expressed in guard cells, like $p G C l$ (Yang et al. 2008) the function of class-II TGA factors in stomatal closure could be investigated.

\subsection{The absence of class-II TGA factors partially rescues the enhanced susceptibility phenotype of the sid2-2 mutant regarding flg22-triggered defense against Pst DC3000}

Comparison of bacterial growth between mock-pretreated and flg22-pretreated plants also revealed a negative effect of class-II TGA factors on PAMP-triggered defense responses. A difficulty in obtaining the role of TGA2, TGA5 and TGA6 in basal or flg22-mediated resistance to Pst DC3000 is the circumstance that SA signaling is involved in this defense responses (Tsuda et al., 2008) and as consequence, the tga2,5,6 mutant is abolished in SAR (Zhang et al., 2003). To be able to analyze the flg22 response in the absence of the SAdependent defense pathway, a tga2,5,6/sid2-2 mutant was used for the experiments.

After pretreatment with flg22, a significant difference in bacterial growth between the sid22 and the tga2,5,6/sid2-2 mutant was observed, indicating a negative regulation of flg22induced defense by class-II TGA factors (Figure 4-20). This experiment shows that the negative effect of TGA factors on PAMP signaling has a consequence for bacterial growth. Still, the bacterial titer in the tga2,5,6/sid2-2 mutant is not reduced to levels found in wild 
type plants, indicating that the de-repression of the PAMP-pathway cannot fully complement for the lack of the SA-responses. The tga2,5,6 mutant showed the same

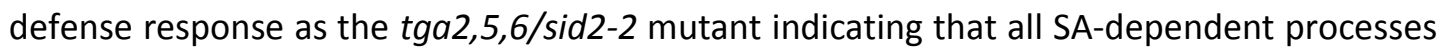
relevant for this resistance are dependent on class II TGA factors.

Unexpectedly, mock pretreated tga,2,5,6 plants show no difference in bacterial growth compared to the wild type as well as tga2,5,6/sid2-2 plants do not in comparison to sid2-2. Thus, class II TGA factors are mediators of flg22 induced resistance but do not play a role in the absence of preactivation by PTI. The bacterial growth experiments were obtained upon infiltration of the bacterial solution directly into the apoplast. Thus, the effect of class-II TGA factors in coronatine-induced stomatal re-opening was not assessed. The tga2,5,6 mutant is insensitive to COR-induced stomatal re-opening. Due to this fact, it is possible that an infection by spray application or dipping may unravel an increased resistant phenotype of the tga2,5,6 mutant despite its lack of major parts of the SA-signaling pathway. In this context, the tga2,5,6/sid2-2 mutant cannot be used for direct comparison, because PAMP- or bacterial-mediated stomatal closure is SA-dependent (Melotto et al., 2006).

\subsection{Influence of SA and JA on flg22-induced gene expression}

Regarding activation of the basal defense marker gene FRK1, the activation of the SApathway acts synergistically to flg22 (Figure 4-22), whereas simultaneous application of coronatine had the opposite effect (Figure 4-21). The antagonism between SA and JA dependent pathways is well established and several observations indicate an involvement of TGA factors together with NPR1 or GRX480 in SA/JA crosstalk beside their function in establishment of SAR (Spoel et al., 2003; Ndamukong et al., 2007).

One hypothesis applying the antagonism between JA- and SA-pathways deals with the assumption that COR promotes susceptibility to $P$. syringae infection by stimulating JAsignaling in plants. The consequence is inhibition of SA-mediated defenses that normally limit $P$. syringae growth. In this context, the transcription factor MYC2 could be identified as important mediator of COR or JA-lle dependent suppression of SA signaling. The MYC2 mutant jin1 exhibit both reduced susceptibility to Pst DC3000 and reduced sensitivity to COR or MeJA. The reduced disease susceptibility in jin1 mutants is correlated with elevated 
expression of $P R-1$ and is dependent on SA accumulation (Laurie-Berry et al., 2006). MYC2 acts as positive regulator for JA-responsive genes like VSP2 and LOX3, but has a negative effect on JA/ET-inducible genes like PDF1.2 (Lorenzo et al., 2004). In turn, class-II TGA factors are required to antagonize the negative effect of MYC2 on PDF1.2 expression (Zander et al., 2009). The cross-talk mediated suppression of SA on JA-induced gene expression of PDF1.2 occurs normally in the tga2,5,6 mutant (Ndamukong et al., 2007), whereas class-II TGA factors are required to mediate the SA-JA/ET crosstalk in the jin1-1 mutant background (Zander et al., 2009).

\subsection{Functional analysis of class-II TGA factors in basal resistance}

Binding sites for TGA factors exist in many genes, responding to diverse signals in pathogen defense and xenobiotic stresses (Thibaud-Nissen et al., 2006; Ndamukong et al., 2007; Fode et al., 2008). It is evident from these studies that the specific activity of a TGA factor is determined or modified by its interacting protein. Until now, three proteins interacting with class-II TGA transcription factors could be identified by yeast-two-hybrid screens (Després et al., 2000; Ndamukong et al., 2007; Fode et al., 2008). SCL14 is essential for induction of stress-inducible promoters (Fode et al., 2008), whereas the nuclear function of NPR1 plays a role for activation of SA-responsive genes and SA homeostasis, the cytosolic function of NPR1 is involved in SA/JA crosstalk (Glazebrook et al., 2003; Zhang et al., 2010; Leon-Reyes et al., 2009). The TGA-interacting GRX480, which is transcriptionally activated by $S A$, is a negative effector of JA-inducible expression of PDF1.2 and therefore represents a potential regulatory component of the SA/JA antagonism (Ndamukong et al., 2007). TGA4, a class-I TGA factor interacts with AtEBP, which binds the ethylene response element present in many $P R$ gene promoters and with OBP1, a protein belonging to the Dof family (Büttner and Singh, 1997; Zhang et al., 1995).

In several studies it was observed that TGA2 may act as a constitutive repressor, but its role in basal defense responses was never described before. By using an in vivo plant transcription assay, it could be shown that TGA2 behaves like a constitutive repressor, but forms an enhanceosome with NPR1 (Rochon et al., 2006). The analysis of several single and multiple knock outs revealed that the tga2-2 knockout mutant, un-induced and grown on 
plates containing the SA-analogon INA, showed higher expression of $P R-1$ (Kesarwani et al., 2007).

By chromatin-immunoprecipitation (ChIP), it was shown that class-II TGA factors bind constitutively to the PR-1 promoter, independently of SA and NPR1 (Rochon et al., 2006; Fode et al., 2008). More recently, it was demonstrated that purified TGA2 protein forms enormous oligomers containing 40 and more units of TGA2 (Boyle et al., 2009). This oligomer binds to TGACG motives to suppress transcription by an unknown mechanism. NPR1 negates the TGA2 repressor function by excluding TGA2 oligomers from the DNA (Boyle et al., 2009). A concentration-dependent regulation of gene expression by transcription factors is known for the Krüppel zinc-finger protein, which can act both as an activator and repressor on the same DNA element in Drosophila (Sauer and Jäckle, 1991). At low concentration, Krüppel binds DNA as a monomer and activates transcription, but at higher concentration, it forms a homodimer and acts as a repressor (Sauer and Jäckle, 1993).

However, it cannot be excluded that TGA transcription factors may function as repressors if they are associated with other TGA factors or regulators. TGA transcription factors belong to the bZIP family. For other bZIP-proteins it was documented that they differ in their function depending on the heterodimerisation partner (Weltmeier et al., 2009). A similar mechanism could be responsible for the observation that different TGA factors are involved in growth inhibition and gene expression. A further explanation display post-transcriptional mechanisms, which may determine the distribution of the TGA gene products in a particular tissue. In a study with transgenic tobacco expressing GFP-tagged TGA 1, TGA2 or TGA3 from Arabidopsis, TGA1 and TGA3 are rapidly degraded in mature tissues whereas TGA2 levels remained essentially constant. In contrast to this differential regulation in mature tissues, all three TGA factors were present in seedlings, which demonstrate the existence of a post-transcriptional mechanism controlling the presence of specific TGA factors in different tissues during development (Pontier et al., 2002).

ChIP analysis was performed to prove, whether class-II TGA factors bind directly to the promoters of the up-regulated genes (Figure 4-26). The promoter region of WRKY22 shows no enhanced binding of class-II TGA factors. So it seems to be obvious that the influence of the TGA factors on basal defense responses occurs indirectly by regulating a regulator. Other members of the WRKY transcription factor family would present ideal candidates for this regulator because many WRKY genes are transcriptionally regulated and putative targets for the regulation by class-II TGA factors (Table 4-2). Many defense related genes 
contain W-boxes in their promoter region, including WRKY genes themselves, like WRKY22 and WRKY29 (Dong et al., 2003), to build a big network (Eulgem and Somssich, 2007). In addition, it was shown that some defense related WRKYs are transcriptionally regulated by TGA factors and NPR1 (Wang et al., 2006). In order to differentiate the function of TGA2 and TGA5, it would be necessary to analyze single mutants. Unfortunately, the tga2-2 mutant characterized by Kesarwani et al., 2007 is generated in the Ws-0 ecotype a natural fls2 mutant insensitive to flg22 (Zipfel et al., 2004). So far, no single mutant for TGA5 is known. A screen of other T-DNA insertion lines or the creation of RNAi-lines would be useful for further characterizations. 


\subsection{Proposed model}

Recognition of PAMPs activates a signaling cascade leading to different immune responses. Class-II TGA transcription factors are involved in some of these responses, like callose deposition, transcriptional activation or by suppression of an unknown factor. The bacterial toxin coronatine (COR) works together with the TGA factors against some of the observed immune responses. On the one hand, COR and class-II TGA factors suppress the transcription of flg22-responsive genes and on the other hand, they are necessary to stimulate stomatal re-opening to facilitate bacterial entry.

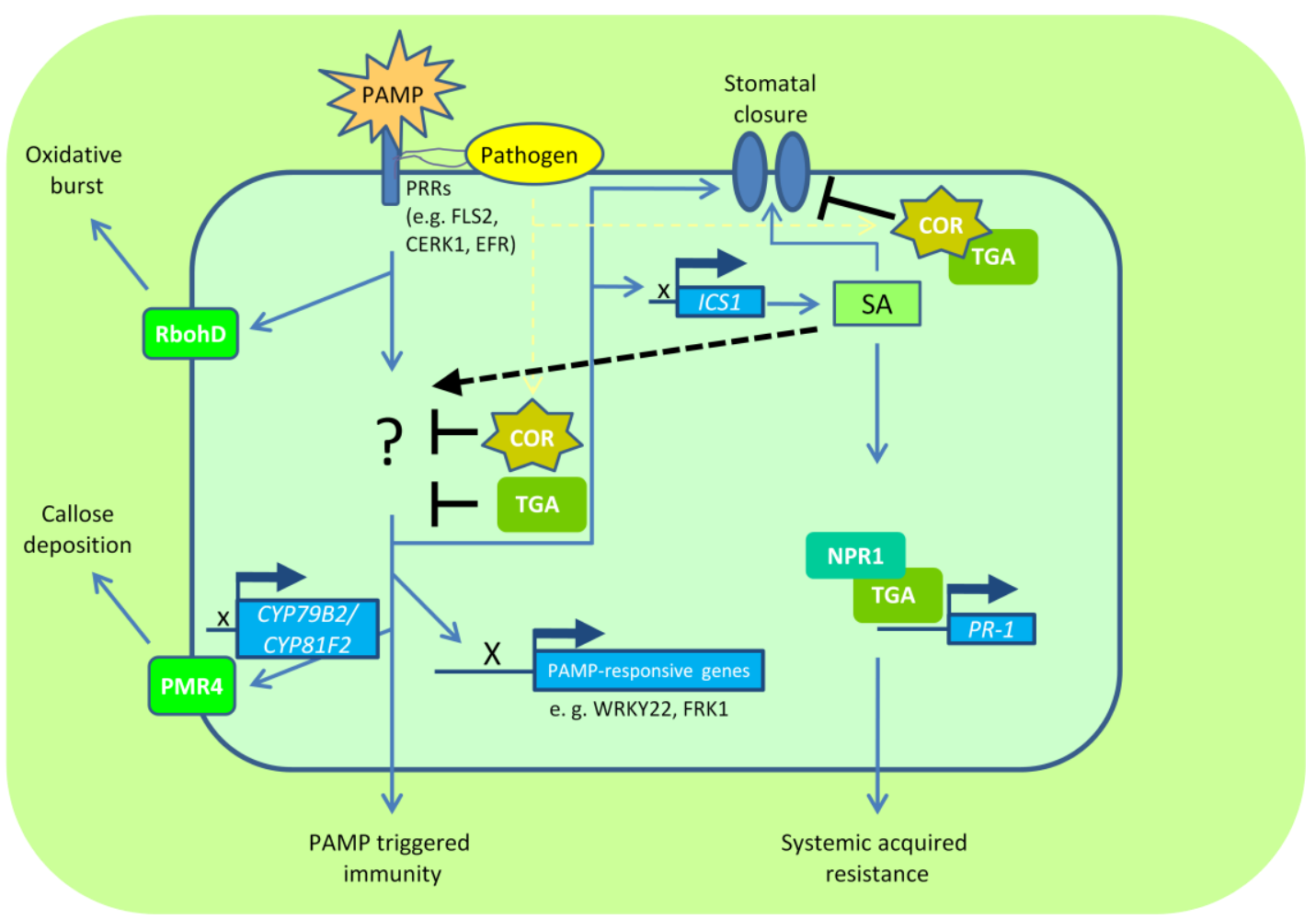

Figure 5-1| Model for negative regulation of PAMP-induced defense responses by class-II TGA factors.

Bacteria or fungal derived PAMPs are recognized by specific receptors (PRRs) located in the plasma membrane. Oxidative burst occurs by enzymatic activity of RbohD and is not regulated by class-II TGA factors. Callose deposition depending on callose synthase PMR4, and expression of PAMP-responsive genes are located more downstream and are negatively regulated by an unknown mechanism dependent on class-II TGA factors, prominently TGA2. Flg22-induced ICS1 expression is also suppressed by class-II TGA factors. Downstream of SA, TGAs and NPR1 build an enhanceosome to activate $P R-1$ gene expression and systemic acquired resistance. The bacterial toxin coronatine (COR) suppresses PAMP-signaling independent of class-II TGA factors, but acts together with them to activate stomatal re-opening. 


\section{Supplemental data}

Table 6-1| Putative class-II TGA target genes identified as enriched (IP/RAW) in ChIP-onchip array. The genes are sorted according to their grade of enrichment.

\begin{tabular}{|c|c|c|}
\hline AGI code & Gene description & IP/RAW \\
\hline At3g50850/60 & unknown protein & 3.03 \\
\hline At1g21670/80 & unknown protein & 2.97 \\
\hline At1g02450 & NIMIN1 & 2.94 \\
\hline At1g03230 & extracellular dermal glycoprotein, putative & 2.90 \\
\hline At5g01900 & WRKY62 WRKY Transcription Factor; Group III & 2.88 \\
\hline At3g53400 & unknown protein & 2.86 \\
\hline At4g18020 & pseudo-response regulator 2 (APRR2) (TOC2) & 2.80 \\
\hline At5g51990 & $\begin{array}{l}\text { CBF4 member of the DREB subfamily A-1 of ERF/AP2 } \\
\text { transcription factor family. }\end{array}$ & 2.66 \\
\hline At4g34060 & $\begin{array}{l}\text { similar to HhH-GPD base excision DNA repair family } \\
\text { protein (ROS1) }\end{array}$ & 2.63 \\
\hline At5g54540/50 & unknown protein & 2.60 \\
\hline At3g11780/800/810 & unknown protein & 2.59 \\
\hline At1g76600 & unknown protein & 2.59 \\
\hline At2g44980/90 & transcription regulatory protein SNF2 & 2.55 \\
\hline At5g25070/80 & unknown protein & 2.51 \\
\hline At5g13760 & unknown protein & 2.48 \\
\hline At5g05240/50 & unknown protein & 2.35 \\
\hline At3g13810/20 & zinc finger ( $\mathrm{C} 2 \mathrm{H} 2$ type) family protein & 2.31 \\
\hline At2g40750 & WRKY54 WRKY Transcription Factor; Group III & 2.30 \\
\hline At1g12460 & $\begin{array}{l}\text { leucine-rich repeat transmembrane protein kinase, } \\
\text { putative }\end{array}$ & 2.29 \\
\hline At2g28640/50 & A member of EXO70 gene family & 2.19 \\
\hline At5g66910/20 & disease resistance protein (CC-NBS-LRR class) & 2.06 \\
\hline At5g61990/62000 & pentatricopeptide (PPR) repeat-containing protein & 2.06 \\
\hline At4g00370 & sugar transporter family protein & 2.05 \\
\hline At5g22450 & unknown protein & 2.03 \\
\hline At5g64810 & WRKY51 WRKY Transcription Factor; Group II-c & 2.01 \\
\hline At3g13224 & RNA recognition motif (RRM)-containing protein & 2.00 \\
\hline At1g50060 & pathogenesis-related protein, putative & 1.99 \\
\hline At2g29420 & $\begin{array}{l}\text { ATGSTU7 glutathione transferase belonging to the tau } \\
\text { class of GSTs }\end{array}$ & 1.83 \\
\hline At3g03190 & $\begin{array}{l}\text { ATGSTF11 glutathione transferase belonging to the phi } \\
\text { class of GSTs }\end{array}$ & 1.77 \\
\hline At2g05940 & protein kinase, putative & 1.75 \\
\hline At2g47730 & $\begin{array}{l}\text { ATGSTF8 glutathione transferase belonging to the phi } \\
\text { class of GSTs }\end{array}$ & 1.71 \\
\hline At3g53020/30 & RPL24A encodes ribosomal protein L24 & 1.70 \\
\hline At3g12690 & $\begin{array}{l}\text { AGC KINASE } 1.5 \text { putative serine/threonine kinase } \\
\text { expressed specifically in pollen }\end{array}$ & 1.65 \\
\hline
\end{tabular}




\begin{tabular}{|c|c|c|}
\hline At1g80590 & WRKY66 WRKY Transcription Factor; Group III & 1.64 \\
\hline At4g18170 & WRKY28 WRKY Transcription Factor; Group II-C & 1.64 \\
\hline At4g01720 & WRKY47 WRKY Transcription Factor; Group II-b & 1.64 \\
\hline At2g29480 & $\begin{array}{l}\text { ATGSTU2 glutathione transferase belonging to the tau } \\
\text { class of GSTs. }\end{array}$ & 1.59 \\
\hline At3g56400 & WRKY70 WRKY Transcription Factor; Group III. & 1.55 \\
\hline At1g69150/60 & unknown protein & 1.53 \\
\hline At3g52060/70 & unknown protein & 1.52 \\
\hline At1g78380 & $\begin{array}{l}\text { ATGSTU19 glutathione transferase that is a member of } \\
\text { Tau GST gene family }\end{array}$ & 1.51 \\
\hline At1g78340 & $\begin{array}{l}\text { TAU22 glutathione transferase belonging to the tau } \\
\text { class of GSTs. }\end{array}$ & 1.50 \\
\hline At2g29490 & $\begin{array}{l}\text { GST19 glutathione transferase belonging to the tau } \\
\text { class of GSTs }\end{array}$ & 1.45 \\
\hline At1g49860 & $\begin{array}{l}\text { ATGSTF14 glutathione transferase belonging to the phi } \\
\text { class of GSTs. }\end{array}$ & 1.42 \\
\hline At1g17180 & $\begin{array}{l}\text { ATGSTU25 gluthatione transferase belonging to the tau } \\
\text { class of GSTs. }\end{array}$ & 1.37 \\
\hline At1g18250 & ATLP-1 thaumatin-like protein & 1.37 \\
\hline At5g67040 & unknown protein & 1.35 \\
\hline At4g32020 & unknown protein & 1.32 \\
\hline At2g17860 & pathogenesis-related thaumatin family protein & 1.29 \\
\hline At4g36000 & unknown protein & 1.28 \\
\hline At1g78370 & unknown protein & 1.28 \\
\hline At1g66550 & WRKY67 WRKY Transcription Factor; Group III & 1.27 \\
\hline At1g62300 & WRKY6 WRKY Transcription Factor; Group II-b & 1.25 \\
\hline At1g78360 & $\begin{array}{l}\text { ATGSTU21 glutathione transferase belonging to the tau } \\
\text { class of GSTs }\end{array}$ & 1.21 \\
\hline At2g21900 & WRKY59 WRKY Transcription Factor; Group II-c & 1.21 \\
\hline At2g29470 & $\begin{array}{l}\text { ATGSTU3 glutathione transferase belonging to the tau } \\
\text { class of GSTs }\end{array}$ & 1.18 \\
\hline At5g49520 & WRKY48 WRKY Transcription Factor; Group II-c & 1.16 \\
\hline At4g31550 & WRKY11 WRKY Transcription Factor; Group II-d & 1.15 \\
\hline At5g10030 & $\begin{array}{l}\text { TGA4 member of basic leucine zipper transcription gene } \\
\text { family }\end{array}$ & 1.14 \\
\hline At2g29450 & $\begin{array}{l}\text { ATGSTU1/5 member of the TAU glutathione S- } \\
\text { transferase gene family }\end{array}$ & 1.14 \\
\hline At2g29470 & $\begin{array}{l}\text { ATGSTU3 glutathione transferase belonging to the tau } \\
\text { class of GSTs }\end{array}$ & 1.12 \\
\hline At4g38670 & pathogenesis-related thaumatin family protein & 1.11 \\
\hline At2g29460 & $\begin{array}{l}\text { ATGSTU4 glutathione transferase belonging to the tau } \\
\text { class of GSTs }\end{array}$ & 1.11 \\
\hline At1g77920 & bZIP family transcription factor & 1.11 \\
\hline At1g02920 & $\begin{array}{l}\text { ATGST11 glutathione transferase belonging to the phi } \\
\text { class of GSTs }\end{array}$ & 1.11 \\
\hline At3g09270 & $\begin{array}{l}\text { ATGSTU8 glutathione transferase belonging to the tau } \\
\text { class of GSTs }\end{array}$ & 1.11 \\
\hline At1g73620 & $\begin{array}{l}\text { thaumatin-like protein, putative / pathogenesis-related } \\
\text { protein }\end{array}$ & 1.10 \\
\hline At1g17170 & ATGSTU24 glutathione transferase belonging to the tau & 1.10 \\
\hline
\end{tabular}




\begin{tabular}{|c|l|c|}
\hline & class of GSTs & \\
\hline At5g62480 & $\begin{array}{l}\text { ATGSTU9 glutathione transferase belonging to the tau } \\
\text { class of GSTs }\end{array}$ & 1.09 \\
\hline At5g22570 & WRKY38 WRKY Transcription Factor; Group III & 1.09 \\
\hline At5g02790 & In2-1 protein, putative & 1.09 \\
\hline At1g20030 & pathogenesis-related thaumatin family protein & 1.08 \\
\hline At2g14610 & PR-1 & 1.08 \\
\hline At3g11010 & ATRLP34 receptor like protein 34 & 1.07 \\
\hline At1g13960 & WRKY4 WRKY Transcription Factor; Group I & 1.06 \\
\hline At1g77290 & $\begin{array}{l}\text { tetrachloro-p-hydroquinone reductive dehalogenase- } \\
\text { related }\end{array}$ & 1.04 \\
\hline At4g04450 & WRKY42 WRKY Transcription Factor; Group II-b & 1.03 \\
\hline At4g29940 & $\begin{array}{l}\text { PRHA PATHOGENESIS RELATED HOMEODOMAIN } \\
\text { PROTEIN A }\end{array}$ & 1.03 \\
\hline At4g08555/60 & unknown protein & 1.03 \\
\hline At5g13080 & WRKY75 WRKY Transcription Factor & 1.02 \\
\hline At4g24180 & unkown protein & 1.01 \\
\hline At2g43570 & CHI chitinase, putative & 1.01 \\
\hline
\end{tabular}

Chromatin immunoprecipitated with antiserum against TGA2,5 was hybridized to a mini array representing 200 putative target promoters for TGA2 (cooperation with C. Town, Institute for Genomic Research, Rockwille, USA). The average from three independent experiments, normalized to the signal derived from raw-chromatin, is shown. 
Table 6-2| Putative class-II TGA target genes identified as enriched (IP/RAW) in ChIP-on-chip array. The genes are sorted according to their increase of enrichment (fold induction) after 12h SA-treatment in comparison to mock treatment.

\begin{tabular}{|c|c|c|c|c|}
\hline AGI code & description & $\begin{array}{c}\text { IP/RAW } \\
\text { OhSA }\end{array}$ & $\begin{array}{c}\text { IP/RAW } \\
\text { 12hSA }\end{array}$ & $\begin{array}{c}\text { fold } \\
\text { induction }\end{array}$ \\
\hline At4g23810 & WRKY53 WRKY Transcription Factor; Group III & 0.84 & 1.45 & 1.73 \\
\hline At2g46400 & WRKY46 WRKY Transcription Factor; Group III & 0.98 & 1.64 & 1.69 \\
\hline At5g22570 & WRKY38 WRKY Transcription Factor; Group III & 1.09 & 1.76 & 1.61 \\
\hline At2g14610 & PR-1 & 1.08 & 1.69 & 1.56 \\
\hline At1g80840 & WRKY40 Transcription factor; Group II-a & 0.73 & 1.11 & 1.53 \\
\hline At1g62300 & WRKY6 WRKY Transcription Factor; Group II-b & 1.25 & 1.73 & 1.38 \\
\hline At5g13080 & WRKY75 WRKY Transcription Factor & 1.02 & 1.36 & 1.33 \\
\hline At5g61990/62000 & pentatricopeptide (PPR) repeat-containing protein & 2.06 & 2.67 & 1.30 \\
\hline At2g21900 & WRKY59 Transcription Factor; Group II-c & 1.21 & 1.50 & 1.24 \\
\hline At1g76600 & unkown protein & 2.59 & 3.19 & 1.23 \\
\hline At1g78380 & ATGSTU19 glutathione transferase that is a member of Tau GST gene family & 1.51 & 1.85 & 1.22 \\
\hline At5g22450 & unkown protein & 2.03 & 2.48 & 1.22 \\
\hline At1g21670/80 & unkown protein & 2.97 & 3.61 & 1.21 \\
\hline At2g44980/90 & transcription regulatory protein SNF2 & 2.55 & 3.09 & 1.21 \\
\hline At2g38470 & WRKY33 Transcription Factor, Group I & 0.94 & 1.13 & 1.21 \\
\hline At4g22070 & WRKY31 WRKY Transcription Factor; Group II-b & 0.87 & 1.01 & 1.16 \\
\hline At4g01250 & WRKY22 Transcription Factor; Group II-e & 0.90 & 1.04 & 1.15 \\
\hline At3g53020/30 & RPL24A encodes ribosomal protein L24, homolog of cytosolic RPL24 & 1.70 & 1.94 & 1.14 \\
\hline At1g02450 & NIMIN1 & 2.94 & 3.35 & 1.14 \\
\hline At3g56400 & WRKY70 WRKY Transcription Factor; Group III & 1.55 & 1.75 & 1.13 \\
\hline At1g50060 & pathogenesis-related protein, putative & 1.99 & 2.24 & 1.13 \\
\hline At1g13960 & WRKY4 WRKY Transcription Factor; Group I & 1.06 & 1.20 & 1.13 \\
\hline At2g28640/50 & member of EXO70 gene family & 2.19 & 2.45 & 1.12 \\
\hline At2g47730 & ATGSTF8 glutathione transferase belonging to the phi class of GSTs & 1.71 & 1.86 & 1.09 \\
\hline At4g01720 & WRKY47 WRKY Transcription Factor; Group II-b & 1.64 & 1.75 & 1.07 \\
\hline At4g18170 & WRKY28 WRKY Transcription Factor; Group II-c & 1.64 & 1.74 & 1.06 \\
\hline
\end{tabular}


6 Supplemental data 96

\begin{tabular}{|c|c|c|c|c|}
\hline At4g36000 & unknown protein & 1.28 & 1.36 & 1.06 \\
\hline At5g66910/20 & disease resistance protein (CC-NBS-LRR class), putative & 2.06 & 2.18 & 1.06 \\
\hline At5g64810 & WRKY51 WRKY Transcription Factor; Group II-c & 2.01 & 2.11 & 1.05 \\
\hline At4g34060 & similar to HhH-GPD base excision DNA repair family protein (ROS1) & 2.63 & 2.74 & 1.04 \\
\hline At1g17180 & ATGSTU25 glutathione transferase belonging to the tau class of GSTs & 1.37 & 1.42 & 1.04 \\
\hline At1g17170 & ATGSTU24 glutathione transferase belonging to the tau class of GSTs & 1.10 & 1.13 & 1.03 \\
\hline At5g49520 & WRKY48 WRKY Transcription Factor; Group II-c & 1.16 & 1.18 & 1.02 \\
\hline At5g62480 & ATGSTU9 glutathione transferase belonging to the tau class of GSTs & 1.09 & 1.12 & 1.02 \\
\hline At2g29450 & ATGSTU1/5 member of the TAU glutathione S-transferase gene family & 1.14 & 1.16 & 1.02 \\
\hline At4g00370 & sugar transporter family protein & 2.05 & 2.09 & 1.02 \\
\hline At2g40750 & WRKY54 WRKY Transcription Factor; Group III & 2.30 & 2.33 & 1.01 \\
\hline At1g02920 & ATGST11 glutathione transferase belonging to the phi class of GSTs & 1.11 & 1.12 & 1.01 \\
\hline At2g29420 & ATGSTU7 glutathione transferase belonging to the tau class of GSTs & 1.83 & 1.84 & 1.01 \\
\hline
\end{tabular}

Chromatin immunoprecipitated with antiserum against TGA2,5 was hybridized to a mini array representing 200 putative target promoters for TGA2 (cooperation with C. Town,

Institute for Genomic Research, Rockwille, USA). The average \pm SD from three independent experiments, normalized to the signal derived from raw-chromatin, is shown. 
Table 6-3| List of genes that are more elevated in tga2,5,6 vs. Col-0 (cell culture, Mueller et al., 2008) and up-regulated $1 \mathrm{~h}$ or $3 \mathrm{~h}$ after flg22 treatment (Col-0 seedlings, Denoux et al., 2008).

$(+)$ means an $\geq 10$ fold increased transcript level. (-) display transcript levels $<10$ fold increased at the indicated time point. WRKY4O, WRKY53 and WRKY75 are spotted on the ChIP-on-chip array and enrichment of IP in comparison to raw-chromatin is shown.

\begin{tabular}{|c|c|c|c|c|c|}
\hline AGI code & description & 1h flg22 & $3 h$ flg22 & $\begin{array}{l}\text { IP/RAW } \\
\text { Oh SA }\end{array}$ & $\begin{array}{l}\text { IP/RAW } \\
\text { 12h SA }\end{array}$ \\
\hline AT1G80840 & WRKY40 & + & - & 0.73 & 1.11 \\
\hline AT4G23810 & WRKY53 & + & + & 0.84 & 1.45 \\
\hline AT5G13080 & WRKY75 & + & + & 1.02 & 1.36 \\
\hline AT2G44480 & BGLU17 (BETA GLUCOSIDASE 17) & - & + & / & / \\
\hline AT2G24850 & $\begin{array}{l}\text { TAT3 (TYROSINE } \\
\text { AMINOTRANSFERASE 3) }\end{array}$ & + & + & / & / \\
\hline AT3G11080 & $\begin{array}{l}\text { ATRLP35 (RECEPTOR LIKE } \\
\text { PROTEIN 35) }\end{array}$ & + & - & / & / \\
\hline
\end{tabular}




\section{Bibliography}

Abramovitch, R. B., Anderson, J. C., and Martin, G. B. (2006). Bacterial elicitation and evasion of plant innate immunity. Nat. Rev. Mol. Cell Biol 7, 601-611.

AbuQamar, S., Chen, X., Dhawan, R., Bluhm, B., Salmeron, J., Lam, S., Dietrich, R. A., and Mengiste, T. (2006). Expression profiling and mutant analysis reveals complex regulatory networks involved in Arabidopsis response to Botrytis infection. The Plant Journal 48, 28-44.

Achard, P., Renou, J., Berthomé, R., Harberd, N. P., and Genschik, P. (2008). Plant DELLAs restrain growth and promote survival of adversity by reducing the levels of reactive oxygen species. Curr. Biol 18, 656-660.

Adams-Phillips, L., Briggs, A. G., and Bent, A. F. (2010). Disruption of poly(ADP-ribosyl)ation mechanisms alters responses of Arabidopsis to biotic stress. Plant Physiol 152, 267280.

Ali, R., Ma, W., Lemtiri-Chlieh, F., Tsaltas, D., Leng, Q., von Bodman, S., and Berkowitz, G. A. (2007). Death don't have no mercy and neither does calcium: Arabidopsis CYCLIC NUCLEOTIDE GATED CHANNEL2 and innate immunity. Plant Cell 19, 1081-1095.

Altenbach, D., and Robatzek, S. (2007). Pattern recognition receptors: from the cell surface to intracellular dynamics. Mol. Plant Microbe Interact 20, 1031-1039.

Anderson, J. P., Badruzsaufari, E., Schenk, P. M., Manners, J. M., Desmond, O. J., Ehlert, C., Maclean, D. J., Ebert, P. R., and Kazan, K. (2004). Antagonistic interaction between abscisic acid and jasmonate-ethylene signaling pathways modulates defense gene expression and disease resistance in Arabidopsis. Plant Cell 16, 34603479.

Andreasson, E., Jenkins, T., Brodersen, P., Thorgrimsen, S., Petersen, N. H. T., Zhu, S., Qiu, J., Micheelsen, P., Rocher, A., Petersen, M., et al. (2005). The MAP kinase substrate MKS1 is a regulator of plant defense responses. EMBO J 24, 2579-2589.

Apel, K., and Hirt, H. (2004). Reactive oxygen species: metabolism, oxidative stress, and signal transduction. Annu Rev Plant Biol 55, 373-399.

Asai, T., Tena, G., Plotnikova, J., Willmann, M. R., Chiu, W., Gomez-Gomez, L., Boller, T., Ausubel, F. M., and Sheen, J. (2002). MAP kinase signalling cascade in Arabidopsis innate immunity. Nature 415, 977-983.

Bender, C. L., Alarcón-Chaidez, F., and Gross, D. C. (1999). Pseudomonas syringae phytotoxins: mode of action, regulation, and biosynthesis by peptide and polyketide synthetases. Microbiol. Mol. Biol. Rev 63, 266-292. 
Benschop, J. J., Mohammed, S., O'Flaherty, M., Heck, A. J. R., Slijper, M., and Menke, F. L. H. (2007). Quantitative phosphoproteomics of early elicitor signaling in Arabidopsis. Mol. Cell Proteomics 6, 1198-1214.

Bethke, G., Unthan, T., Uhrig, J. F., Pöschl, Y., Gust, A. A., Scheel, D., and Lee, J. (2009). Flg22 regulates the release of an ethylene response factor substrate from MAP kinase 6 in Arabidopsis thaliana via ethylene signaling. Proc. Natl. Acad. Sci. U.S.A 106, 8067-8072.

Blanco, F., Salinas, P., Cecchini, N. M., Jordana, X., Van Hummelen, P., Alvarez, M. E., and Holuigue, L. (2009). Early genomic responses to salicylic acid in Arabidopsis. Plant Mol. Biol 70, 79-102.

Boursiac, Y., Boudet, J., Postaire, O., Luu, D., Tournaire-Roux, C., and Maurel, C. (2008). Stimulus-induced downregulation of root water transport involves reactive oxygen species-activated cell signalling and plasma membrane intrinsic protein internalization. Plant J 56, 207-218.

Bowling, S. A., Clarke, J. D., Liu, Y., Klessig, D. F., and Dong, X. (1997). The cpr5 mutant of Arabidopsis expresses both NPR1-dependent and NPR1-independent resistance. Plant Cell 9, 1573-1584.

Boyle, P., Le Su, E., Rochon, A., Shearer, H. L., Murmu, J., Chu, J. Y., Fobert, P. R., and Després, C. (2009). The BTB/POZ domain of the Arabidopsis disease resistance protein NPR1 interacts with the repression domain of TGA2 to negate its function. Plant Cell 21, 3700-3713.

Bradley, D. J., Kjellbom, P., and Lamb, C. J. (1992). Elicitor- and wound-induced oxidative cross-linking of a proline-rich plant cell wall protein: a novel, rapid defense response. Cell 70, 21-30.

Brooks, D. M., Bender, C. L., and Kunkel, B. N. (2005). The Pseudomonas syringae phytotoxin coronatine promotes virulence by overcoming salicylic acid-dependent defences in Arabidopsis thaliana. Molecular Plant Pathology 6, 629-639.

Brooks, D. M., Hernández-Guzmán, G., Kloek, A. P., Alarcón-Chaidez, F., Sreedharan, A., Rangaswamy, V., Peñaloza-Vázquez, A., Bender, C. L., and Kunkel, B. N. (2004). Identification and characterization of a well-defined series of coronatine biosynthetic mutants of Pseudomonas syringae pv. tomato DC3000. Mol. Plant Microbe Interact 17, 162-174.

Büttner, M., and Singh, K. B. (1997). Arabidopsis thaliana ethylene-responsive element binding protein (AtEBP), an ethylene-inducible, GCC box DNA-binding protein interacts with an ocs element binding protein. Proc Natl Acad Sci U S A 94, 59615966.

Cao, D., Cheng, H., Wu, W., Soo, H. M., and Peng, J. (2006). Gibberellin mobilizes distinct DELLA-dependent transcriptomes to regulate seed germination and floral development in Arabidopsis. Plant Physiol 142, 509-525. 
Cao, H., Glazebrook, J., Clarke, J. D., Volko, S., and Dong, X. (1997). The Arabidopsis NPR1 gene that controls systemic acquired resistance encodes a novel protein containing ankyrin repeats. Cell 88, 57-63.

Chen, H., Xue, L., Chintamanani, S., Germain, H., Lin, H., Cui, H., Cai, R., Zuo, J., Tang, X., Li, $X$., et al. (2009). ETHYLENE INSENSITIVE3 and ETHYLENE INSENSITIVE3-LIKE1 repress SALICYLIC ACID INDUCTION DEFICIENT2 expression to negatively regulate plant innate immunity in Arabidopsis. Plant Cell 21, 2527-2540.

Chomczynski, P. (1993). A reagent for the single-step simultaneous isolation of RNA, DNA and proteins from cell and tissue samples. BioTechniques 15, 532-534, 536-537.

Clay, N. K., Adio, A. M., Denoux, C., Jander, G., and Ausubel, F. M. (2009). Glucosinolate metabolites required for an Arabidopsis innate immune response. Science 323, 95101.

Conrath, U., Pieterse, C. M. J., and Mauch-Mani, B. (2002). Priming in plant-pathogen interactions. Trends Plant Sci 7, 210-216.

Creelman, R. A., and Mullet, J. E. (1995). Jasmonic acid distribution and action in plants: regulation during development and response to biotic and abiotic stress. Proc. Natl. Acad. Sci. U.S.A 92, 4114-4119.

Dangl, J. L., and Jones, J. D. (2001). Plant pathogens and integrated defence responses to infection. Nature 411, 826-833.

De Vos, M., Van Oosten, V. R., Van Poecke, R. M. P., Van Pelt, J. A., Pozo, M. J., Mueller, M. J., Buchala, A. J., Métraux, J., Van Loon, L. C., Dicke, M., et al. (2005). Signal signature and transcriptome changes of Arabidopsis during pathogen and insect attack. Mol. Plant Microbe Interact 18, 923-937.

De Vos, M., Van Zaanen, W., Koornneef, A., Korzelius, J. P., Dicke, M., Van Loon, L., and Pieterse, C. M. (2006). Herbivore-Induced Resistance against Microbial Pathogens in Arabidopsis. Plant Physiol 142, 352-363.

Dean, J. V., and Delaney, S. P. (2008). Metabolism of salicylic acid in wild-type, ugt74f1 and ugt74f2 glucosyltransferase mutants of Arabidopsis thaliana. Physiol Plant 132, 417-425.

Delaney, T. P., Uknes, S., Vernooij, B., Friedrich, L., Weymann, K., Negrotto, D., Gaffney, T., Gut-Rella, M., Kessmann, H., Ward, E., et al. (1994). A Central Role of Salicylic Acid in Plant Disease Resistance. Science 266, 1247-1250.

Demkura, P. V., Abdala, G., Baldwin, I. T., and Ballare, C. L. (2009). Jasmonate dependent and independent pathways mediate specific effects of solar ultraviolet-B radiation on leaf phenolics and anti-herbivore defense. Plant Physiol., pp.109.148999.

Denoux, C., Galletti, R., Mammarella, N., Gopalan, S., Werck, D., De Lorenzo, G., Ferrari, S., Ausubel, F. M., and Dewdney, J. (2008). Activation of Defense Response Pathways by OGs and Flg22 Elicitors in Arabidopsis Seedlings. Mol Plant 1, 423-445.

Desikan, R., A-H-Mackerness, S., Hancock, J. T., and Neill, S. J. (2001). Regulation of the Arabidopsis transcriptome by oxidative stress. Plant Physiol 127, 159-172. 
Desikan, R., Hancock, J. T., Bright, J., Harrison, J., Weir, I., Hooley, R., and Neill, S. J. (2005). A role for ETR1 in hydrogen peroxide signaling in stomatal guard cells. Plant Physiol 137, 831-834.

Deslandes, L., Olivier, J., Peeters, N., Feng, D. X., Khounlotham, M., Boucher, C., Somssich, I., Genin, S., and Marco, Y. (2003). Physical interaction between RRS1-R, a protein conferring resistance to bacterial wilt, and PopP2, a type III effector targeted to the plant nucleus. Proc. Natl. Acad. Sci. U.S.A 100, 8024-8029.

Després, C., Chubak, C., Rochon, A., Clark, R., Bethune, T., Desveaux, D., and Fobert, P. R. (2003). The Arabidopsis NPR1 disease resistance protein is a novel cofactor that confers redox regulation of DNA binding activity to the basic domain/leucine zipper transcription factor TGA1. Plant Cell 15, 2181-2191.

Després, C., DeLong, C., Glaze, S., Liu, E., and Fobert, P. R. (2000). The Arabidopsis NPR1/NIM1 protein enhances the DNA binding activity of a subgroup of the TGA family of bZIP transcription factors. Plant Cell 12, 279-290.

Devaiah, B. N., Karthikeyan, A. S., and Raghothama, K. G. (2007). WRKY75 transcription factor is a modulator of phosphate acquisition and root development in Arabidopsis. Plant Physiol 143, 1789-1801.

Dong, J., Chen, C., and Chen, Z. (2003). Expression profiles of the Arabidopsis WRKY gene superfamily during plant defense response. Plant Mol. Biol 51, 21-37.

Dong, X., Hong, Z., Chatterjee, J., Kim, S., and Verma, D. P. S. (2008). Expression of callose synthase genes and its connection with Npr1 signaling pathway during pathogen infection. Planta 229, 87-98.

Durrant, W. E., and Dong, X. (2004). Systemic acquired resistance. Annu Rev Phytopathol 42, 185-209.

Encinas-Villarejo, S., Maldonado, A. M., Amil-Ruiz, F., de los Santos, B., Romero, F., PliegoAlfaro, F., Muñoz-Blanco, J., and Caballero, J. L. (2009). Evidence for a positive regulatory role of strawberry (Fragaria $x$ ananassa) Fa WRKY1 and Arabidopsis At WRKY75 proteins in resistance. J. Exp. Bot 60, 3043-3065.

Eulgem, T., and Somssich, I. E. (2007). Networks of WRKY transcription factors in defense signaling. Curr. Opin. Plant Biol 10, 366-371.

Eulgem, T., Rushton, P. J., Robatzek, S., and Somssich, I. E. (2000). The WRKY superfamily of plant transcription factors. Trends Plant Sci 5, 199-206.

Felix, G., Duran, J. D., Volko, S., and Boller, T. (1999). Plants have a sensitive perception system for the most conserved domain of bacterial flagellin. Plant J 18, 265-276.

Felix, G., Regenass, M., and Boller, T. (1993). Specific perception of subnanomolar concentrations of chitin fragments by tomato cells: induction of extracellular alkalinization, changes in protein phosphorylation, and establishment of a refractory state. The Plant Journal 4, 307-316. 
Feys, B. J., Moisan, L. J., Newman, M. A., and Parker, J. E. (2001). Direct interaction between the Arabidopsis disease resistance signaling proteins, EDS1 and PAD4. EMBO J 20, 5400-5411.

Feys, B., Benedetti, C. E., Penfold, C. N., and Turner, J. G. (1994). Arabidopsis Mutants Selected for Resistance to the Phytotoxin Coronatine Are Male Sterile, Insensitive to Methyl Jasmonate, and Resistant to a Bacterial Pathogen. Plant Cell 6, 751-759.

Flors, V., Ton, J., van Doorn, R., Jakab, G., García-Agustín, P., and Mauch-Mani, B. (2008). Interplay between JA, SA and ABA signalling during basal and induced resistance against Pseudomonas syringae and Alternaria brassicicola. Plant J 54, 81-92.

Fode, B., Siemsen, T., Thurow, C., Weigel, R., and Gatz, C. (2008). The Arabidopsis GRAS protein SCL14 interacts with class II TGA transcription factors and is essential for the activation of stress-inducible promoters. Plant Cell 20, 3122-3135.

Folta, K. M., and Kaufman, L. S. (2000). Preparation of transcriptionally active nuclei from etiolated Arabidopsis thaliana. Plant Cell Reports 19, 504-510.

Fonseca, S., Chico, J. M., and Solano, R. (2009). The jasmonate pathway: the ligand, the receptor and the core signalling module. Curr. Opin. Plant Biol 12, 539-547.

Gimenez-Ibanez, S., Hann, D. R., Ntoukakis, V., Petutschnig, E., Lipka, V., and Rathjen, J. P. (2009). AvrPtoB targets the LysM receptor kinase CERK1 to promote bacterial virulence on plants. Curr. Biol 19, 423-429.

Glazebrook, J. (2005). Contrasting mechanisms of defense against biotrophic and necrotrophic pathogens. Annu Rev Phytopathol 43, 205-227.

Glazebrook, J., Chen, W., Estes, B., Chang, H., Nawrath, C., Métraux, J., Zhu, T., and Katagiri, F. (2003). Topology of the network integrating salicylate and jasmonate signal transduction derived from global expression phenotyping. Plant J 34, 217228.

Göhre, V., Spallek, T., Häweker, H., Mersmann, S., Mentzel, T., Boller, T., de Torres, M., Mansfield, J. W., and Robatzek, S. (2008). Plant pattern-recognition receptor FLS2 is directed for degradation by the bacterial ubiquitin ligase AvrPtoB. Curr. Biol 18, 1824-1832.

Gómez-Gómez, L., and Boller, T. (2000). FLS2: an LRR receptor-like kinase involved in the perception of the bacterial elicitor flagellin in Arabidopsis. Mol. Cell 5, 1003-1011.

Gómez-Gómez, L., Felix, G., and Boller, T. (1999). A single locus determines sensitivity to bacterial flagellin in Arabidopsis thaliana. Plant J 18, 277-284.

Guo, H., and Ecker, J. R. (2003). Plant responses to ethylene gas are mediated by SCF(EBF1/EBF2)-dependent proteolysis of EIN3 transcription factor. Cell 115, 667677. 
Gust, A. A., Biswas, R., Lenz, H. D., Rauhut, T., Ranf, S., Kemmerling, B., Götz, F., Glawischnig, E., Lee, J., Felix, G., et al. (2007). Bacteria-derived peptidoglycans constitute pathogen-associated molecular patterns triggering innate immunity in Arabidopsis. J. Biol. Chem 282, 32338-32348.

Hammond, D. E., Urbé, S., Vande Woude, G. F., and Clague, M. J. (2001). Down-regulation of MET, the receptor for hepatocyte growth factor. Oncogene 20, 2761-2770.

Hanahan, D. (1983). Studies on transformation of Escherichia coli with plasmids. J. Mol. Biol 166, 557-580.

Hauck, P., Thilmony, R., and He, S. Y. (2003). A Pseudomonas syringae type III effector suppresses cell wall-based extracellular defense in susceptible Arabidopsis plants. Proc. Natl. Acad. Sci. U.S.A 100, 8577-8582.

He, P., Shan, L., Lin, N., Martin, G. B., Kemmerling, B., Nürnberger, T., and Sheen, J. (2006). Specific bacterial suppressors of MAMP signaling upstream of MAPKKK in Arabidopsis innate immunity. Cell 125, 563-575.

Heinekamp, T., Kuhlmann, M., Lenk, A., Strathmann, A., and Dröge-Laser, W. (2002). The tobacco bZIP transcription factor BZI-1 binds to G-box elements in the promoters of phenylpropanoid pathway genes in vitro, but it is not involved in their regulation in vivo. Mol. Genet. Genomics 267, 16-26.

Hong, Z., Delauney, A. J., and Verma, D. P. (2001). A cell plate-specific callose synthase and its interaction with phragmoplastin. Plant Cell 13, 755-768.

Innes, R. W., Bent, A. F., Kunkel, B. N., Bisgrove, S. R., and Staskawicz, B. J. (1993). Molecular analysis of avirulence gene avrRpt2 and identification of a putative regulatory sequence common to all known Pseudomonas syringae avirulence genes. J. Bacteriol 175, 4859-4869.

Iriti, M., and Faoro, F. (2009). Chitosan as a MAMP, searching for a PRR. Plant Signal Behav 4, 66-68.

Jacobs, A. K., Lipka, V., Burton, R. A., Panstruga, R., Strizhov, N., Schulze-Lefert, P., and Fincher, G. B. (2003). An Arabidopsis Callose Synthase, GSL5, Is Required for Wound and Papillary Callose Formation. Plant Cell 15, 2503-2513.

Jakoby, M., Weisshaar, B., Dröge-Laser, W., Vicente-Carbajosa, J., Tiedemann, J., Kroj, T., and Parcy, F. (2002). bZIP transcription factors in Arabidopsis. Trends Plant Sci 7, 106-111.

Jiang, C., and Fu, X. (2007). GA action: turning on de-DELLA repressing signaling. Curr. Opin. Plant Biol 10, 461-465.

Jiang, K., Meng, Y. L., and Feldman, L. J. (2003). Quiescent center formation in maize roots is associated with an auxin-regulated oxidizing environment. Development 130, 1429-1438. 
Jones, J. D. G., and Dangl, J. L. (2006). The plant immune system. Nature 444, 323-329.

Journot-Catalino, N., Somssich, I. E., Roby, D., and Kroj, T. (2006). The transcription factors WRKY11 and WRKY17 act as negative regulators of basal resistance in Arabidopsis thaliana. Plant Cell 18, 3289-3302.

Kaku, H., Nishizawa, Y., Ishii-Minami, N., Akimoto-Tomiyama, C., Dohmae, N., Takio, K., Minami, E., and Shibuya, N. (2006). Plant cells recognize chitin fragments for defense signaling through a plasma membrane receptor. Proceedings of the National Academy of Sciences 103, 11086-11091.

Katagiri, F., Lam, E., and Chua, N. H. (1989). Two tobacco DNA-binding proteins with homology to the nuclear factor CREB. Nature 340, 727-730.

Katagiri, Roger Thilmony, and Sheng Yang He (2002). BioOne Online Journals - The Arabidopsis Thaliana-Pseudomonas Syringae Interaction. Available at: http://www.bioone.org/doi/abs/10.1199/tab.0039.

Katsir, L., Chung, H. S., Koo, A. J. K., and Howe, G. A. (2008). Jasmonate signaling: a conserved mechanism of hormone sensing. Curr. Opin. Plant Biol 11, 428-435.

Kemmerling, B., Schwedt, A., Rodriguez, P., Mazzotta, S., Frank, M., Qamar, S. A., Mengiste, T., Betsuyaku, S., Parker, J. E., Müssig, C., et al. (2007). The BRI1associated kinase 1, BAK1, has a brassinolide-independent role in plant cell-death control. Curr. Biol 17, 1116-1122.

Kesarwani, M., Yoo, J., and Dong, X. (2007). Genetic interactions of TGA transcription factors in the regulation of pathogenesis-related genes and disease resistance in Arabidopsis. Plant Physiol 144, 336-346.

Kim, H. S., and Delaney, T. P. (2002). Over-expression of TGA5, which encodes a bZIP transcription factor that interacts with NIM1/NPR1, confers SAR-independent resistance in Arabidopsis thaliana to Peronospora parasitica. Plant J 32, 151-163.

Kim, K., Fan, B., and Chen, Z. (2006). Pathogen-induced Arabidopsis WRKY7 is a transcriptional repressor and enhances plant susceptibility to Pseudomonas syringae. Plant Physiol 142, 1180-1192.

Kim, M. G., da Cunha, L., McFall, A. J., Belkhadir, Y., DebRoy, S., Dangl, J. L., and Mackey, D. (2005). Two Pseudomonas syringae type III effectors inhibit RIN4-regulated basal defense in Arabidopsis. Cell 121, 749-759.

Klüsener, B., Young, J. J., Murata, Y., Allen, G. J., Mori, I. C., Hugouvieux, V., and Schroeder, J. I. (2002). Convergence of Calcium Signaling Pathways of Pathogenic Elicitors and Abscisic Acid in Arabidopsis Guard Cells. Plant Physiol 130, 2152-2163.

Krawczyk, S., Thurow, C., Niggeweg, R., and Gatz, C. (2002). Analysis of the spacing between the two palindromes of activation sequence-1 with respect to binding to different TGA factors and transcriptional activation potential. Nucleic Acids Res 30, 775-781. 
Kunkel, B. N., and Brooks, D. M. (2002). Cross talk between signaling pathways in pathogen defense. Curr. Opin. Plant Biol 5, 325-331.

Kunze, G., Zipfel, C., Robatzek, S., Niehaus, K., Boller, T., and Felix, G. (2004). The N terminus of bacterial elongation factor Tu elicits innate immunity in Arabidopsis plants. Plant Cell 16, 3496-3507.

Lam, E. (2004). Controlled cell death, plant survival and development. Nat. Rev. Mol. Cell Biol 5, 305-315.

Lam, E., Benfey, P. N., Gilmartin, P. M., Fang, R. X., and Chua, N. H. (1989). Site-specific mutations alter in vitro factor binding and change promoter expression pattern in transgenic plants. Proc. Natl. Acad. Sci. U.S.A 86, 7890-7894.

Lam, E., and Lam, Y. K. (1995). Binding site requirements and differential representation of TGF factors in nuclear ASF-1 activity. Nucleic Acids Res 23, 3778-3785.

Lamb, C., and Dixon, R. A. (1997). THE OXIDATIVE BURST IN PLANT DISEASE RESISTANCE. Annu. Rev. Plant Physiol. Plant Mol. Biol 48, 251-275.

Laurie-Berry, N., Joardar, V., Street, I. H., and Kunkel, B. N. (2006). The Arabidopsis thaliana JASMONATE INSENSITIVE 1 gene is required for suppression of salicylic acid-dependent defenses during infection by Pseudomonas syringae. Mol. Plant Microbe Interact 19, 789-800.

Lebel, E., Heifetz, P., Thorne, L., Uknes, S., Ryals, J., and Ward, E. (1998). Functional analysis of regulatory sequences controlling PR-1 gene expression in Arabidopsis. Plant J 16, 223-233.

Lee, S., Choi, H., Suh, S., Doo, I. S., Oh, K. Y., Choi, E. J., Schroeder Taylor, A. T., Low, P. S., and Lee, Y. (1999). Oligogalacturonic acid and chitosan reduce stomatal aperture by inducing the evolution of reactive oxygen species from guard cells of tomato and Commelina communis. Plant Physiol 121, 147-152.

Lemaire, S. D. (2004). The glutaredoxin family in oxygenic photosynthetic organisms. Photosyn. Res 79, 305-318.

León, J., Rojo, E., and Sánchez-Serrano, J. J. (2001). Wound signalling in plants. J. Exp. Bot 52, 1-9.

Leon-Reyes, A., Spoel, S. H., De Lange, E. S., Abe, H., Kobayashi, M., Tsuda, S., Millenaar, F. F., Welschen, R. A. M., Ritsema, T., and Pieterse, C. M. J. (2009). Ethylene modulates the role of NONEXPRESSOR OF PATHOGENESIS-RELATED GENES1 in cross talk between salicylate and jasmonate signaling. Plant Physiol 149, 17971809.

Levine, A., Tenhaken, R., Dixon, R., and Lamb, C. (1994). H2O2 from the oxidative burst orchestrates the plant hypersensitive disease resistance response. Cell 79, 583-593.

Li, J., Brader, G., and Palva, E. T. (2004). The WRKY70 transcription factor: a node of convergence for jasmonate-mediated and salicylate-mediated signals in plant defense. Plant Cell 16, 319-331. 
Li, J., Brader, G., Kariola, T., and Palva, E. T. (2006). WRKY70 modulates the selection of signaling pathways in plant defense. The Plant Journal 46, 477-491.

Li, J., Zhao-Hui, C., Batoux, M., Nekrasov, V., Roux, M., Chinchilla, D., Zipfel, C., and Jones, J. D. G. (2009). Specific ER quality control components required for biogenesis of the plant innate immune receptor EFR. Proc. Natl. Acad. Sci. U.S.A 106, 1597315978.

Libault, M., Wan, J., Czechowski, T., Udvardi, M., and Stacey, G. (2007). Identification of 118 Arabidopsis transcription factor and 30 ubiquitin-ligase genes responding to chitin, a plant-defense elicitor. Mol. Plant Microbe Interact 20, 900-911.

Liu, J., Elmore, J. M., Fuglsang, A. T., Palmgren, M. G., Staskawicz, B. J., and Coaker, G. (2009). RIN4 Functions with Plasma Membrane H+-ATPases to Regulate Stomatal Apertures during Pathogen Attack. PLoS Biol 7, e1000139.

Liu, Y., and Zhang, S. (2004). Phosphorylation of 1-aminocyclopropane-1-carboxylic acid synthase by MPK6, a stress-responsive mitogen-activated protein kinase, induces ethylene biosynthesis in Arabidopsis. Plant Cell 16, 3386-3399.

Livaja, M., Zeidler, D., von Rad, U., and Durner, J. (2008). Transcriptional responses of Arabidopsis thaliana to the bacteria-derived PAMPs harpin and lipopolysaccharide. Immunobiology 213, 161-171.

Loake, G., and Grant, M. (2007). Salicylic acid in plant defence-the players and protagonists. Curr. Opin. Plant Biol 10, 466-472.

Lorenzo, O., Chico, J. M., Sánchez-Serrano, J. J., and Solano, R. (2004). JASMONATEINSENSITIVE1 encodes a MYC transcription factor essential to discriminate between different jasmonate-regulated defense responses in Arabidopsis. Plant Cell 16, 1938-1950.

Ludwig, A. A., Saitoh, H., Felix, G., Freymark, G., Miersch, O., Wasternack, C., Boller, T., Jones, J. D. G., and Romeis, T. (2005). Ethylene-mediated cross-talk between calcium-dependent protein kinase and MAPK signaling controls stress responses in plants. Proc. Natl. Acad. Sci. U.S.A 102, 10736-10741.

Mackey, D., Belkhadir, Y., Alonso, J. M., Ecker, J. R., and Dangl, J. L. (2003). Arabidopsis RIN4 is a target of the type III virulence effector AvrRpt2 and modulates RPS2mediated resistance. Cell 112, 379-389.

Mackey, D., Holt, B. F., Wiig, A., and Dangl, J. L. (2002). RIN4 interacts with Pseudomonas syringae type III effector molecules and is required for RPM1-mediated resistance in Arabidopsis. Cell 108, 743-754.

Maldonado, A. M., Doerner, P., Dixon, R. A., Lamb, C. J., and Cameron, R. K. (2002). A putative lipid transfer protein involved in systemic resistance signalling in Arabidopsis. Nature 419, 399-403.

Mauch-Mani, B., and Mauch, F. (2005). The role of abscisic acid in plant-pathogen interactions. Curr. Opin. Plant Biol 8, 409-414. 
Mauch-Mani, B., and Metraux, J. (1998). Salicylic Acid and Systemic Acquired Resistance to Pathogen Attack. Ann Bot 82, 535-540.

Mauch-Mani, B., and Slusarenko, A. J. (1996). Production of Salicylic Acid Precursors Is a Major Function of Phenylalanine Ammonia-Lyase in the Resistance of Arabidopsis to Peronospora parasitica. Plant Cell 8, 203-212.

Melotto, M., Underwood, W., Koczan, J., Nomura, K., and He, S. Y. (2006). Plant stomata function in innate immunity against bacterial invasion. Cell 126, 969-980.

Mészáros, T., Helfer, A., Hatzimasoura, E., Magyar, Z., Serazetdinova, L., Rios, G., Bardóczy, V., Teige, M., Koncz, C., Peck, S., et al. (2006). The Arabidopsis MAP kinase kinase MKK1 participates in defence responses to the bacterial elicitor flagellin. Plant J 48, 485-498.

Miao, Y., Laun, T., Zimmermann, P., and Zentgraf, U. (2004). Targets of the WRKY53 transcription factor and its role during leaf senescence in Arabidopsis. Plant Mol. Biol 55, 853-867.

Miao, Z. H., Liu, X., and Lam, E. (1994). TGA3 is a distinct member of the TGA family of bZIP transcription factors in Arabidopsis thaliana. Plant Mol. Biol 25, 1-11.

Mishina, T. E., and Zeier, J. (2007). Pathogen-associated molecular pattern recognition rather than development of tissue necrosis contributes to bacterial induction of systemic acquired resistance in Arabidopsis. Plant J 50, 500-513.

Mithöfer, A., Ebel, J., and Felle, H. H. (2005). Cation fluxes cause plasma membrane depolarization involved in beta-glucan elicitor-signaling in soybean roots. Mol. Plant Microbe Interact 18, 983-990.

Mittal, S., and Davis, K. R. (1995). Role of the phytotoxin coronatine in the infection of Arabidopsis thaliana by Pseudomonas syringae pv. tomato. Mol. Plant Microbe Interact 8, 165-171.

Mittler, R., Vanderauwera, S., Gollery, M., and Van Breusegem, F. (2004). Reactive oxygen gene network of plants. Trends Plant Sci 9, 490-498.

Miya, A., Albert, P., Shinya, T., Desaki, Y., Ichimura, K., Shirasu, K., Narusaka, Y., Kawakami, N., Kaku, H., and Shibuya, N. (2007). CERK1, a LysM receptor kinase, is essential for chitin elicitor signaling in Arabidopsis. Proc. Natl. Acad. Sci. U.S.A 104, 19613-19618.

Mou, Z., Fan, W., and Dong, X. (2003). Inducers of plant systemic acquired resistance regulate NPR1 function through redox changes. Cell 113, 935-944.

Mueller, S., Hilbert, B., Dueckershoff, K., Roitsch, T., Krischke, M., Mueller, M. J., and Berger, S. (2008). General detoxification and stress responses are mediated by oxidized lipids through TGA transcription factors in Arabidopsis. Plant Cell 20, 768785. 
Munemasa, S., Oda, K., Watanabe-Sugimoto, M., Nakamura, Y., Shimoishi, Y., and Murata, Y. (2007). The coronatine-insensitive 1 mutation reveals the hormonal signaling interaction between abscisic acid and methyl jasmonate in Arabidopsis guard cells. Specific impairment of ion channel activation and second messenger production. Plant Physiol 143, 1398-1407.

Mur, L. A., Kenton, P., Atzorn, R., Miersch, O., and Wasternack, C. (2006). The Outcomes of Concentration-Specific Interactions between Salicylate and Jasmonate Signaling Include Synergy, Antagonism, and Oxidative Stress Leading to Cell Death. Plant Physiol 140, 249-262.

Murray, S. L., Ingle, R. A., Petersen, L. N., and Denby, K. J. (2007). Basal resistance against Pseudomonas syringae in Arabidopsis involves WRKY53 and a protein with homology to a nematode resistance protein. Mol. Plant Microbe Interact 20, 14311438.

Navarro, L., Bari, R., Achard, P., Lisón, P., Nemri, A., Harberd, N. P., and Jones, J. D. G. (2008). DELLAs control plant immune responses by modulating the balance of jasmonic acid and salicylic acid signaling. Curr. Biol 18, 650-655.

Navarro, L., Dunoyer, P., Jay, F., Arnold, B., Dharmasiri, N., Estelle, M., Voinnet, O., and Jones, J. D. G. (2006). A plant miRNA contributes to antibacterial resistance by repressing auxin signaling. Science 312, 436-439.

Navarro, L., Zipfel, C., Rowland, O., Keller, I., Robatzek, S., Boller, T., and Jones, J. D. (2004). The Transcriptional Innate Immune Response to flg22. Interplay and Overlap with Avr Gene-Dependent Defense Responses and Bacterial Pathogenesis. Plant Physiol. 135, 1113-1128.

Ndamukong, I., Abdallat, A. A., Thurow, C., Fode, B., Zander, M., Weigel, R., and Gatz, C. (2007). SA-inducible Arabidopsis glutaredoxin interacts with TGA factors and suppresses JA-responsive PDF1.2 transcription. Plant J 50, 128-139.

Newman, M., Roepenack-Lahaye, E. V., Parr, A., Daniels, M. J., and Dow, J. M. (2002). Prior exposure to lipopolysaccharide potentiates expression of plant defenses in response to bacteria. The Plant Journal 29, 487-495.

Nimchuk, Z., Eulgem, T., Holt, B. F., and Dangl, J. L. (2003). Recognition and response in the plant immune system. Annu. Rev. Genet 37, 579-609.

Nishimura, M. T., Stein, M., Hou, B., Vogel, J. P., Edwards, H., and Somerville, S. C. (2003). Loss of a callose synthase results in salicylic acid-dependent disease resistance. Science 301, 969-972.

Nühse, T. S., Bottrill, A. R., Jones, A. M. E., and Peck, S. C. (2007). Quantitative phosphoproteomic analysis of plasma membrane proteins reveals regulatory mechanisms of plant innate immune responses. Plant J 51, 931-940.

Ochsenbein, C., Przybyla, D., Danon, A., Landgraf, F., Göbel, C., Imboden, A., Feussner, I., and Apel, K. (2006). The role of EDS1 (enhanced disease susceptibility) during singlet oxygen-mediated stress responses of Arabidopsis. Plant J 47, 445-456. 
Park, S., Kaimoyo, E., Kumar, D., Mosher, S., and Klessig, D. F. (2007). Methyl salicylate is a critical mobile signal for plant systemic acquired resistance. Science 318, 113-116.

Penaloza-Vazquez, A., Preston, G. M., Collmer, A., and Bender, C. L. (2000). Regulatory interactions between the Hrp type III protein secretion system and coronatine biosynthesis in Pseudomonas syringae pv. tomato DC3000. Microbiology 146, 24472456.

Petersen, M., Brodersen, P., Naested, H., Andreasson, E., Lindhart, U., Johansen, B., Nielsen, H. B., Lacy, M., Austin, M. J., Parker, J. E., et al. (2000). Arabidopsis map kinase 4 negatively regulates systemic acquired resistance. Cell 103, 1111-1120.

Pontier, D., Privat, I., Trifa, Y., Zhou, J., Klessig, D. F., and Lam, E. (2002). Differential regulation of TGA transcription factors by post-transcriptional control. Plant J 32, 641-653.

Reymond, P., Bodenhausen, N., Van Poecke, R. M. P., Krishnamurthy, V., Dicke, M., and Farmer, E. E. (2004). A conserved transcript pattern in response to a specialist and a generalist herbivore. Plant Cell 16, 3132-3147.

Robatzek, S., and Somssich, I. E. (2002). Targets of AtWRKYG regulation during plant senescence and pathogen defense. Genes Dev 16, 1139-1149.

Robatzek, S., Chinchilla, D., and Boller, T. (2006). Ligand-induced endocytosis of the pattern recognition receptor FLS2 in Arabidopsis. Genes Dev 20, 537-542.

Rochon, A., Boyle, P., Wignes, T., Fobert, P. R., and Després, C. (2006). The coactivator function of Arabidopsis NPR1 requires the core of its BTB/POZ domain and the oxidation of C-terminal cysteines. Plant Cell 18, 3670-3685.

Sauer, F., and Jäckle, H. (1991). Concentration-dependent transcriptional activation or repression by Krüppel from a single binding site. Nature 353, 563-566.

Sauer, F., and Jäckle, H. (1993). Dimerization and the control of transcription by Krüppel. Nature 364, 454-457.

Schmittgen, T. D., and Livak, K. J. (2008). Analyzing real-time PCR data by the comparative C(T) method. Nat Protoc 3, 1101-1108.

Shan, L., He, P., Li, J., Heese, A., Peck, S. C., Nürnberger, T., Martin, G. B., and Sheen, J. (2008). Bacterial effectors target the common signaling partner BAK1 to disrupt multiple MAMP receptor-signaling complexes and impede plant immunity. Cell Host Microbe 4, 17-27.

Shen, Q., Saijo, Y., Mauch, S., Biskup, C., Bieri, S., Keller, B., Seki, H., Ulker, B., Somssich, I. E., and Schulze-Lefert, P. (2007). Nuclear activity of MLA immune receptors links isolate-specific and basal disease-resistance responses. Science 315, 1098-1103.

Spoel, S. H., Koornneef, A., Claessens, S. M. C., Korzelius, J. P., Van Pelt, J. A., Mueller, M. J., Buchala, A. J., Métraux, J., Brown, R., Kazan, K., et al. (2003). NPR1 modulates cross-talk between salicylate- and jasmonate-dependent defense pathways through a novel function in the cytosol. Plant Cell 15, 760-770. 
Stintzi, A., Weber, H., Reymond, P., Browse, J., and Farmer, E. E. (2001). Plant defense in the absence of jasmonic acid: the role of cyclopentenones. Proc. Natl. Acad. Sci. U.S.A 98, 12837-12842.

Suarez-Rodriguez, M. C., Adams-Phillips, L., Liu, Y., Wang, H., Su, S., Jester, P. J., Zhang, S., Bent, A. F., and Krysan, P. J. (2007). MEKK1 is required for flg22-induced MPK4 activation in Arabidopsis plants. Plant Physiol 143, 661-669.

Suhita, D., Raghavendra, A. S., Kwak, J. M., and Vavasseur, A. (2004). Cytoplasmic alkalization precedes reactive oxygen species production during methyl jasmonateand abscisic acid-induced stomatal closure. Plant Physiol 134, 1536-1545.

Tang, Frederick, Zhou, Halterman, Jia, and Martin (1996). Initiation of Plant Disease Resistance by Physical Interaction of AvrPto and Pto Kinase. Science 274, 20602063.

Thibaud-Nissen, F., Wu, H., Richmond, T., Redman, J. C., Johnson, C., Green, R., Arias, J., and Town, C. D. (2006). Development of Arabidopsis whole-genome microarrays and their application to the discovery of binding sites for the TGA2 transcription factor in salicylic acid-treated plants. Plant J 47, 152-162.

Thomma, B. P., Eggermont, K., Tierens, K. F., and Broekaert, W. F. (1999). Requirement of functional ethylene-insensitive 2 gene for efficient resistance of Arabidopsis to infection by Botrytis cinerea. Plant Physiol 121, 1093-1102.

Thordal-Christensen, H., Zhang, Z., Wei, Y., and Collinge, D. B. (1997). Subcellular localization of $\mathrm{H} 2 \mathrm{O} 2$ in plants. $\mathrm{H} 2 \mathrm{O} 2$ accumulation in papillae and hypersensitive response during the barley-powdery mildew interaction. The Plant Journal 11, 1187-1194.

Titarenko, E., Rojo, E., León, J., and Sánchez-Serrano, J. J. (1997). Jasmonic acid-dependent and -independent signaling pathways control wound-induced gene activation in Arabidopsis thaliana. Plant Physiol 115, 817-826.

Torres, M. A., Dangl, J. L., and Jones, J. D. G. (2002). Arabidopsis gp91phox homologues AtrbohD and AtrbohF are required for accumulation of reactive oxygen intermediates in the plant defense response. Proceedings of the National Academy of Sciences of the United States of America 99, 517-522.

Trujillo, M., Ichimura, K., Casais, C., and Shirasu, K. (2008). Negative regulation of PAMPtriggered immunity by an E3 ubiquitin ligase triplet in Arabidopsis. Curr. Biol 18, 1396-1401.

Tsuda, K., Sato, M., Glazebrook, J., Cohen, J. D., and Katagiri, F. (2008). Interplay between MAMP-triggered and SA-mediated defense responses. Plant J 53, 763-775.

Turck, F., Zhou, A., and Somssich, I. E. (2004). Stimulus-dependent, promoter-specific binding of transcription factor WRKY1 to Its native promoter and the defenserelated gene PcPR1-1 in Parsley. Plant Cell 16, 2573-2585.

Uknes, S., Mauch-Mani, B., Moyer, M., Potter, S., Williams, S., Dincher, S., Chandler, D., Slusarenko, A., Ward, E., and Ryals, J. (1992). Acquired resistance in Arabidopsis. Plant Cell 4, 645-656. 
Underwood, W., Zhang, S., and He, S. Y. (2007). The Pseudomonas syringae type III effector tyrosine phosphatase HopAO1 suppresses innate immunity in Arabidopsis thaliana. Plant J 52, 658-672.

Uppalapati, S. R., Ishiga, Y., Wangdi, T., Kunkel, B. N., Anand, A., Mysore, K. S., and Bender, C. L. (2007). The phytotoxin coronatine contributes to pathogen fitness and is required for suppression of salicylic acid accumulation in tomato inoculated with Pseudomonas syringae pv. tomato DC3000. Mol. Plant Microbe Interact 20, 955965.

Van Loon, L. (1997). Induced resistance in plants and the role of pathogenesis-related proteins. European Journal of Plant Pathology 103, 753-765.

van Loon, L. C., Geraats, B. P. J., and Linthorst, H. J. M. (2006). Ethylene as a modulator of disease resistance in plants. Trends Plant Sci 11, 184-191.

van Loon, L. C., Rep, M., and Pieterse, C. M. J. (2006). Significance of inducible defenserelated proteins in infected plants. Annu Rev Phytopathol 44, 135-162.

Vernooij, B., Friedrich, L., Morse, A., Reist, R., Kolditz-Jawhar, R., Ward, E., Uknes, S., Kessmann, H., and Ryals, J. (1994). Salicylic Acid Is Not the Translocated Signal Responsible for Inducing Systemic Acquired Resistance but Is Required in Signal Transduction. Plant Cell 6, 959-965.

Walters, D. R., and McRoberts, N. (2006). Plants and biotrophs: a pivotal role for cytokinins? Trends Plant Sci 11, 581-586.

Wan, J., Zhang, X., Neece, D., Ramonell, K. M., Clough, S., Kim, S., Stacey, M. G., and Stacey, G. (2008). A LysM receptor-like kinase plays a critical role in chitin signaling and fungal resistance in Arabidopsis. Plant Cell 20, 471-481.

Wang, D., Amornsiripanitch, N., and Dong, X. (2006). A genomic approach to identify regulatory nodes in the transcriptional network of systemic acquired resistance in plants. PLoS Pathog 2, e123.

Weiler, E. W., Kutchan, T. M., Gorba, T., Brodschelm, W., Niesel, U., and Bublitz, F. (1994). The Pseudomonas phytotoxin coronatine mimics octadecanoid signalling molecules of higher plants. FEBS Lett 345, 9-13.

Weltmeier, F., Rahmani, F., Ehlert, A., Dietrich, K., Schütze, K., Wang, X., Chaban, C., Hanson, J., Teige, M., Harter, K., et al. (2009). Expression patterns within the Arabidopsis C/S1 bZIP transcription factor network: availability of heterodimerization partners controls gene expression during stress response and development. Plant Mol Biol 69, 107-119.

Whalen, M. C., Innes, R. W., Bent, A. F., and Staskawicz, B. J. (1991). Identification of Pseudomonas syringae pathogens of Arabidopsis and a bacterial locus determining avirulence on both Arabidopsis and soybean. Plant Cell 3, 49-59.

Wildermuth, M. C., Dewdney, J., Wu, G., and Ausubel, F. M. (2001). Isochorismate synthase is required to synthesize salicylic acid for plant defence. Nature $414,562-$ 565. 
Xiang, T., Zong, N., Zou, Y., Wu, Y., Zhang, J., Xing, W., Li, Y., Tang, X., Zhu, L., Chai, J., et al. (2008). Pseudomonas syringae effector AvrPto blocks innate immunity by targeting receptor kinases. Curr. Biol 18, 74-80.

Xu, X., Chen, C., Fan, B., and Chen, Z. (2006). Physical and functional interactions between pathogen-induced Arabidopsis WRKY18, WRKY40, and WRKY60 transcription factors. Plant Cell 18, 1310-1326.

Yan, J., Zhang, C., Gu, M., Bai, Z., Zhang, W., Qi, T., Cheng, Z., Peng, W., Luo, H., Nan, F., et al. (2009). The Arabidopsis CORONATINE INSENSITIVE1 protein is a jasmonate receptor. Plant Cell 21, 2220-2236.

Yang, Y., Costa, A., Leonhardt, N., Siegel, R. S., and Schroeder, J. I. (2008) .Isolation of a strong Arabidopsis guard cell promoter and its potential as a research tool. Plant Methods 4, 6-6.

Yoo, S., Cho, Y., and Sheen, J. (2009). Emerging connections in the ethylene signaling network. Trends Plant Sci 14, 270-279.

Zander, M., La Camera, S., Lamotte, O., Métraux, J., and Gatz, C. (2009). Arabidopsis thaliana class II TGA transcription factors are essential activators of jasmonic acid/ethylene-induced defense responses. Plant J. 61 200-210

Zhang, B., Chen, W., Foley, R. C., Büttner, M., and Singh, K. B. (1995). Interactions between distinct types of DNA binding proteins enhance binding to ocs element promoter sequences. Plant Cell 7, 2241-2252.

Zhang, X., Chen, S., and Mou, Z. (2010). Nuclear localization of NPR1 is required for regulation of salicylate tolerance, isochorismate synthase 1 expression and salicylate accumulation in Arabidopsis. J. Plant Physiol 167, 144-148.

Zhang, Y., Tessaro, M. J., Lassner, M., and Li, X. (2003). Knockout analysis of Arabidopsis transcription factors TGA2, TGA5, and TGA6 reveals their redundant and essential roles in systemic acquired resistance. Plant Cell 15, 2647-2653.

Zhao, Y., Thilmony, R., Bender, C. L., Schaller, A., He, S. Y., and Howe, G. A. (2003). Virulence systems of Pseudomonas syringae pv. tomato promote bacterial speck disease in tomato by targeting the jasmonate signaling pathway. Plant J 36, 485499.

Zheng, Z., Mosher, S. L., Fan, B., Klessig, D. F., and Chen, Z. (2007). Functional analysis of Arabidopsis WRKY25 transcription factor in plant defense against Pseudomonas syringae. BMC Plant Biol 7, 2.

Zheng, Z., Qamar, S. A., Chen, Z., and Mengiste, T. (2006). Arabidopsis WRKY33 transcription factor is required for resistance to necrotrophic fungal pathogens. Plant J 48, 592-605.

Zhou, J. M., Trifa, Y., Silva, H., Pontier, D., Lam, E., Shah, J., and Klessig, D. F. (2000). NPR1 differentially interacts with members of the TGA/OBF family of transcription factors that bind an element of the PR-1 gene required for induction by salicylic acid. Mol. Plant Microbe Interact 13, 191-202. 
Zipfel, C., and Felix, G. (2005). Plants and animals: a different taste for microbes? Curr. Opin. Plant Biol 8, 353-360.

Zipfel, C., Kunze, G., Chinchilla, D., Caniard, A., Jones, J. D. G., Boller, T., and Felix, G. (2006). Perception of the bacterial PAMP EF-Tu by the receptor EFR restricts Agrobacterium-mediated transformation. Cell 125, 749-760.

Zipfel, C., Robatzek, S., Navarro, L., Oakeley, E. J., Jones, J. D. G., Felix, G., and Boller, T. (2004). Bacterial disease resistance in Arabidopsis through flagellin perception. Nature 428, 764-767. 


\section{$8 \quad$ Acknowledgement}

Zunächst möchte ich mich ganz herzlich bei allen bedanken, die mir diese Arbeit ermöglicht haben.

Von all jenen hat natürlich Christiane Gatz den größten Anteil an dieser Arbeit. Durch viele anregende Diskussionen sind innovative Ideen entstanden, die meine Arbeit sehr bereichert haben.

Auch Wolfgang Dröge-Laser möchte ich sehr herzlich für die Übernahme des Korreferats. Trotz Umzugsstress danken. Wolfgang, viel Erfolg in Würzburg!

Ein ganz besonderer Dank geht an Corinna Thurow für die vielen hilfreichen Ratschläge zu meinem Projekt. Du warst mir immer eine Hilfe beim Versuch, dem Laborchaos Einhalt zu gebieten.

Ein riesiger Dank geht auch an Guido Kriete. Danke Guido, für deine stete Hilfestellung bei jedem noch so kleinen Problem, besonders, wenn die Computer mal wieder nicht so wollten, wie sie sollten. Heike Freundt danke ich für ihre Unterstützung in organisatorischen Dingen und ihre Hilfe bei der Auswertung von Callose-Färbungen und Wurzellängenmessungen.

Außerdem möchte ich mich auch bei der Abteilung Zellbiologie bedanken. Ganz besonderer Dank gebührt hierbei Christian Löfke für seine Tipps rum um das Thema Wurzel, Christine Klapprodt für den Exkurs in die Welt des Mehltaus und Elena Petutschnig für den Support bezüglich der ROS-Messungen.

Ein herzliches Dankeschön auch an Thomas Griebel (Uni Würzburg) für die Möglichkeit, beim Meister der SAR zu lernen und für das zur Verfügung stellen von Pseudomonas syringae-Stämmen.

Unseren TAs Anette Gunkel, Larissa Kunz, Ronald Scholz und Anna Hermann möchte ich für die zuverlässige und gewissenhafte Hilfe im Labor danken. Ihr habt mir meine Arbeit unglaublich erleichtert. Auch unseren Gärtnern Uwe Wedemeyer und Feli Glasenapp möchte ich vor allem für die Bereitstellung von Tabletts mit Erde gestopften Töpfen danken. Jenny Krüger möchte ich sehr dafür danken, dass sie mich in die Welt der Meeresaquaristik eingeführt hat, nichts entspannt mehr und ist zugleich so faszinierend.

Ein riesengroßes Dankeschön an meine einzigartigen Laborkollegen, die mir das Laborleben abwechslungsreich und angenehm gestaltet haben. Den "Jungs" danke ich für die vielfältigen Ablenkungsmanöver in Zeiten des Trübsal-Blasens, die Teilnahme an Pokerrunden trotz: „ich muss jetzt gehen, mein Zug fährt“ und die kreative Gestaltung des Mittagessens. Julia danke ich besonders für ihre Bereitschaft, Wochenendschichten mit einem Eis zu versüßen und die unermüdliche Beschaffung von Literatur.

Auf jeden Fall sollen auch noch die „alten Hasen“ genannt werden:

Zu aller erst natürlich vielen, vielen Dank dir, meine liebe Ulli, du bist mir immer eine teure Freundin, zu jeder Tages- und Nachtzeit. Mit dir teile ich meine Vorliebe für Chai-Tee und 
blasse Engländer. Gott sei Dank gibt es Telefon-Flat-Rate. Katrin und Ben, die RollenspielNachmittage mit euch werde ich nie vergessen, und Thula Bärentöter bestimmt auch nicht. Der modernen Technik sei gedankt, dass wir, trotz der riesen Entfernung über den großen Teich, doch Nachbarn sein können. Auch danke ich Hella für ihr offenes Ohr und Rat und Tat in jeder Lebenslage.

An dieser Stelle möchte ich mich ganz herzlich bei meiner Familie bedanken, die meine Leidenschaft bezüglich der Forschung zwar nicht immer nachvollziehen konnten, aber toleriert und mich unterstützt haben.

$\mathrm{Zu}$ guter Letzt möchte ich noch dem wichtigsten Menschen in meinem Leben danken, meinem Mann Mic. Danke, dass du mein Taxi gespielt hast, meine Haushaltshilfe und Koch warst, ohne groß zu murren meine exotischen Arbeitszeiten ertragen, und meinen Probevorträgen geduldig zugehört hast. 


\title{
9 Curriculum Vitae
}

\section{Persönliche Daten}

\author{
Name: Katja Rindermann geb. Rakowski \\ Geburtsdatum: $\quad 28.04 .1978$ in Korbach \\ Staatsangehörigkeit: deutsch
}

\section{Beruflicher Hintergrund}

02/2004-06/2005

$10 / 2003-01 / 2004$

\section{Studium}

08/2005-04/2010

$1997-2003$

Schule

$1994-1997$

\section{Praktika}

03/2001 - 04/2001

$05 / 2002-06 / 2002$ wiss. Mitarbeiterin im Institut für klinische Biochemie und Pathobiochemie am Deutschen Diabetes Zentrum, Düsseldorf wiss. Hilfskraft in der Abt. Entwicklungsbiologie der Universität Kassel

Promotion an der Georg-August-Universität Göttingen "The Role of Arabidopsis Class-II TGA Transcription Factors in PAMP-mediated Defense Responses "

Diplom-Biologie an der Universität Kassel

Gesamtnote: sehr gut Diplomarbeit:

„Charakterisierung einer P-Element-Insertionslinie von Drosophila melanogaster, die männliche Sterilität hervorruft"

Jacob-Grimm-Schule, Kassel -Oberstufen-Gymnasium-

Abschluss: Abitur

Note: 2,7

Klinikum Kassel, Zentrallabor

Einbecker Brauhaus, Betriebsstätte Kassel, Abt. Qualitätssicherung 